Aus der Klinik für Unfallchirurgie und Orthopädie Abteilung Unfallchirurgie, Plastische- und Wiederherstellungschirurgie (Prof. Dr. med. K. M. Stürmer) im Zentrum Chirurgie der Medizinischen Fakultät der Universität Göttingen

\title{
Einfluss der vertikalen Ganzkörpervibration in Kombination mit Strontiumranelat und Parathormon auf das osteoporotische Rattenfemur.
}

\author{
INAUGURAL-DISSERTATION \\ zur Erlangung des Doktorgrades \\ der Medizinischen Fakultät der \\ Georg-August Universität zu Göttingen
}

vorgelegt von

Christine Eimer

aus

Rotenburg/Wümme

Göttingen 2014 
Dekan:

I. Berichterstatter/in:

II. Berichterstatter/in:

III. Berichterstatter/in:

Tag der mündlichen Prüfung:
Prof. Dr. rer. nat. H. K. Kroemer

PD Dr. med. S. Sehmisch

Prof. Dr. Dr. F.-J. Kramer

24.03.2015 



\section{Inhaltsverzeichnis}

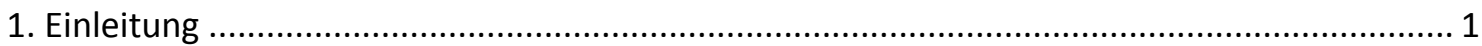

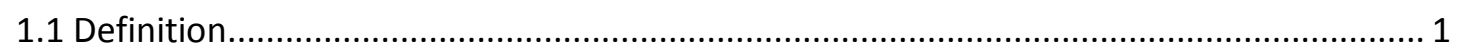

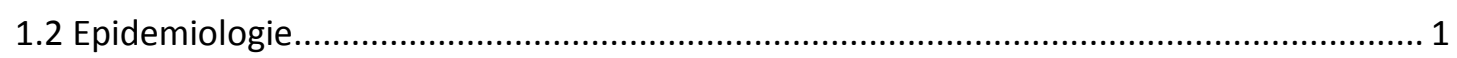

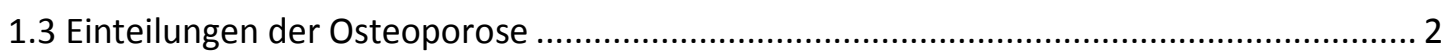

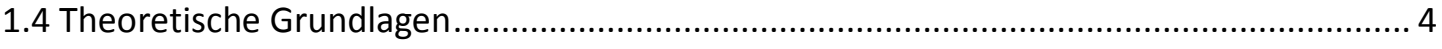

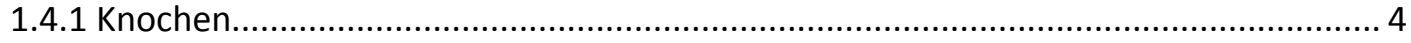

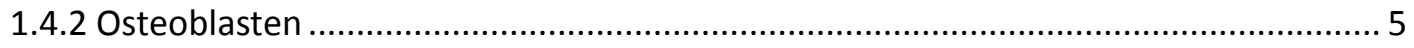

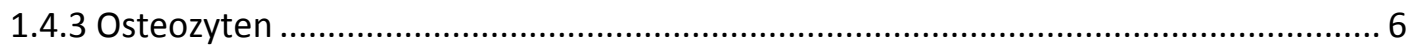

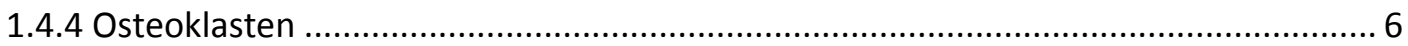

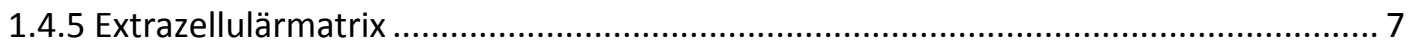

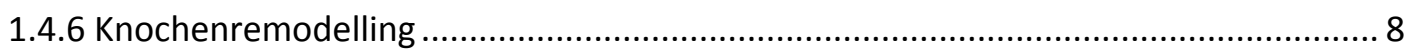

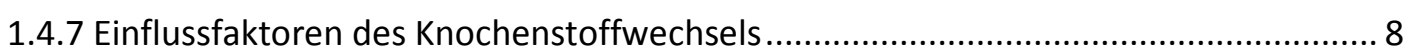

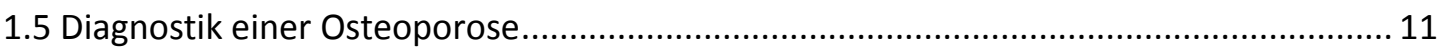

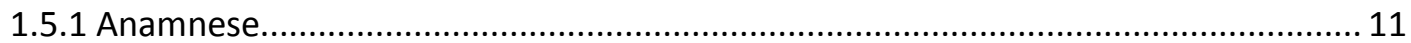

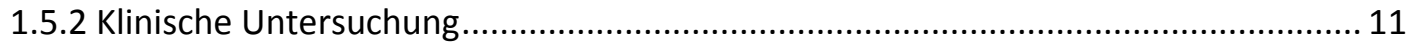

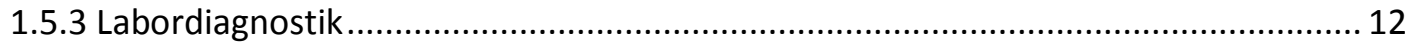

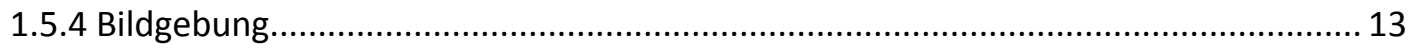

1.6 Therapie, Verlauf und Prognose ................................................................................ 16

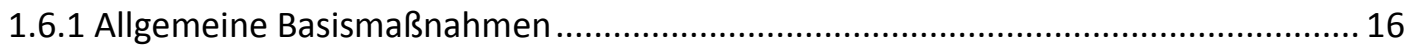

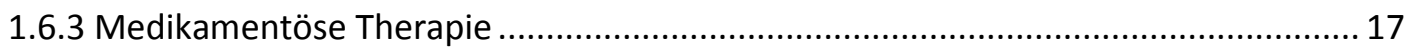

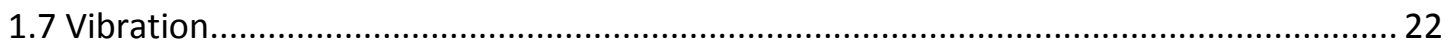

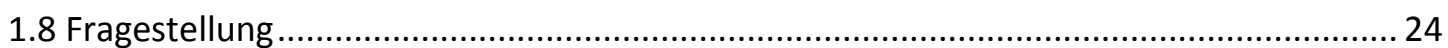

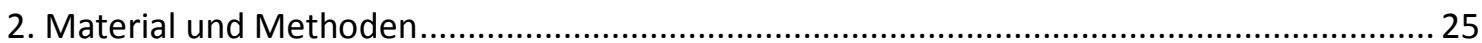

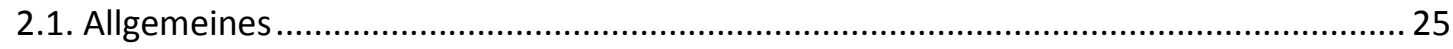

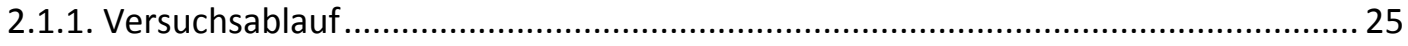

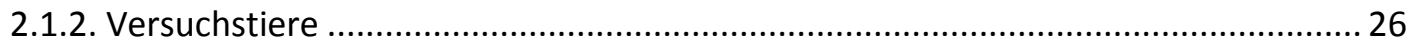

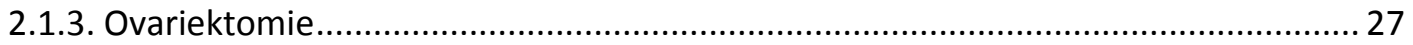

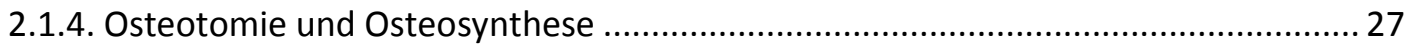

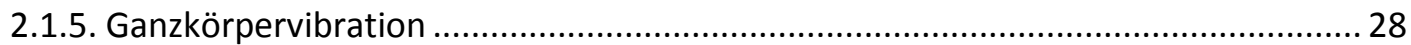




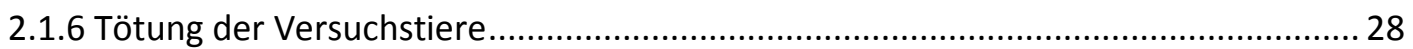

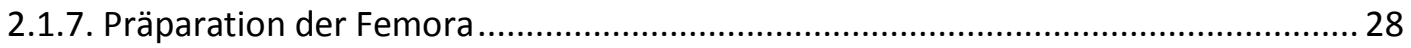

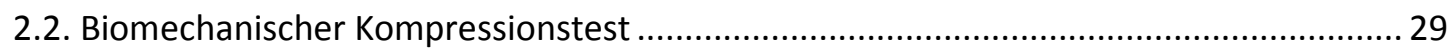

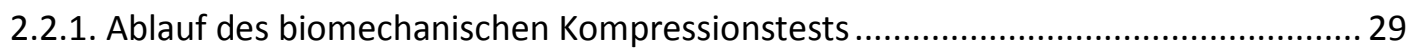

2.2.2. Messparameter des biomechanischen Kompressionstests...................................... 29

2.2.3. Validierung des Untersuchers für den biomechanischen Kompressionstest ............ 30

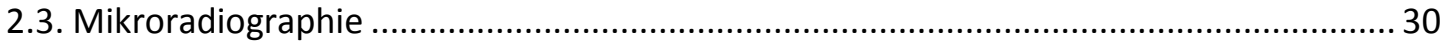

2.3.1. Digitalisieren der Mikroradiographie .................................................................. 31

2.3.2. Histomorphometrische Auswertung der Mikroradiographien ................................. 31

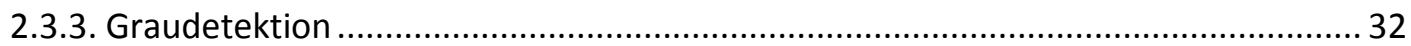

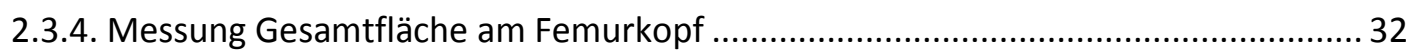

2.3.5. Messung der endostalen Gesamtfläche und des Trabekelwerks ............................. 32

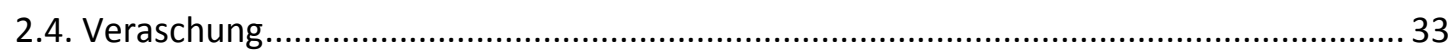

2.4.1. Bestimmung von Kalzium-, Phosphat- und Strontiumgehalt................................... 34

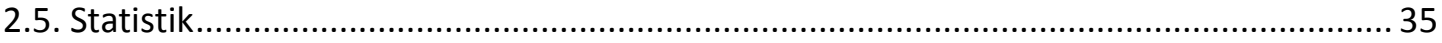

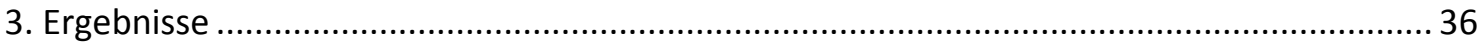

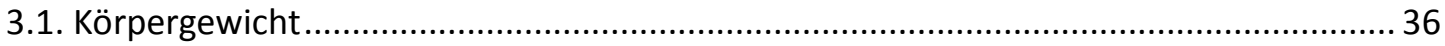

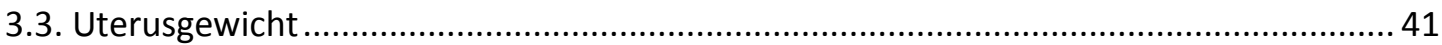

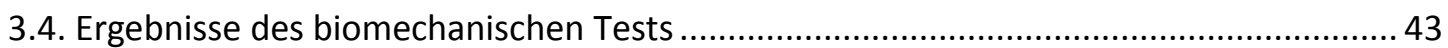

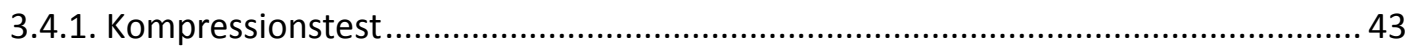

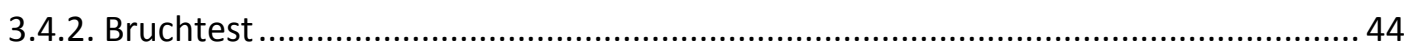

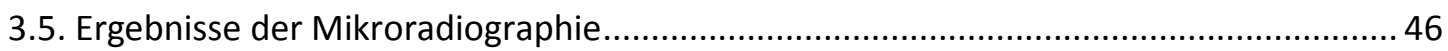

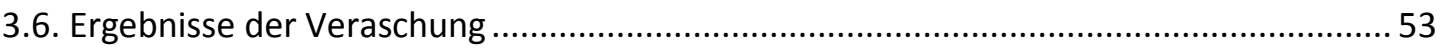

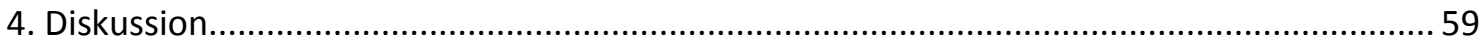

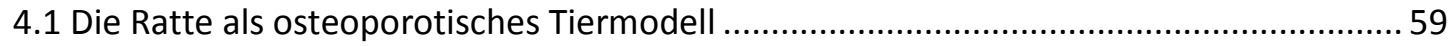

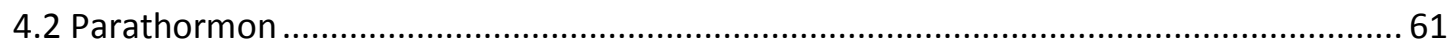

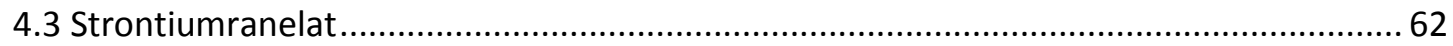

4.4 Vergleich der Wirksamkeit von Parathormon und Strontiumranelat................................ 64

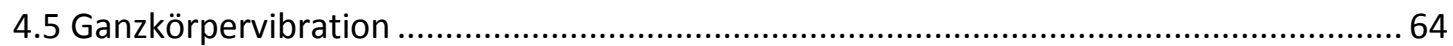

4.6 Vergleich der Wirksamkeit von Parathormon und Strontiumranelat in Kombination mit

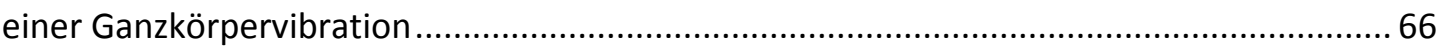

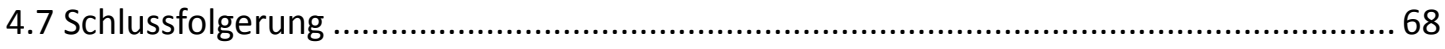


Zusammenfassung der Arbeit .

Abbildungsverzeichnis

Tabellenverzeichnis 72

Literaturverzeichnis 73

Appendix 85

Daten 85 


\section{Einleitung}

\subsection{Definition}

Bei der Osteoporose handelt es sich um eine systemische Erkrankung des Skeletts, die zum einen mit einer Verminderung der Knochenmasse und zum anderen mit einer Verschlechterung der Mikroarchitektur des Knochens einhergeht (Pfeilschifter 2006). Durch die krankhafte Veränderung seiner Struktur verliert der Knochen an Stabilität und es entsteht ein Missverhältnis zwischen Belastung und Belastbarkeit (DVO 2009). Die an Osteoporose erkrankten Patienten haben daher im Vergleich zur gesunden Bevölkerung eine erhöhte Knochenbrüchigkeit und im Verlauf der Krankheit ein stetig ansteigendes Frakturrisiko bei bereits geringen Belastungen (Minne et al. 2002).

\subsection{Epidemiologie}

Weltweit sind 200 Millionen Menschen an einer Osteoporose erkrankt (Lane 2006). Allein in den USA werden pro Jahr 1,5 Millionen Osteoporose-assoziierte Frakturen verzeichnet (Gardner et al. 2006). Im Jahr 2003 wurde in Deutschland eine Studie zur Epidemiologie der Osteoporose durchgeführt und die Daten von 1,5 Millionen Patienten erhoben. In Deutschland waren zum Zeitpunkt der Studie nachweislich 7,8 Millionen Menschen an einer Osteoporose erkrankt, 83 \% der Patienten waren weiblichen Geschlechts. 4,3 \% aller Patienten hatten zum Zeitpunkt der Studie mindestens eine klinisch relevante osteoporosebedingte Fraktur erlitten. Eine medikamentöse Therapie erhielten 21,7 \% aller Patienten. Die ökonomischen Folgen der Erkrankung wurden in der angeführten Studie mit bis zu 5,4 Mrd. Euro pro Jahr beziffert, wobei die Therapie der Frakturen den größten Kostenfaktor darstellte (Häussler et al. 2007). Osteoporose wurde durch die WHO aufgrund dieser Fakten in die Liste der 10 wichtigsten Volkskrankheiten aufgenommen. 


\subsection{Einteilungen der Osteoporose}

Knochen wachsen im Kindesalter zunächst unabhängig von Sexualhormonen, ab der Pubertät ist das Knochenwachstum jedoch von diesen Hormonen abhängig. Die Knochenmasse eines Menschen erreicht durch die Wirkung von Sexualhormonen um das 20.-30. Lebensjahr ihren Höhepunkt, auch bezeichnet als peak bone mass. Nach dem 40. Lebensjahr kommt es unter einer Verminderung des Hormoneinflusses zu einer Verringerung der Knochenmasse um 0,5 - max. $1 \%$ pro Jahr. Beim Mann ist diese Kurve stabil bis ins hohe Lebensalter, bei Frauen meist jedoch nicht. Nach der Definition der Weltgesundheitsorganisation (WHO) liegt eine Osteoporose vor, wenn die Knochendichte um 2,5 Standardabweichungen von der Knochendichte gesunder Menschen zum Zeitpunkt der peak bone mass abweicht. Eine präklinische Osteoporose liegt vor wenn die Standardabweichung von der Knochendichte gesunder Knochen um $1-2,5$ abweicht. Die Knochendichte wird definiert als das Verhältnis der mineralisierten Knochensubstanz zum Knochenvolumen (Herold 2013).

Eine Osteoporose kann generalisiert auftreten und zu einem spongiosabetonten Knochenmassenverlust führen wie im Fall einer postmenopausalen Osteoporose. Bei der senilen Osteoporose verursacht sie einen die Spongiosa und die Kompakta betreffenden Knochenmassenverlust. Eine Osteoporose kann jedoch auch lokal auftreten, als Beispiel ist das Sudeck-Syndrom zu nennen, eine gelenknahe Osteoporose bei rheumatoider Arthritis.

Aus klinischer Sicht wird bei der Osteoporose eine primäre von einer sekundären Form unterschieden, wobei in $95 \%$ aller Fälle eine primäre Osteoporose vorliegt (Lin und Lane 2004). Die primäre Osteoporose gliedert sich in eine postmenopausale Osteoporose (Typ 1) und eine senile Osteoporose (Typ 2).

Die als Typ 1 bezeichnete postmenopausale Osteoporose betrifft Frauen ab dem 50. Lebensjahr, ursächlich sind hormonelle Veränderungen, wie beispielsweise der Estrogenabfall im Rahmen der Menopause. Durch den Abfall des Hormons entfällt ein 
Schutzfaktor für das Skelett und dieser führt zu einem ausgeprägten Knochensubstanzverlust. Der Substanzverlust bei der Osteoporose Typ 1 ist eher trabekulär als kortikal lokalisiert.

Bei der senilen Osteoporose (Typ 2) findet der Knochenabbau gleichermaßen trabekulär und kortikal statt, klassische Frakturen finden sich am proximalen Femur, an Radius und Humerus. Ursächlich für die Osteoporose Typ 2 sind Alterungsprozesse, Bewegungsmangel (siehe auch 1.7 Vibration) und ein Mangel an Kalzium und Vitamin D.

Die sekundäre Osteoporose entsteht als Folge anderer Erkrankungen. Als Ursachen gelten endokrinologische Störungen wie der Hyperkortisolismus und der Hypogonadismus, aber auch Malabsorptionssyndrome, Immobilisation (siehe 1.7) und medikamentöse Langzeittherapien, die alle einen negativen Effekt auf den Knochenstoffwechsel haben.

Tabelle 1: Ursachen für Osteoporose

\begin{tabular}{|l|l|}
\hline 1. Primäre Osteoporose & 2. Sekundäre Osteoporose \\
\hline - idiopathische Osteoporose & - Hyperkortisolismus \\
- Postmenopausale Osteoporose & - Hypogonadismus \\
(Typ 1) & - Hyperthyreose \\
- Senile Osteoporose (Typ 2) & - Malabsorptionssyndrom \\
& - Immobilisation \\
& - iatrogen \\
& - medikamentöse Langzeittherapien \\
\hline
\end{tabular}

(modifiziert nach Herold 2014)

Die klinisch relevante Konsequenz einer Osteoporose ist der Anstieg von Schenkelhalsfrakturen, Radiusfrakturen und Wirbelkörperfrakturen. Im Gegensatz zu Frakturen bei jungen Menschen, die in aller Regel eine traumatische Ursache haben, kommt eine osteoporotische Fraktur häufig nach Bagatelltraumen oder spontan vor. Ferner bringen Osteoporose-assoziierte Frakturen eine deutliche Einschränkung der Lebens- 
qualität mit sich (Adachi et al. 2002; Borgström 2006). Die Patienten leiden unter Funktionseinschränkungen (Fechtenbaum et al. 2005) und meist auch unter chronischen Schmerzen, Morbidität und Mortalität sind erhöht (Miyakoshi et al. 2003; Johnell et al. 2004). Oberschenkelhalsfrakturen haben eine Ein-Jahres-Mortalitätsrate von 10-20\% (Herold 2013). Ziel ist es daher, durch eine angepasste Prävention und Therapie der Osteoporose die Frakturrate und somit Morbidität und Mortalität zu senken.

\subsection{Theoretische Grundlagen}

\subsubsection{Knochen}

Zusammen mit den Muskeln und Bindegeweben, bildet das Skelett des Menschen den Bewegungsapparat. Das Knochengewebe schützt innere Organe, hat Stütz- und Haltefuntion und darüber hinaus auch metabolische Funktionen als Kalzium-, Magnesium- und Phosphatspeicher. Außerdem befindet sich im Inneren des Knochens das sogenannte Knochenmark, welches für die Bildung von Erythrozyten, Leukozyten und Thrombozyten zuständig ist. Die jeweilige Architektur des Knochens ist das Resultat eines dynamischen und lebenslang anhaltenden Umbauprozesses, der durch hormonelle und metabolische Vorgänge gesteuert wird.

Knochengewebe ist ein spezialisiertes Bindegewebe, das aus einer mineralisierten Extrazellulärmatrix und unterschiedlichen Knochenzellen besteht. Die Extrazellulärmatrix gliedert sich in Kollagenfibrillen und Hydroxylapatitkristalle und verleiht dem Knochen Zug- und Druckfestigkeit. Die verschiedenen Zellen des Knochengewebes, nämlich Osteoblasten, Osteozyten und Osteoklasten, sorgen für einen ausgeglichenen Umbau und Neuaufbau von Knochenstrukturen. Wobei Osteoblasten für die Knochenbildung verantwortlich sind. Sie entwickeln sich aus undifferenzierten Mesenchymzellen und lagern sich an der Knochenoberfläche schichtartig an. Sie bilden indirekt die Grundlage für neue Knochensubstanz, indem sie vor allem Typ-1-Kollagen, Kalziump- 
hosphate und -karbonate in den interstitiellen Raum ausscheiden. Im Verlauf des Prozesses werden sie zu einem Gerüst aus nicht mehr teilungsfähigen Osteozyten, die mineralisieren. Osteoklasten sind mehrkernige Zellen, die durch Fusion von mononukleären Vorläuferzellen aus dem Knochenmark entstehen und insbesondere für die Resorption der Knochensubstanz verantwortlich sind (siehe auch 1.4.2, 3 und 4). Außerdem enthalten die Knochen rotes und gelbes Knochenmark, Knorpel, Bindegewebe sowie Nerven und Gefäße.

Am Knochen wird eine Substantia corticalis von einer Substantia spongiosa unterschieden. Die Spongiosa ist in zahlreichen kleinen Knochenbälkchen (Trabekel), die nach sogenannten Trajektionslinien ausgerichtet sind, organisiert und befindet sich im Inneren des Knochens. Wird die mechanische Belastung am Knochen geringer, so verringert sich auch die Zahl der Bälkchen, und die Stabilität des Knochenskeletts nimmt ab. In die Zwischenräume dieses Trabekelwerkes ist das Knochenmark eingelagert (Junqueira et al. 2004; Paulsen und Lüllmann-Rauch 2012).

\subsubsection{Osteoblasten}

Die Osteoblasten synthetisieren Kollagen Typ 1 für neue Knochenlamellen, sie bilden nicht-kollagene Proteine und steuern die Knochenmineralisation. Osteoblasten bilden mit ihren Zellkörpern auf bereits bestehender Knochenmatrix eine einschichtige Lage und sind durch noch nicht mineralisierte Kollagenfibrillen von der mineralisierten Matrix getrennt. Diese Osteoidschicht bildet die Grundstruktur der neuen Knochenlamelle. Im Verlauf der Mineralisierung der Kollagenfibrillen werden die Osteoblasten in der mineralisierten Matrix eingeschlossen und somit zu Osteozyten.

Der Osteoblast hat darüber hinaus die Funktion, einige nicht-kollagene Proteine (RANK-L, Osteocalcin, Osteopontin, Knochensialoprotein, M-CSF, Osteoprotegerin) herzustellen. Diese Proteine werden über die Zelloberfläche abgegeben. Das Protein Osteocalcin ist für die Knochenmineralisierung erforderlich. Der Osteoblast produziert außerdem Osteopontin (Sialoprotein), welches die Versiegelungszone der Osteoklasten (siehe 1.4.4) bildet. Das Knochensialoprotein stellt die Bindung der Osteoblasten 
an die Matrix her. Osteoprotegerin ist eine RANK-Variante zur Deaktivierung und damit Regulation von Osteoklasten.

Osteoblasten regulieren über mehrere Wege den Knochenabbau. Zum einen, indem sie Osteoidsäume abbauen und hierdurch Osteoklasten direkten Zugang zur verkalkten Matrix bekommen. Zum anderen, indem Osteoblasten mit Osteoklasten interagieren. Für die Aktivierung des Osteoklasten und die Verhinderung der Apoptose setzt der Osteoblast das membranständige Protein RANKL frei. Das Protein RANKL bindet dann an RANK auf der Oberfläche der Osteoklastenvorläuferzellen und führt zur Aktivierung dieser Zellen (Paulsen und Lüllmann-Rauch 2012).

\subsubsection{Osteozyten}

Bei den Osteozyten handelt es sich um veränderte Osteoblasten, die im Verlauf der Matrixbildung in den neuen Knochen eingeschlossen worden sind. Sie bilden zahlreiche Zellfortsätze (Nexus) zur Kommunikation mit anderen Knochenzellen aus. Nexus verbinden benachbarte Zellen und ermöglichen einen Strom von Elektrolyten und kleineren Molekülen, außerdem sorgen sie für einen Stofffluss von außen liegenden Osteoblasten zu den Osteozyten. Osteozyten befinden sich in sogenannten Lakunen, von welchen viele kleine Knochenkanäle abgehen, in denen die Zellausläufer der Osteozyten zu liegen kommen. Die Knochenkanälchen bilden also ein Labyrinth, das den gesamten Knochen durchzieht und somit die Kommunikation mit allen eingemauerten Osteozyten ermöglicht. Die Funktion der Osteozyten ist bislang nicht vollständig geklärt. Es wird vermutet, dass Osteozyten u.a. Informationen über den Zustand des Knochens liefern und somit Aufschluss über die Reparaturbedürftigkeit geben (Paulsen und Lüllmann-Rauch 2012).

\subsubsection{Osteoklasten}

Osteoklasten bauen mineralisierte Matrix ab und können somit als Gegenspieler der Osteoblasten bezeichnet werden. Sie entstehen durch die Verschmelzung von bis zu 100 hämatopoetischen, monozytären Vorläuferzellen. Die Osteoklasten liegen der Knochenmatrix direkt an und konstruieren durch den Abbau der Matrix kleine soge- 
nannte Howship-Lakunen in die Trabekeloberfläche. An der Lakune erfolgt die Anheftung des Osteoklasten an die verkalkte Knochenmatrix. Die so entstehende Versiegelungszone wird aus Aktinfilamenten und Osteopontin gebildet. Aktive Osteoklasten lassen sich dabei an ihrem ausgeprägten Faltensaum, an dem die Mineralresorption stattfindet, erkennen. Inaktiven Osteoklasten fehlt ein solcher Faltensaum. Für den Abbau der mineralisierten Matrix ist die Sekretion von Protonen maßgeblich. In den Osteoklasten sorgt die Carboanhydrase 2 aus der Reaktion von $\mathrm{CO}_{2}$ und $\mathrm{H}_{2} \mathrm{O}$ für die Generierung von Protonen $\left(\mathrm{H}^{+}\right)$. Diese Protonen werden dann mithilfe einer ATP-abhängigen Pumpe in die Howship-Lakunen gepumpt. Der durch diesen Prozess reduzierte $\mathrm{pH}$-Wert in den Lakunen beträgt 4,5 und führt so über eine Ansäuerung zu einer Demineralisierung der Matrix. Die Einhaltung des niedrigen pHWertes wird außerdem über einen im Faltensaum liegenden Chloridkanal gewährleistet. Nach der Ansäuerung der Matrix werden Enzyme (Cathepsin K, Proteasen, Phosphatasen und Metalloprotease 9) innerhalb der Howship-Lakune freigesetzt, die für den Abbau der Kollagene, nicht-kollagenen Proteine und Proteoglykane benötigt werden. Die einzelnen Fragmente der Matrix werden dann endozytotisch in den Osteoklasten aufgenommen und auf der Rückseite der Zelle in die Blutbahn abgegeben.

Die Tätigkeit der Osteoklasten unterliegt einer strengen Regulation durch Hormone und die Tätigkeit der Osteoblasten. Die Differenzierung der Osteoklasten aus hämatopoetischen Vorläuferzellen wird maßgeblich durch Vitamin D beeinflusst. Hauptsächlich hemmt das Hormon Calcitonin die Osteoklastenaktivität. Zytokine der Osteoblasten wiederum fördern die Osteoklastentätigkeit (Paulsen und Lüllmann-Rauch 2012).

\subsubsection{Extrazellulärmatrix}

Die Extrazellulärmatrix des Knochens setzt sich hauptsächlich aus Kollagenfibrillen Typ 1 und Hydroxylapatitkristallen zusammen und dient verschiedenen Zellen als Verankerung. Anhand der räumlichen Anordnung der Extrazellulärmatrix kann ein sogenannter Geflechtknochen von einem Lamellenknochen unterschieden werden. Im 
Geflechtknochen sind die Kollagenfibrillen ineinander verwoben. Biomechanisch hochwertiger ist jedoch der Lamellenknochen, die Kollagenfibrillen liegen parallel zueinander, was dem Knochen seine Biegefestigkeit verleiht (Drenckhahn 2008).

\subsubsection{Knochenremodelling}

Der Prozess der Knochenremodellierung umfasst den Abbau alter Knochensubstanz durch Osteoklasten und den Aufbau neuer Knochensubstanz durch Osteoblasten.

Die Knochenremodellierung passt das Skelett an wechselnde Beanspruchungen an und gleicht strukturelle Schädigungen am Knochen aus, mit dem Ziel, stets ein funktionsfähiges und belastbares Knochenskelett zu erhalten. Durch die Remodellierung wird die Mikroarchitektur des Knochens zeitlebens verändert und im Falle einer Fraktur wieder ganz neu hergestellt. Jährlich werden ca. 3 \% der kortikalen Knochenmasse erneuert und etwa 25 \% des spongiösen Knochens (Paulsen und Lüllmann-Rauch 2012).

\subsubsection{Einflussfaktoren des Knochenstoffwechsels}

Für den Knochenaufbau, -umbau und -abbau sind die im Folgenden beschriebenen Stoffe bzw. Hormone essentiell.

Prozentual sind die beiden wichtigsten Stoffe für den Knochen Kalzium und Phosphat. Der menschliche Körper enthält ungefähr 1 kg Kalzium, davon befinden sich $99 \%$ in Knochen und Zähnen. Kalzium ist im Körper in der Regel an Phosphat gebunden, diese Kalziumphosphatsalze haben eine begrenzte Löslichkeit und bilden die Grundlage der Knochenmineralisierung. Freies Kalzium hat zahlreiche Wirkungen, es dient als Transmitter in der Regulation von Muskelkontraktion, Ausschüttung von Transmittern und Hormonen, Stoffwechsel, Genexpression, Zellproliferation und Zelltod. Kalzium ist zusätzlich an der Blutgerinnung beteiligt, es dichtet Endothelien und Epithelien ab und mindert die neuromuskuläre Erregbarkeit.

Der Körper enthält 0,7 kg Phosphat, etwa 86 \% befinden sich im Knochen, etwa $13 \%$ intrazellulär. Phosphat spielt eine entscheidende Rolle in Phosphatverbindungen wie 
ATP als Energiespeicher, und im Rahmen der Glykolyse ist die Kopplung von Glukose an Phosphat ein unverzichtbarer Bestandteil der Energiegewinnung. Phosphat ist außerdem Bestandteil von Zellmembranen und ist als Puffer an der Konstanthaltung des pH-Wertes beteiligt. Hypophosphatämie (Absinken des Phosphatspiegels) führt zu einer Demineralisierung des Knochens und zu einer Beeinträchtigung des Energiestoffwechsels mit Auswirkungen auf die Herzfunktion, das Nervensystem und die Muskulatur (Welsch 2006).

Vitamin $D$ ist für den Knochen von wesentlicher Bedeutung, da es die enterale Kalziumaufnahme und den Einbau von Kalzium in die Knochensubstanz fördert, im Zuge einer Osteoporosetherapie verbessert es die Muskelfunktion und verringert das Sturzrisiko (Bischoff-Ferrari et al. 2004). Die biologisch aktive Form ist das Calcitriol. Am Knochen stimuliert Calcitriol die Herstellung der Knochenmatrix und durch die vermehrte Bereitstellung von Kalzium die Knochenmineralisation. Osteoblasten und Osteoklasten besitzen eigene Rezeptoren für Calcitriol. Im Osteoblasten stimuliert es die Synthese von Kalzium-bindenen Proteinen für den Knochenaufbau und Matrixmetalloproteinasen für Knochenumbauprozesse. Calcitriol fördert die Entwicklung von Osteoklasten aus Osteoklastenvorläuferzellen. Dies ist allerdings nur in Zusammenarbeit mit den Osteoblasten möglich, da sie das essentielle RANKL bilden, welches die Osteoklasten für ihre Differenzierung benötigen.

Parathormon ist das zentrale Hormon des Kalziumsstoffwechsels, in seiner Funktion sorgt es für die Erhöhung der Plasmakalziumkonzentration. Synthese und Ausschüttung des Hormons werden durch Kalziummangel und das Vorliegen von PhosphatIonen ausgelöst. Ausschüttungshemmend wirken wiederum hohe Kalziumkonzentrationen im Blut. Drüsenzellen der Nebenschilddrüsen enthalten in ihrer Membran sogenannte Kalziumsensorproteine, welche bereits kleinste Schwankungen der extrazellulären Kalziummenge erfassen. Am Knochen kommt es zunächst zu einer Aktivierung der Osteoblasten, die wiederum M-CSF und RANKL exprimieren. Über 
diese Signalwege werden Osteoklastenvorläuferzellen aktiviert und es kommt zu Knochenabbau. Dieser Prozess führt zu einer Freisetzung von Kalzium und Phosphat ins Blut.

Ein weiteres Hormon ist Calcitonin, welches die Plasmakalziumkonzentration senkt. Bei Hyperkalziämie wird viel Calcitonin ausgeschüttet, bei Hypokalziämie wird die Sekretion verringert. Wie beim Parathormon wird die Wirkung des Calcitonins über Proteinrezeptoren vermittelt. Calcitonin hemmt über Rezeptoren auf den Osteoklasten die Aktivität dieser Knochenzellen und verhindert auf diese Weise die weitere Freisetzung von Kalzium. Hohe Mengen des Calcitonins führen zu einer gesteigerten Ausscheidung von Kalzium und Phosphat über die Nieren.

$\mathrm{Zu}$ den wichtigsten natürlichen Estrogenen gehört das $\beta$-Estradiol. Die ausgeprägte Prävalenz der Osteoporose in postmenopausalen Frauen lässt vermuten, dass die verminderte Estrogensynthese in der Entwicklung der Osteoporose eine wichtige Rolle spielt. Die Zellen des Knochens, Osteoblasten, Osteozyten und Osteoklasten besitzen auf ihrer Oberfläche Rezeptoren für Estrogene.

Estrogene sind ein Schutzfaktor für das Skelett, denn sie sorgen über mehrere Signalwege für eine Verminderung des Knochenabbaus. Über die Hemmung von Interleukin 1 und 6 und Tumornekrosefaktor 1 und 2 kommt es zu einer Verkürzung der Osteoklastenlebensdauer. Außerdem sorgt ß-Estradiol für die Ausschüttung von Osteoprotegerin und hemmt somit zusätzlich die Osteoklasten in ihrer Funktion. ß-Estradiol beeinflusst die Ausschüttung von RANKL und verzögert die Differenzierung der Osteoklastenvorläuferzellen. Das Klimakterium führt zu einem mengenmäßigen Abfall der Estrogene, und der Schutz vor Knochenabbau geht verloren.

Glukokortikoide sind Steroidhormone, die den Knochenabbau über verschiedene Mechanismen fördern. Sie hemmen die Produktion von Osteoprotegerin, steigern die Bildung von RANKL und führen auf diesem Weg zu vermehrtem Knochenabbau. 
Darüber hinaus induzieren Glukokortikoide Apoptose in Osteoblasten und Osteozyten und verhindern somit die Bildung neuer Knochenmatrix.

\subsection{Diagnostik einer Osteoporose}

\subsubsection{Anamnese}

Anamnese und klinische Untersuchung sind häufig richtungsweisend in der Diagnostik einer Osteoporose, demnach sollte ein ausführliches Gespräch mit dem Patienten an erster Stelle stehen. In der Anamnese müssen aktuelle Beschwerden und Funktionseinschränkungen des Patienten besprochen werden, außerdem sollten Vorerkrankungen, familiäre Erkrankungen, medikamentöse Langzeittherapien und Risikofaktoren erfasst werden. Weitere wichtige Aspekte sind das Alter, die Entwicklung der Größe und des Gewichts, sportliche Aktivitäten und vorangegangene Stürze und Frakturereignisse. Die Anamnese ergibt das Risikoprofil des Patienten und die Indikation zur weiteren Diagnostik (Wülker 2010).

\subsubsection{Klinische Untersuchung}

Die klinische Untersuchung am Patienten dient der Feststellung bereits eingetretener Pathologien am Bewegungsapparat. Innerhalb der körperlichen Untersuchung sollten deshalb Statik und Körperhaltung, Bewegungseinschränkungen, Rundrücken, Wirbelsäulendeformitäten, Muskelverspannungen, Klopfschmerzen und eine Verringerung der Körpergröße unbedingt überprüft werden.

Im fortgeschrittenen Stadium einer Osteoporose kann es bereits bei geringen Belastungen zum Einbrechen eines oder mehrerer Wirbel mit subperiostaler Blutung und akuten Schmerzen kommen. Das Einsinken der Wirbelkörper resultiert in einer progredienten Kyphoisierung der Brustwirbelsäule mit Rundrücken und einer Abnahme der Körpergröße. Diagnostisch wegweisend ist ein Körpergrößenverlust von mehr als $4 \mathrm{~cm}$. Die Deformität der Wirbelsäule kann so ausgeprägt sein, dass die unteren Rippen die Beckenkämme berühren und zu einer Periostreizung mit starken Schmerzen 
führen. Die Volumina von Bauch- und Brustraum verändern sich, häufig haben die Patienten einen ausladenden Kugelbauch (Fußballabdomen) und leiden aufgrund der Volumenverminderung im Brustraum unter einer restriktiven Hyperventilation. Ein weiteres Merkmal der Wirbelkörperdeformität sind die schräg abwärts verlaufenden Hautfalten am Rücken (Tannenbaumphänomen).

In der Untersuchung sollte anhand von Muskelkraft und Koordination das Sturzrisiko des Patienten überprüft werden. Die Leitlinie der DVO empfiehlt die Durchführung von drei einfachen Tests. Der (1) Chair-rising test prüft vor allem die Muskulatur der unteren Extremität, der Patient wird dazu aufgefordert, aus einem Stuhl so schnell wie möglich fünf Mal hintereinander aufzustehen und sich wieder zu setzen. Wenn der Patient länger als 11 Sekunden für diesen Test benötigt, ist eine Gangunsicherheit anzunehmen. Für den (2) Timed-up and go test muss der Patient einmal aus einem Stuhl aufstehen, drei Meter gehen, sich drehen und zum Stuhl zurückkehren. Benötigt der Patient für diese Übung länger als 10 Sekunden, ist von einer Beeinträchtigung von Muskelkraft und Koordination auszugehen. Der (3) Tandem-Test überprüft die Balance. Der Patient wird dazu aufgefordert, die Füße auf einer Linie direkt hintereinander zu stellen, diese Position sollte der Patient mindestens 10 Sekunden halten können. Gerät der Patient vor Ablauf der 10 Sekunden aus dem Gleichgewicht, ist von einem erhöhten Sturzrisiko aufgrund verminderter Balance, auszugehen (Wülker 2010).

\subsubsection{Labordiagnostik}

Die Labordiagnostik umfasst bei Verdacht auf Osteoporose die Analyse von Blut und Urin des Patienten. Diagnostische Bedeutung hat die Laboruntersuchung in der Feststellung der sekundären Osteoporose. Anhand bestimmter Knochenmarker können Informationen über Knochenformationsprozesse gewonnen werden und somit den Arzt in der Auswahl der geeigneten Therapie unterstützen (Arastéh et al. 2012). Besonders wichtig für die Diagnostik sind die Parameter des Knochenstoffwechsels, wobei zwischen Markern der Knochenresorption und des Knochenanbaus unterschieden wird. Der Knochenanbau kann anhand der Konzentration von Osteocalcin und der 
knochenspezifischen alkalischen Phosphatase beurteilt werden, sie werden von den Osteoblasten gebildet und gelten als die geeignetsten Marker. Der Knochenabbau kann über die Messung von Pyridinolin und Desoxypyridinolin erfasst werden. Diese Metaboliten werden von Osteoklasten synthestisiert und sind knochenspezifisch. Sie werden nicht metabolisiert und eignen sich als Parameter für den Therapierfolg bei Hormonsubstitution und Bisphosphonatgabe.

\subsubsection{Bildgebung}

\subsubsection{Konventionelles Röntgen}

Das Röntgen der Wirbelsäule in zwei Ebenen dient in erster Linie dem Nachweis von Frakturen und der Erfassung degenerativer Veränderungen an den einzelnen Wirbeln. Mithilfe des Röntgens kann außerdem das Ausmaß einer Osteoporose beurteilt werden und eine regelmäßige Verlaufskontrolle durchgeführt werden (Genant et al. 2007).

Der Mineralisierungsgrad eines Knochens kann an einem regulären Röntgenbild nicht beurteilt werden. Die Röntgenaufnahme zeigt im Falle einer Osteoporose eine Rarefizierung der Trabekel, der Knochen erleidet dadurch eine sogenannte hypertrophische Atrophie. Durch lakunäre Kompaktadefekte nimmt die Kompaktadicke der Röhrenknochen zum Teil deutlich ab. Kompressionsfrakturen führen zur Ausbildung von Keilwirbeln im thorakalen Bereich. An der lumbalen Wirbelsäule entstehen durch den Einbruch der Deck- und Grundplatten bikonkave Fischwirbel.

\subsubsection{Knochendichtemessung}

Die Osteodensitometrie ermöglicht die Beurteilung des Schweregrades einer Osteoporose und umfasst verschiedene Verfahren zur Messung der Knochenmineraldichte (bone mineral density) und des Knochenmineralgehaltes (bone mineral content). Die Untersuchung sollte an Knochen mit erhöhtem Frakturrisiko durchgeführt werden, es eignen sich also besonders die Wirbelsäule und der Schenkelhals. Anhand der Kno- 
chendichtemessung kann die Diagnose Osteoporose frühzeitig gestellt werden und das individuelle Ausmaß des Knochensubstanzverlusts festgestellt werden, was maßgeblich in der Abschätzung des Frakturrisikos und der Entwicklung eines individuellen Therapieplans für den Patienten ist.

In der Berechnung der Knochendichte wird mit der Standardabweichung (SD) von der Norm, dem T-Wert, gerechnet (Tabelle 2). Der T-Score wird bestimmt, um bei der Knochendichtemessung entscheiden zu können, ob eine Osteoporose vorliegt oder nicht. Man geht von einer Vorstufe der Osteoporose aus wenn der T-Score 1,0 bis 2,5 Standardabweichungen unterhalb des Mittelwertes liegt. Bei einem T-Score, welcher mehr als 2,5 Standardabweichungen unterhalb des Mittelwertes liegt, handelt es sich definitionsgemäß um eine Osteoporose. Der Z-Score ist neben dem T-Score ein weiterer Parameter der Knochendichtemessung. Der T-Score kann einen Anhaltspunkt dafür geben, ob eine Osteoporose therapiebedürftig ist. Der Z-Score ergibt sich aus der Standardabweichung der gemessenen Knochendichte vom Mittelwert einer Vergleichsgruppe mit gleichem Alter. Damit nimmt er einen anderen Wert an als der T-Score, welcher die Knochendichte des Patienten mit dem Durchschnittswert von 30jährigen und knochengesunden Erwachsenen vergleicht (Herold 2014).

Tabelle 2: T-Werte in Abhängigkeit von Lebensalter und Geschlecht

\begin{tabular}{|l|l|l|}
\hline \multicolumn{2}{|l|}{ Lebensalter in Jahren } & T-Werte aus der Osteodensitometrie \\
\hline Frau & Mann & \\
\hline $50-60$ & $60-70$ & $-4,0$ \\
\hline $60-65$ & $70-75$ & $-3,5$ \\
\hline $65-70$ & $75-80$ & $-3,0$ \\
\hline $70-75$ & $80-85$ & $-2,5$ \\
\hline$>75$ & $>85$ & $-2,0$ \\
\hline
\end{tabular}

Angegeben sind T-Werte die im Mittel mit einem 30\%-igen Frakturrisiko für Wirbelkörper- und proximale Femurfrakturen in 10. Jahren assoziiert sind. (Modifiziert nach Herold 2014) 


\subsubsection{Dual-X-Ray Absorptiometrie (DXA)}

Die Knochendichtemessung mittels DXA gilt als Methode der Wahl bei der Diagnosestellung einer Osteoporose und wird als Standardverfahren von der WHO und dem DVO empfohlen (de Laet et al. 2002). Bei der Messung werden Röntgenstrahlen unterschiedlicher Energie durch das Knochengewebe geleitet und die Absorption der Strahlung gemessen. Anhand der Strahlenabsorption kann der Mineralgehalt des Knochens ermittelt werden (Link und Majumdar 2003).

Die Vorteile dieser Messung, im Vergleich zu anderen Methoden, liegen zum einen in der hohen Messgenauigkeit und zum anderen in der geringen Strahlenbelastung, so dass sich die DXA auch als Verlaufskontrolle eignet.

Die Messung kann an allen Knochen des Körpers erfolgen, normalerweise findet die Messung an Lendenwirbelsäule und Femur statt (Brunader und Shelton 2002). An der Wirbelsäule wird der T-Wert anhand von Messungen an den Lendenwirbelkörpern 1-4 ermittelt. Degenerative Veränderungen an den Wirbeln, Skoliosen und die Messung frakturierter Wirbel können zu falschen Messergebnissen führen und müssen daher überprüft werden. Für eine 10-Jahres Prognose werden jeweils die niedrigsten T-Werte von Lendenwirbelsäule, Femurhals und Gesamtfemur verwendet.

\subsubsection{Quantitative Computertomographie (QCT)}

Die quantitative Computertomographie ist eine Spezialform der Computertomographie, anhand derer eine direkte Messung der volumetrischen Knochendichte durchgeführt werden kann (Brunader und Shelton 2002). In der QCT werden Absorptionskoeffizienten von Wirbelkörpern bestimmt und mit Referenzwerten verglichen.

Die QCT ist insofern vorteilhaft, als das mit dieser Methode trabekuläre Anteile von kortikalen deutlich besser unterschieden werden können und osteoporotische Veränderungen deutlich früher detektiert werden, als mit der DXA (Brunader und Shelton 2002). Während das DXA-Verfahren eine flächenprojizierte Masse misst, erfolgt die Messung beim QCT dreidimensional. Nachteile der QCT sind die wesentlich höhere Strahlenbelastung, sodass das QCT als Verlaufsroutine nicht geeignet ist. 


\subsubsection{Quantitative Sonographie}

Der quantitative Ultraschall ist ein leicht durchzuführendes Verfahren zur Messung der Knochendichte von peripheren tastbaren Knochen ohne Verwendung von Strahlung. Mithilfe von Ultraschallsender und Empfänger werden Ultraschallwellen durch den Knochen geleitet und dann Schallabschwächung und Schallgeschwindigkeit gemessen. Aus den ermittelten Werten können Rückschlüsse auf die Knochenformation und Knochendichte gezogen werden, die Ergebnisse sind allerdings bei weitem nicht so genau wie bei der DXA oder dem QCT.

Die Ultraschalluntersuchung der Knochen kann nur an den Extremitäten durchgeführt werden, die Messung an besonders frakturgefährdeten Orten wie der Lendenwirbelsäule oder dem proximalen Femur sind mit dem Ultraschallverfahren nicht möglich. Darüberhinaus kann eine per Ultraschall gemessene unauffällige Knochendichte der Extremitäten eine bestehende Osteoporose an der Wirbelsäule nicht ausschließen. Der DVO hat in seiner Leitlinie, trotz des Vorteils ohne Strahlen auszukommen, von der Ultraschallmessung in seiner Empfehlung Abstand genommen, da nur Knochen der Extremitäten untersucht werden können und die Messungen wesentlich ungenauer als bei der DXA und dem QCT sind (DVO 2009).

\subsection{Therapie, Verlauf und Prognose}

Ziele der Therapie sind die Stabilisierung der Knochenstruktur mit einer Reduktion des Frakturrisikos, die Linderung von krankheitsbedingten Schmerzen und die Reduktion des Sturzrisikos sowie die Verbesserung der Lebensqualität.

\subsubsection{Allgemeine Basismaßnahmen}

Die Basistherapie der Osteoporose umfasst eine Reihe nicht-medikamentöser Therapiestrategien, prinzipiell gilt, dass körperliche Betätigung eine anabole Wirkung auf den Knochenstoffwechsel hat. Bei jeder Form der manifesten Osteoporose erfolgt die 
kombinierte Gabe von Kalzium und Vitamin D. Während die erforderliche Kalziumaufnahme auch über eine bewusst gestaltete Nahrungsaufnahme zu erreichen ist, muss Vitamin D meist supplementiert werden. In einer Studie aus dem Jahre 1994 konnte an Bewohnern einiger Altenheime nachgewiesen werden, dass die Gabe von Kalzium und Vitamin $D$ das Auftreten von hüftgelenksnahen Frakturen um $30 \%$ reduzieren konnte (Chapuy et al. 1994). Es hat sich auch als sinnvoll erwiesen, sturzgefährdete Patienten mit Hüftprotektoren (Parker et al. 2000) auszustatten, um die Folgen eines potentiellen Sturzes möglichst gering zu halten.

Die Patienten nach stattgehabten Wirbelfrakturen sind chronische Schmerzpatienten und benötigen eine angemessene schmerztherapeutische Versorgung nach dem WHOStufenschema unter Beachtung der Nebenwirkungen wie Schwindel und Sturzneigung, damit physiotherapeutische Maßnahmen zur Verbesserung der Koordination und Muskelkraft durchgeführt werden können (Roth, und Abendroth 2006).

Die WHO hat einen Fracture Risk Assessment Test entwickelt, mit dem die 10-Jahreswahrscheinlichkeit, eine osteoporotische Fraktur zu erleiden, berechnet werden kann (Kanis et al. 2009). Risikofaktoren für osteoporotische Frakturen sind nach diesem Test unter anderem Nikotinkonsum, die Einnahme oraler Glukokortikoide, Alkoholkonsum und bereits vorliegende osteoporotischen Frakturen in der Vergangenheit (Kanis et al. 2008). Es ist daher unabdingbar, die Patienten auch hinsichtlich einer Lebensstiländerung zu beraten.

\subsubsection{Medikamentöse Therapie}

Die Indikation für eine medikamentöse Osteoporosetherapie ergibt sich aus epidemiologischen Daten und den Werten der Knochendichtemessung. Liegt das 10-Jahres Risiko für Wirbelkörper- und proximale Femurfrakturen über $30 \%$ und sind die Werte der DXA an mindestens einem Knochen verringert, so ist eine medikamentöse Therapie unabhängig vom Alter oder Geschlecht des Patienten zu empfehlen.

Die medikamentöse Therapie einer Osteoporose umfasst verschiedene Konzepte. Man unterscheidet zunächst einmal antiresorptive und osteoanabole Substanzen. Antire- 
sorptive Medikamente hemmen über eine Anlagerung an oberflächliche Rezeptoren die Mineralisation des Knochens und über einen zweiten Wirkmechanismus den weiteren Knochenabbau. Durch die Erhöhung der Knochendichte konnte das Frakturrisiko um 40-50 \% an der Lendenwirbelsäule und um 20-40 \% an nicht vertebralen Frakturen gesenkt werden. Die osteoanabolen Substanzen aktivieren Osteoblasten, so dass es zu einem Anstieg der Knochendichte kommt.

\subsubsection{Selektive Estrogenrezeptor-Modulatoren (SERM)}

Selektive Estrogenrezeptormodulatoren (SERMs) binden an Estrogenrezeptoren und wirken abhängig vom Zielgewebe agonistisch oder antagonistisch. SERM wirken am Knochen agonistisch und verhindern einen weiteren Knochenverlust. Aus der Gruppe der selektiven Estrogenrezeptor-Modulatoren ist bisher nur das Raloxifen für die Osteoporosetherapie zugelassen. Raloxifen verhindert Knochenabbau und verringert das Risiko für vertebrale Frakturen um 30-50 \% (Delmas et al. 1997; Ettinger et al. 1999).

\subsubsection{Estrogene}

Estrogenmangel im Zuge der Menopause führt zu einem beschleunigten Knochenverlust und einem erheblichen Anstieg des Frakturrisikos. Ferner konnte gezeigt werden, dass der Estrogenmangel die Knochenresorption fördert, indem die Lebenszeit der Osteoklasten verlängert wird und der Knochenaufbau abnimmt aufgrund einer Lebenszeitverringerung der Osteoblasten (Seeman 2003).

Die Einnahme von Estrogenen reduziert den durch die Menopause induzierten Knochenverlust und verhindert, unabhängig vom Patientenalter, den progredienten Knochenverlust. Wird die Hormonersatztherapie durchgeführt, erhöht sich die Knochemineraldichte in 1-3 Jahren Therapiedauer um 5-10 \% (Delmas 2002). Estrogene reduzieren das Risiko für vertebrale und nicht-vertebrale Frakturen um $30 \%$ (Delmas 2002).

Die Behandlung mit Estrogenen birgt zahlreiche Nebenwirkungen, das Risiko für tiefe 
Beinvenenthrombosen ist erhöht, nach Langzeiteinnahmen ist das Risiko für gynäkologische Tumoren erhöht (Rossouw et al. 2002) .

\subsubsection{Bisphosphonate}

Für Patienten, bei denen bereits eine manifeste Osteoporose diagnostiziert worden ist, gilt die Behandlung mit Bisphosphonaten als Therapie der ersten Wahl. Bisphosphonate werden zunächst an Hydroxylapatit gebunden und wirken dann in den osteoklastischen Resorptionslakunen des Knochens. Stickstoffhaltige Bisphosphonate haben eine zytotoxische Wirkung auf die Osteoklasten und führen zum Zelltod. Stickstofffreie Bisphosphonate wiederum hemmen die Farnesyldiphosphat-Synthase und vermindern dadurch die Mobilität der Osteoklasten. Auch dies führt zum programmierten Zelltod der Osteoklasten. Über beide Mechanismen kommt es zu einer Hemmung der osteoklastischen Knochenresorption (Rogers et al. 1999). Da eine hohe osteoklastische Aktivität häufig mit Schmerzen einhergeht, haben sich Bisphosphonate außerdem als Analgetikum bei Knochenerkrankungen bewährt.

In verschiedenen Studien konnte für Alendronat (Black et al. 1996; Cummings et al. 1998) und Risedronat (Kanis et al. 2005) eine Verringerung von Wirbelkörper- und peripheren Frakturen ermittelt werden.

\subsubsection{Denosumab}

Denosumab ist ein humaner monoklonaler IgG-Antikörper gegen den Oberflächenrezeptor RANKL, der wesentlich für die Bildung, Funktion und das Überleben der Osteoklasten ist (Boyle et al. 2003). Durch die Bindung von Denosumab an RANKL wird die Interaktion mit seinem Rezepetor RANK auf Osteoklasten und Osteoklastenvorläuferzellen verhindert. Dieses Wirkprinzip führt zu einer indirekten Hemmung der Knochenresorption und somit zu einer Erhöhung der Knochenmineraldichte (Delmas 2008). In verschiedenen Studien konnte gezeigt werden, dass die subkutane Applikation von 60 mg Denosumab in halbjährlichen Abständen den Knochenverlust reduzieren und die Knochenmineraldichte erhöhen konnte (McClung et al. 2006; Bone et al. 
2008). In einer Studie aus dem Jahr 2009 konnte bei Patientinnen unter Therapie mit Denosumab das Risiko für vertebrale Frakturen um 68 \% gesenkt und das Risiko für Beckenringfrakturen um $40 \%$ reduziert werden (Cummings et al. 2009). Die Effektivität einer Behandlung mit Denosumab scheint nach der aktuellen Datenlage der Bisphosphonattherapie überlegen zu sein (Brown et al. 2009). Das Risiko für Osteonekrosen und atypische Femurfrakturen ist gegenüber der Bisphosphonattherapie geringer, allerdings zeigte sich ein erhöhtes Risiko für Infektionen und die Entstehung von Neoplasmen (Sutton und Riche 2012).

\subsubsection{Parathormon (PTH) und Teriparatid}

Parathormon und Teriparatid aktivieren Osteoblasten und Osteoklasten und führen zu einer Verbesserung der Knochenstruktur. Bei hohen Plasmaspiegeln von PTH kommt es zu einer Steigerung des osteoklastischen Knochenabbaus und einer Mobilisation von Kalzium aus dem Knochen. Niedrige Plasmaspiegel von PTH und Teriparatid führen hingegen zu einer höheren osteoblastischen Aktivität und wirken somit osteoanabol. In verschiedenen Studien konnte durch eine Therapie mit PTH das Risiko für ein Neuauftreten von vertebralen und nicht-vertebralen Frakturen signifikant verringert werden (Neer et al. 2001; Marcus et al. 2003). PTH und Teriparatid erhöhen die Knochenmineraldichte und verbessern die Mikroarchitektur des Knochens. In Experimenten an der ovariektomierten Ratte konnte unter Therapie mit Parathormon die biomechanische Belastbarkeit der Femurschenkelhälse im Vergleich zur nicht therapierten Kontrollgruppe signifikant verbessert werden (Tezval et al. 2010). Eine Behandlung mit PTH führte zu einer trabekulären, intrakortikalen und periostalen Zunahme der Knochenmasse (Sehmisch et al. 2009b).

PTH und Teriparatid sind indiziert, wenn eine progrediente Osteoporose mit unerwartetem und deutlichem Abfall der Knochenmineraldichte und neu aufgetretenen Frakturen vorliegt. Die Therapie umfasst eine subkutane Applikation des Medikaments pro Tag. Die Behandlungsdauer sollte zwei Jahre nicht überschreiten, da in Tierexperimenten die Inzidenz von Osteosarkomen nach Langzeittherapien erhöht war. Um den 
Effekt der Behandlung zu sichern, sollte im Anschluss an die Therapie mit Parathormon eine antiresorptive Behandlung über weitere zwei Jahre angeschlossen werden (Orwoll et al. 2003).

\subsubsection{Strontiumranelat}

Strontiumranelat ist ein antiosteoporotisches Medikament, welches sich chemisch aus einem organischen Anteil, der Ranelicsäure und zwei Atomen des Erdalkalimetalles Strontium zusammensetzt. Strontiumranelat vermittelt seinen Effekt über einen dualen Wirkmechanismus. Es reduziert den Knochenabbau (1) durch eine Hemmung der Differenzierung und Aktivität osteoklastischer Zellen und fördert den Knochenaufbau (2) über eine Steigerung der Präosteoblastenreplikation (Marie 2006). Zur Überprüfung der Wirksamkeit von Strontiumranelat wurden zwei große klinische Studien (SOTI-Studie $=$ Spinal Osteoporosis Therapeutic Intervention Study; TROPOSStudie $=$ Treatment Of Peripheral Osteoporosis Study) an postmenopausalen Frauen durchgeführt. Im Rahmen der Studien konnte gezeigt werden, dass das Risiko für vertebrale Frakturen nach einjähriger Strontiumranelattherapie um $49 \%$ und nach 3-jähriger Einnahme um 41 \% gesenkt werden konnte (Meunier et al. 2004). In der TROPOS-Studie konnte nachgewiesen werden, dass die Einnahme von Strontiumranelat das Risiko für Beckenfrakturen bei Hochrisikopatientinnen um 36 \% reduziert werden konnte. Ferner konnte die Knochenmineraldichte am Femurschenkelhals in drei Jahren um 8,2 \% erhöht werden (Reginster et al. 2005).

In verschiedenen an ovariektomierten Ratten durchgeführten Studien verringerte Strontiumranelat den trabekulären Knochenverlust und verbesserte die Mikroarchitektur und Festigkeit des Knochens (Marie et al. 1993).

Strontiumranelat hat sich zudem in der Schmerztherapie als sinnvoll erwiesen. In der nichtinterventionellen PERSPECTIVES-Studie wurde der Einfluss von Strontiumranelat auf die Schmerzintensität und den Analgetikaverbrauch untersucht. Die Gesamthäufigkeit von Schmerzen konnte unter der Einnahme von Strontiumranelat deutlich reduziert werden, die Zahl der Patientinnen mit Dauerschmerzen reduzierte sich um $66 \%$ (Felsenberg et al. 2012). 
Strontiumranelat ist neben den Bisphosphonaten ein Präparat der ersten Wahl bei manifester Osteoporose (DVO 2009). Im Januar 2014 sprach ein Ausschuss der Europäischen Arzneimittel-Agentur (EMA) die Empfehlung aus, die Therapieempfehlung für Strontiumranelat weiter einzuschränken, da vermehrt Herzinfarkte und venöse Thrombosen nach Strontiumranelateinnahme aufgetreten waren (Rote Liste ${ }^{\circledR}$ 2014).

\subsection{Vibration}

Bei der Ganzkörpervibration handelt es sich um eine Intervention für den Erhalt und die Verbesserung des Knochenskeletts bei Menschen mit einer verringerten Knochenmineraldichte. Ganzkörpervibration bezweckt, den Knochenaufbau zu fördern (Lanyon 1996) und den Knochenabbau zu verzögern (Rubin et al. 2000). In verschiedenen klinischen und tierexperimentellen Studien konnte gezeigt werden, dass mechanische Signale Regulatoren von Knochenmasse und Knochenarchitektur sind. Die Sensibilität des Skeletts gegenüber mechanischen Reizen bietet einen neuen therapeutischen und nicht-pharmakologischen Ansatz zur Behandlung der Osteoporose.

Knochen ist ein sich stets im Umbau befindendes Gewebe, welches auf mechanische Reize reagiert und das Skelett den Belastungen optimal anpasst. Dem Wolffschen Gesetz zufolge baut sich Knochen auf und nimmt an Festigkeit zu, wenn er belastet wird (Wolff 1852). Wird Knochen hingegen zu wenig oder etwa gar nicht belastet, kommt es zu einem Knochenabbau. Frost zeigte, dass fehlende körperliche Aktivität die mechanische Stimulation am Knochen vermindert und zu einem fortschreitenden Knochenabbau führt (Frost 1994). Das Phänomen des Knochenverlustes durch fehlende mechanische Reize konnte auch bei Astronauten beobachtet werden und ist möglicherweise eine der am besten erforschten Konsequenzen eines Weltraumaufenthaltes. Der Einsatz von Ganzkörpervibrationen bei Astronauten konnte nachweislich den progredienten Knochen- und Muskelschwund verringern (Goodship et al. 1998).

Die Vibration erfordert das Stehen des Patienten auf einer Vibrationsplattform. Die 
Vibrationsbewegungen werden über die Fußsohlen auf Knochen und Muskeln übertragen. Die Intensität der Vibration ist von 5 Faktoren abhängig, nämlich von der Richtung der Vibration (vertikal oder horizontal), der Vibrationsfrequenz (Hertz), der Vibrationsstärke (Amplitude), der Körperposition des Patienten und der Vibrationsdauer. Die Dauer der Vibration ist definiert als Länge einer Vibrationseinheit, die Empfehlungen liegen zwischen 2-20 Minuten, abhängig vom therapeutischen Ziel (Stewart et al. 2009). Die Bewegung der Vibrationsplattform während der Ganzkörpervibration aktiviert monosynaptische und polysynaptische Reflexbögen und generiert den sogenannten Vibrationsreflex. Dieser Reflex beinhaltet die zyklische An- und Entspannung der Muskeln während der Vibration und vermittelt somit die mechanischen Reize am Knochen (De Gail et al. 1966).

Ganzkörpervibrationsplatten bieten verschiedene Vibrationsfrequenzen und Amplituden. Die inneren Organe des Menschen schwingen mit einer Eigenfrequenz von 5-20 Hz, der Körper des Menschen versucht daher zusätzliche Schwingungen dieser Frequenz mithilfe von Knochen, Knorpel, Synovialflüssigkeit und Weichgewebe auszugleichen, um innere Verletzungen zu verhindern (Wakeling et al. 2002). Wird bei Frequenzen von über $70 \mathrm{~Hz}$ vibriert, so kann es zu Muskelschäden kommen (Carlsöö 1982). Die optimale Frequenz für ein Ganzkörpervibrationstraining als Schutz vor Knochenabbau sollte daher bei Menschen zwischen 20-70 Hz liegen.

In einer Studie aus dem Jahre 2004 wurden 70 randomisierte, postmenopausale Frauen zwischen 58-74 Jahren dreimal wöchentlich für jeweils 30 Minuten einer Ganzkörpervibration mit 35-40 Hz zugeführt. Die Studie erstreckte sich über einen Zeitraum von 6 Monaten. Das Vibrationstraining führte zu einer signifikanten Erhöhung der Knochendichte am proximalen Femur im Vergleich zur Kontrollgruppe (Verschueren et al. 2004).

In einer weiteren Studie aus dem Jahr 2006 wurden 28 postmenopausale Frauen über einen Zeitraum von 8 Monaten dreimal wöchentlich für $6 \times 60$ Sekunden bei $12 \mathrm{~Hz}$ vibriert. Die Knochendichte am Femur zeigte sich im Vergleich zur Kontrollgruppe ebenfalls signifikant erhöht (Gusi et al. 2006). 


\subsection{Fragestellung}

Ziel dieser Arbeit ist es, herauszufinden, ob eine vertikale Ganzkörpervibrationstherapie in Kombination mit einer Gabe von Strontiumranelat oder Parathormon zu einer verbesserten Knochenstruktur im osteoporotischen Rattenfemur führt. 


\section{Material und Methoden}

Das Experiment wurde unter der Leitung von PD Dr. med. Stephan Sehmisch durchgeführt. Der Tierversuch wurde durch das Landesamt für Verbraucherschutz genehmigt (Tierschutzantrag: G854.12).

\subsection{Allgemeines}

\subsubsection{Versuchsablauf}

Der Versuch startete mit 90 Ratten, die in 7 Versuchsgruppen (Tabelle 3) aufgeteilt wurden. Von den 90 Tieren wurde 12 zu Anfang des Versuches der SHAM-Gruppe zugeteilt und von den restlichen Tieren separiert. Die restlichen 78 Ratten wurden auf beiden Seiten ovariektomiert, um eine Osteoporose zu induzieren. Bei der Ovariektomie starben zwei Tiere, so dass sich die Gesamtzahl der Tiere auf 88 verringerte. Die Gruppe der ovariektomierten Ratten wurde nun in 6 Gruppen auf die 6 Versuchsgruppen (OVX, OVX+VIB, SR, SR+VIB, PTH und PTH+VIB) mit jeweils 10-12 Tieren eingeteilt. Je nach Zuteilung der Ratten wurde nach der Osteotomie mit der medikamentösen Therapie begonnen. Die zwei Gruppen OVX und OVX+VIB erhielten keine medikamentöse Therapie. Die zwei Gruppen SR und SR+VIB erhielten über die Nahrungsaufnahme Strontiumranelat in einer Dosierung von 600-625 mg pro kg Körpergewicht pro Tag. Die zwei Gruppen PTH und PTH+VIB erhielten PTH subcutan 5 mal wöchentlich in einer Dosierung von $40 \mu \mathrm{g}$ pro kg Körpergewicht pro Tag. 8 Wochen später erfolgte bei allen ovariektomierten Ratten die Osteotomie und Osteosynthese der metaphysären Tibiae bei den Gruppen OVX, OVX+VIB, SR, SR+VIB, PTH und PTH+VIB. Bei diesem Eingriff starben 12 Tiere, so dass sich das Gesamtkollektiv auf 76 Ratten verringerte. 5 Tage nach der zweiten Operation begann die vertikale Ganzkörpervibration der Ratten aus den Gruppen OVX+VIB, SR+VIB und PTH+VIB bei $70 \mathrm{~Hz}$ für 2x15 Minuten täglich. Um 
nach Ablauf des gesamten Experiments die Aktivität der Knochenzellen und den Knochenumbau beurteilen zu können, wurde bei den Ratten während des Versuches eine Polysequenzmarkierung durchgeführt (Rahn 1976). Die Tiere erhielten dafür am 8. Tag nach Beginn der Ganzkörpervibration Xylenol-Orange, am 13. Tag Calcein Grün, am 19. und 21. Tag Alzarin-Komplexon und am 30. Tag Tetracyclin. 35 Tage nach der Osteotomie wurden die Tiere schließlich in $\mathrm{CO}_{2}$ Narkose durch Dekapitation getötet und Knochen, Muskeln und Blut für weitere Untersuchungen entnommen. Von jedem Versuchstier wurde jeweils einer der gewonnen Oberschenkelknochen wurde für den Bruchtest und die Veraschung verwendet, während der andere für die Mikroradiographie genutzt wurde.

Tabelle 3: Versuchsgruppen

\begin{tabular}{|l|l|}
\hline Abkürzung & Beschreibung \\
\hline SHAM & Kontrollgruppe, nicht ovariektomiert \\
\hline OVX & nur Ovariektomie \\
\hline OVX+VIB & Ovariektomie und Vibration \\
\hline SR & Ovariektomie und Strontiumranelat über Nahrungsaufnahme \\
\hline SR+VIB & $\begin{array}{l}\text { Ovariektomie, Vibration, Strontiumranelat über Nahrungsauf- } \\
\text { nahme }\end{array}$ \\
\hline PTH & Ovariektomie und PTH subkutan \\
\hline PTH+VIB & Ovariektomie, Vibration, PTH subkutan \\
\hline
\end{tabular}

\subsubsection{Versuchstiere}

Für die Experimente wurden drei Monate alte Ratten der Rasse Sprague-Dawley verwendet. Die Tiere wurden während des gesamten Experiments in der tierexperimentellen Einrichtung der Universitätsmedizin Göttingen gehalten und von den dort beschäftigten Tierpflegern täglich kontrolliert und versorgt. Die Tiere lebten in Gruppen bestehend aus 3- 5 Tieren pro Käfig. Die Tiere wurden einmal wöchentlich in neue, desinfizierte Käfige umgesetzt. Sojafreies Futter (ssniff SM R/M, 10mm-Pellets, 
ssniff Spezialdiäten $\mathrm{GmbH}$, Soest) und Wasser wurden ad libitum bereitgestellt. Die Umgebungstemperatur betrug durchgängig $22+/-1{ }^{\circ} \mathrm{C}$ und es wurde ein Hell-Dunkel Wechsel von $12 \mathrm{~h}$ eingehalten. Zur Stoffwechselkontrolle wurden die Tiere wöchentlich gewogen.

\subsubsection{Ovariektomie}

Die Operation erfolgte unter einer intraperitonealen Anästhesie, bestehend aus Ketamin (90 mg pro kg KG, Hostaket ${ }^{\circledR}$, Firma Hoechst, Bad Soden) und Xylazin (7,5 mg pro kg KG, Rompun ${ }^{\circledR}$, Firma Bayer, Leverkusen). Für die Operation waren zunächst eine Entfernung der Haare sowie eine Desinfektion und dann die Eröffnung der Bauchhaut zwischen dem untersten Rippenbögen und den Hinterläufen mit einer scharfen Schere notwendig. Daraufhin wurde das Peritoneum durchtrennt und die Ovarien dargestellt. Die Tubae uterinae wurden ligiert, das Ovar abgetrennt und dann mit einem Skalpell entfernt. Die Adnexe wurden in den Bauchraum zurückverlagert und die Bauchmuskulatur mit Vicrylfaden der Stärke 4x0 genäht. Die Bauchhaut wurde mit Klammern verschlossen. Die Ratten wurden nach der Operation auf einer Wärmeplatte bis zum Erwachen aus der Narkose überwacht und erhielten postoperativ $3 \mathrm{ml}$ $\mathrm{NaCl}$ subkutan zur Stabilisierung des Flüssigkeitshaushaltes.

\subsubsection{Osteotomie und Osteosynthese}

Acht Wochen nach der Ovariektomie, als die Tiere eine Osteoporose entwickelt hatten, folgten die Osteotomie und die Osteosynthese (OVX, OVX+VIB, SR, SR+VIB, PTH und PTH+VIB). Dazu wurde bei den Tieren eine beidseitige transverse Osteotomie der metaphysealen Tibia durchgeführt. Die Operation wurde erneut unter einer Anästhesie, bestehend aus Ketamin und Xylazin durchgeführt. Es erfolgte zunächst die Entfernung der Haare in der entsprechenden Region und die sorgfältige Desinfektion. Dann wurde mit einem Skalpell die Haut auf der Beininnenseite inzidiert und die Patellarsehnen dargestellt. Es wurde eine 5-Loch-T-Platte (Stryker Trauma, Schweiz) aus Titan eingefügt und die Löcher zur Befestigung gebohrt. Ungefähr $7 \mathrm{~mm}$ distal des 
Kniegelenks wurde dann mithilfe einer pulsed ultra sound Säge (Piezosurgery, Mectron Medical Technology, Italien) die Osteotomie durchgeführt, der Frakturspalt hatte eine Dicke von ca. $1 \mathrm{~mm}$. Die 5-Loch-T-Platte wurde ventro-medial mit vier Schrauben befestigt. Der Wundverschluss erfolgte durch das Vernähen der Muskulatur mit Vicrylfaden. Die Haut wurde sorgfältig geklammert. Die Ratten wurden nach der Operation auf einer Wärmeplatte bis zum Erwachen überwacht und erhielten postoperativ $3 \mathrm{ml} \mathrm{NaCL}$ zur Stabilisierung des Flüssigkeitshaushaltes. Zur Schmerzprophylaxe erhielten die Tiere Rimadyl am 1. und 2. postoperativen Tag intramuskulär. Der Heilungsverlauf und die Funktionsfähigkeit der Osteosynthese wurden regelmäßig durch Tierärzte und Tierpfleger kontrolliert.

Die Ergebnisse der Frakturheilung werden in einer anderen Studie ausgewertet.

\subsubsection{Ganzkörpervibration}

Fünf Tage nach der Osteosynthese der Tibiae wurde bei 33 Ratten (OVX+VIB, SR+VIB und $\mathrm{PTH}+\mathrm{VIB}$ ) mit der Ganzkörpervibration begonnen. Die Tiere wurden täglich zur gleichen Uhrzeit 2x 15 Minuten bei $70 \mathrm{~Hz}$ mit einer Amplitude von 0,5 mm vibriert.

Für die Vibration wurden jeweils 6 bis 7 Ratten in eine gepolsterte Vibrationsbox (Vibriertisch VTG, Drehstrom- Vibrationsmotor Typ HVL/HVE, Vibra Schultheis, Offenbach) gesetzt. In dieser Box konnten sich die Ratten frei bewegen, wobei stets darauf geachtet wurde, dass die Ratten Fuß-Bodenkontakt halten und sich nicht aufeinander legen, um den größtmöglichen Effekt der Vibration auszunutzen.

\subsubsection{Tötung der Versuchstiere}

Die Tiere wurde 35 Tage nach der Osteotomie zunächst durch eine tiefe $\mathrm{CO}_{2}$ Narkose betäubt und dann durch Dekapitation getötet.

\subsubsection{Präparation der Femora}

Für die Präparation der Femora wurden nach Dekapitation der Tiere die Hinterläufe im jeweiligen Hüftgelenk der Ratten abgetrennt. Es folgte das Präparieren des Knochens durch Entfernen von Haut, Muskulatur, Sehnen und Knorpel mit dem Skalpell. Muskel- 
reste und Sehnenansätze wurden mit dem scharfen Löffel entfernt. Bis zur weiteren Verwendung wurden die Femora bei $-20^{\circ} \mathrm{C}$ tiefgefroren.

\subsection{Biomechanischer Kompressionstest}

\subsubsection{Ablauf des biomechanischen Kompressionstests}

Die mechanische Stabilität der Femora wurde mithilfe eines biomechanischen Kompressionstests untersucht. Die in Kühlung befindlichen Femora wurden für dieses Experiment zunächst für zwei Stunden bei Raumtemperatur aufgetaut. Für die Untersuchung wurde der Femur mit dem Trochanter major in einer vorgelochten Aluminiumbasis fixiert, um das Verrutschen des Knochens während der Krafteinwirkung zu verhindern. Der Femur und die Aluminiumbasis wurden dann in das Kompressionsgerät (Typ 145660 Z020/TND Zwick/Roell, Ulm, Deutschland) eingespannt und verschraubt. Der Druckstempel des Kompressionsgerätes wurde mit seiner Fläche exakt in einem $90^{\circ}$ Winkel über dem Schenkelhals positioniert. Der Kompressionstest wurde mit der testxpert-Software gestartet. Der Stempel des Kompressionsgerätes bewegte sich auf den eingespannten Femur zu, bis zum Erreichen einer Vorkraft von 1 N. Der Untersucher prüfte nun noch einmal die korrekte Lage des Femur und die optimale Stempelposition über dem Schenkelhals, dann wurde der Test gestartet. Das Kompressionsgerät senkte den Stempel mit einer Geschwindigkeit von $50 \mathrm{~mm} / \mathrm{min}$ immer weiter ab und führte so zu seiner Kompression des Femur in axialer Richtung. Die Kompression wurde bis zur Fraktur des Schenkelhalses durchgeführt (Tezval et al. 2010).

\subsubsection{Messparameter des biomechanischen Kompressionstests}

\subsubsection{Maximalkraft}

Die Maximalkraft $F_{(\max )}$ ist die größte Kraft, die im Kompressionstest aufgebracht werden konnte, bevor es zu einer Fraktur des Femurschenkelhalses kam. 


\subsubsection{Steigung}

Dieser Parameter entspricht der linearen Steigung des Graphen im Kraft-WegDiagramm während der elastischen Verformung des zu untersuchenden Femurs vom Beginn des Kompressionsversuches bis zur Fraktur.

\subsubsection{Validierung des Untersuchers für den biomechanischen Kompressionstest}

Um eine Beeinflussung des Experiments durch den Untersucher auszuschließen, wurde die Reliabilität des Untersuchers vor Beginn des Experimentes überprüft. Für die Validierung wurden jeweils der linke und der rechte Femur von 10 Ratten, die in Gewicht und Größe den Versuchstieren unseres Experiments glichen, einem Kompressionstest unterzogen. Wie bei dem Experiment wurden auch bei der Validierung die beiden Parameter Steigung und Maximalkraft erhoben und intraindividuelle Abweichungen (zwischen dem linken und rechten Femur jeder Ratte) errechnet. In der Auswertung der Ergebnisse durften die einzelnen Werte für Maximalkraft und Steigung nicht mehr als $10 \%$ voneinander variieren.

\subsection{Mikroradiographie}

Die Mikroradiographie wurde nach der abteilungsüblichen Verfahrensweise, wie im Folgenden beschrieben, angefertigt.

Die Femora der Ratten wurden nach Präparation in einer aufsteigenden Ethanolreihe entwässert und entfettet. Die Knochen lagerten zunächst für zweimal drei Tage in $40 \%$ Ethanol, dann zweimal 5-6 Tage in 80 \% Ethanol und zwei Tage in 96 \% Ethanol. Daraufhin wurden die Knochen für zwei Tage in einem Gemisch aus 96 \% Ethanol und Methylmetacrylat in einem Verhältnis von 1:1 gelagert. Darauf folgten zwei weitere Tage Lagerung in reinem Methylmetacrylat. Die Femora wurden nach Durchlaufen der Ethanolreihe einzeln in einem Gemisch aus insgesamt $1000 \mathrm{ml}$ Methylmetacrylat, $200 \mathrm{ml}$ Dibutylphthalat und $29 \mathrm{~g}$ Benzoylperoxid eingebettet. Nach etwa 21 Tagen waren die Methylmetacrylatblöcke ausgehärtet. Mithilfe einer Innenlochsäge (Leica SP 
1600 Diamantsäge, Leica Instruments $\mathrm{GmbH}$, Nussloch) wurden dann aus jedem Femur $10100 \mu \mathrm{m}(+/-20 \mu \mathrm{m})$ dünne Sagittalschnitte gesägt. Die Sagittalschnitte wurden im Faxitron Röntgengerät (Hewlett Packard, San Diego, USA, Model-Nummer 43855A) auf einem Kodak Professional Film (Industrex SR 45) geröntgt. Die Röhrenspannung lag bei einer Belichtungszeit von 6 Minuten bei $40 \mathrm{kV}$ und die Stromstärke bei 0,3 mA (Döll 2011).

\subsubsection{Digitalisieren der Mikroradiographie}

Um digitalisierte Abbildungen von den Sagittalschnitten zu erstellen, wurden jeweils drei Sagittalschnitte pro Femur unter dem Makroskop (Leica Stereomakroskop MZ 7-5) untersucht. Für die mechanische Blende wurde konstant die Schalterposition "B" eingestellt, dies entsprach einer mäßigen Helligkeit (A: geringste Helligkeit, E: maximale Helligkeit). Aus technischen Gründen variierte die Dicke der Schnitte und lag zwischen 80-120 $\mu \mathrm{m}$. Trotz identischer Einstellung war dementsprechend die Helligkeit bei Betrachtung der Bilder unterschiedlich. Dies konnte durch Veränderungen der Temperatur der Kaltlichtlampe (Leica KL 1500 LCD) beeinflusst werden, die Temperatur lag jedoch stets zwischen 2800-3000 K.

Die Sagittalschnitte der Femora wurden einzeln unter dem Makroskop positioniert und über eine mit dem Computer (Intel Pentium 4, 2,6 GHz) verbundene Kamera (Leica DC 300F) eingelesen. Mithilfe des 1,0-Objektivs wurden die eingelesenen Schnitte in optimaler Größe auf dem Monitor abgebildet und die Belichtungszeit konstant auf 766 ms eingestellt. Das digitalisierte Bild konnte dann mit der entsprechenden Software (Leica Quantimet OWin 2003) bearbeitet und mit einem standardisierten Algorithmus ausgewertet werden (Döll 2011).

\subsubsection{Histomorphometrische Auswertung der Mikroradiographien}

Die Untersuchung wurde blind durchgeführt, der Untersucher hatte also keinerlei Kenntnis davon, welcher Versuchsgruppe der zu analysierende Sagittalschnitt zuzuordnen war. Für die digitale Auswertung wurde ein standardisiertes Verfahren 
entwickelt, welches benutzerunabhängig durchgeführt werden konnte. Für die Untersuchung wurde ein Programm spezifisch für die Sagittalschnitte der Femora der Ratte entwickelt. Die Analyse der Mikroradiographien wurde jeweils an einem Sagittalschnitt eines Femurs durchgeführt und umfasste folgende Arbeitsschritte: 1. Graudetektion, 2. Messung der Gesamtfläche des Femurkopfes, 3. Messung der Trabekelfläche, 4. Messung der medialen und lateralen Kortikalisdicke.

\subsubsection{Graudetektion}

Durch die Software wurden automatisch alle als Knochen erkannten Bereiche in den Bildern aus der Mikroradiographie blau gefärbt, Ungenauigkeiten der Software wurden zusätzlich durch den Untersucher manuell korrigiert. Die Graudetektion ermöglichte der Software in den weiteren Auswertungsschritten korrekt zwischen knöchernen und nicht-knöchernen Strukturen eindeutig zu unterscheiden.

\subsubsection{Messung Gesamtfläche am Femurkopf}

In der folgenden Untersuchung wurde die Fläche des Femurkopfes bestimmt. Um die Fläche zu erfassen, wurde entlang des äußeren Randes der Kortikalis durch den Untersucher manuell eine Linie gezogen, wobei ein Pixel einer Länge von 6,73 $\mu \mathrm{m}$ entsprach.

\subsubsection{Messung der endostalen Gesamtfläche und des Trabekelwerks}

Die endostale Gesamtfläche beinhaltet knöcherne und nicht-knöcherne Anteile und wird in $\mathrm{mm}^{2}$ gemessen. Für die Unterscheidung zwischen kortikaler und trabekulärer Gesamtfläche wurde durch den Untersucher manuell eine weitere Linie gezogen. Die Linie verlief entlang des Endosts an der inneren Kortikalis. Als kaudale Begrenzung diente die Epiphysenfuge. Der Bereich innerhalb des Endosts wurde der trabekulären Fläche (Tb. Ar) zugerechnet. Die Fläche zwischen den Linien aus der Messung der Gesamtfläche und der Messung der endostalen Gesamtfläche wurde als Kortikalis (Ct.) bestimmt. Die trabekuläre Knochenfläche bezeichnet die endostale Gesamtfläche abzüglich der nicht-knöchernen Anteile in $\mathrm{mm}^{2}$. Die mittlere Trabekeldicke (Tr. Wi) 
bezeichnet die durchschnittliche Trabekeldicke eines Sagittalschnittes in $\mu \mathrm{m}$. Die Anzahl der Trabekelkreuzungen (Tr. N) ist definiert als gefundene Anzahl an Trabekelkreuzungen innerhalb der trabekulären Knochenfläche. Die Dichte der Trabekelkreuzungen (Tr. N. $\mathrm{mm}^{2}$ ) beschreibt die mittlere Anzahl der Trabekelkreuzungen pro $\mathrm{mm}^{2}$, gemessen innerhalb der trabekulären Knochenfläche. In Klammern beschrieben finden sich die konventionellen histomorphometrischen Parameter nach Parfitt (Parfitt et al. 1987).

\subsection{Veraschung}

Für die Bestimmung des Anteils der organischen und anorganischen (insbesondere des Kalzium- und Phosphat- und Strontiumranelatgehaltes) Knochensubstanz an den Knochenproben der Ratten wurde nach der abteilungsüblichen Verfahrensweise vorgegangen. Zur Bestimmung des Anteils der organischen und anorganischen Knochensubstanz wird ein Glührückstand erzeugt. Ein Porzellantiegel wird zunächst analytisch gewogen. Das Ergebnis ist die Tara. Die Knochenprobe wird in diesen Tiegel gelegt und die Gesamtmasse anschließend wieder analytisch gewogen. Hiermit wurde die Gesamtmasse der Knochen vor der Veraschung ( $m$ vor Veraschung) bestimmt (Masse Knochen und Tiegel - Masse Tiegel). Darauf folgten die Veraschung, indem die Knochen für 30 Minuten auf $750{ }^{\circ} \mathrm{C}$ erhitzt wurden, eine Abkühlung des Glührückstandes auf Raumtemperatur im Exsikkator über Kieselgel und die Bestimmung der Gesamtmasse nach der Veraschung. Durch erneutes analytisches Wiegen erfolgt die Bestimmung der Gesamtmasse ( $m$ nach Veraschung $=$ Masse Glührückstand und Tiegel - Masse Tiegel).

Aus den beiden Gesamtmassen wurde der jeweils prozentuale Anteil von organischer

( $\%$ organische Substanz $)$ und anorganischer ( $\%$ anorganische Substanz $)$ Substanz mit den folgenden Formeln bestimmt:

$$
\begin{array}{ll}
\% \text { organische Substanz } & =((m \text { vor Veraschung }-m \text { nach Veraschung }) * 100) / m \text { vor Veraschung } \\
\% \text { anorganische Substanz } & =100-\% \text { organische Substanz }
\end{array}
$$




\subsubsection{Bestimmung von Kalzium-, Phosphat- und Strontiumgehalt}

Der Kalziumgehalt der Knochensubstanz wurde mittels Atomabsorptionsspektroskopie (DIN EN ISO 7980:2000), der Phosphatgehalt durch Photometrie des PhosphatMolybdänblau-Komplexes (DIN EN ISO 6878:2004) bestimmt. Der Säureaufschluss des Glührückstandes wurde mit 10 \%-Salpetersäure durchgeführt. Dafür wurden zunächst 50 mg des gemörserten Glührückstandes in 200 ml 10 \%-Salpetersäure auf Siedetemperatur erhitzt (Lösung A). Die klare Lösung wurde mit $\mathrm{H}_{2} \mathrm{O}$ auf $1000 \mathrm{ml}$ aufgefüllt. Vor der eigentlichen Bestimmung der Kalzium- und Phosphatwerte erfolgte eine Verdünnung der Probe um Faktor 1:20 (Lösung B), um eine Konzentration zu erhalten, die im Vertrauensbereich des Messverfahrens liegt.

Für die Bestimmung des Phosphatgehaltes wird der Probe (Lösung B) CitronensäureMonohydrat zugesetzt und gelöst, um störendes Kalzium zu komplexieren. Nach Zusatz von Phosphatreagenz erfolgt nach 10-minütiger Reaktionszeit die Messung der Extinktion, bei einer Messwellenlänge von $690 \mathrm{~nm}$, in einer Küvette und mit einer Blindprobe mit destilliertem Wasser verglichen. Um die gemessenen Extinktionen zu bestimmen wurde eine Abgleichgerade erstellt. Hierfür wurden die Extinktionen einer Verdünnungsreihe einer Phosphat-Standardlösung (Konzentrationsintervall 0,25 bis $2,0 \mathrm{mg} / \mathrm{l}$ ) gemessen.

Für die Bestimmung des Kalziumgehaltes wurde eine Flammatomabsorptionsspektroskopie der Probe angewendet. Die Lösung B wurde nach Zugabe von Lanthanchlorid flammatomabsorptionsspektroskopiert. Darauf folgte die Bestimmung der Extinktion der durch Kalzium verursachten Flammenfärbung an der Kalzium-Emissionsbande von $422,8 \mathrm{~nm}$. Um die gemessenen Extinktionen zu bestimmen wurde eine Abgleichgerade erstellt. Hierfür wurden die Extinktionen einer Verdünnungsreihe einer KalziumStandardlösung (Konzentrationsintervall 0,15 bis 5,0 mg/l) gemessen.

Die Bestimmung des Strontiumgehaltes wurde in der unverdünnten Lösung $A$ aus $50 \mathrm{mg}$ des gemörserten Glührückstandes, $200 \mathrm{ml} 10 \%$-Salpetersäure und $\mathrm{H}_{2} \mathrm{O}$ durchgeführt. Die Probe wurde nach Zugabe von Lanthanchlorid flammatomabsorpti- 
onsspektroskopiert. Darauf folgte die Bestimmung der Extinktion der durch Strontium verursachten Flammenfärbung an der Strontium-Emissionbande von 460,7 nm. Hierfür wurde die Extinktion an einer Strontiumranelat-Standardlösung (Konzentrationsintervall $0,1-5,0 \mathrm{mg} / \mathrm{l}$ ) gemessen.

\subsection{Statistik}

Die statistischen Berechnungen sowie die graphischen Darstellungen im Anhang der vorliegenden Arbeit wurden mit der Software GraphPad Prism (Version 4.00a, April 2003, GraphPad Software Inc., San Diego, USA) erstellt. Die graphischen Darstellungen im Ergebniskapitel wurden mit Excel (Microsoft Office 2010) erstellt.

Die Daten aus unseren Experimenten wurden mithilfe einer one-way ANOVA auf signifikante Unterschiede zwischen den einzelnen Versuchsgruppen überprüft. Bei signifikanten Unterschieden erfolgte anschließend eine genauere Analyse dieser Unterschiede mittels Tukey-Kramer post-hoc Test.

Die maximal zulässige Irrtumswahrscheinlichkeit wurde auf $5 \%$ festgelegt, dies entspricht einem Signifikanzniveau $\alpha \leq 0,05$. 


\section{Ergebnisse}

Zur Kontrolle des Experiments wurden verschiedene Parameter erhoben, hierzu gehörten Körpergewicht, Futteraufnahme und das Uterusgewicht nach der Tötung.

\subsection{Körpergewicht}

Im Verlauf des Experiments wurde das Körpergewicht der Ratten wöchentlich gemessen. Das durchschnittliche Gewicht stieg in allen Gruppen über den Zeitraum des Experiments an. Dargestellt ist dies im Folgenden als Verlauf mit wöchentlichen Messungen (Abb. 1), zu den Zeitpunkten der Ovariektomie (Abb. 2), der Osteotomie (Abb. 3) und der Tötung (Abb. 4, Tab. 4).

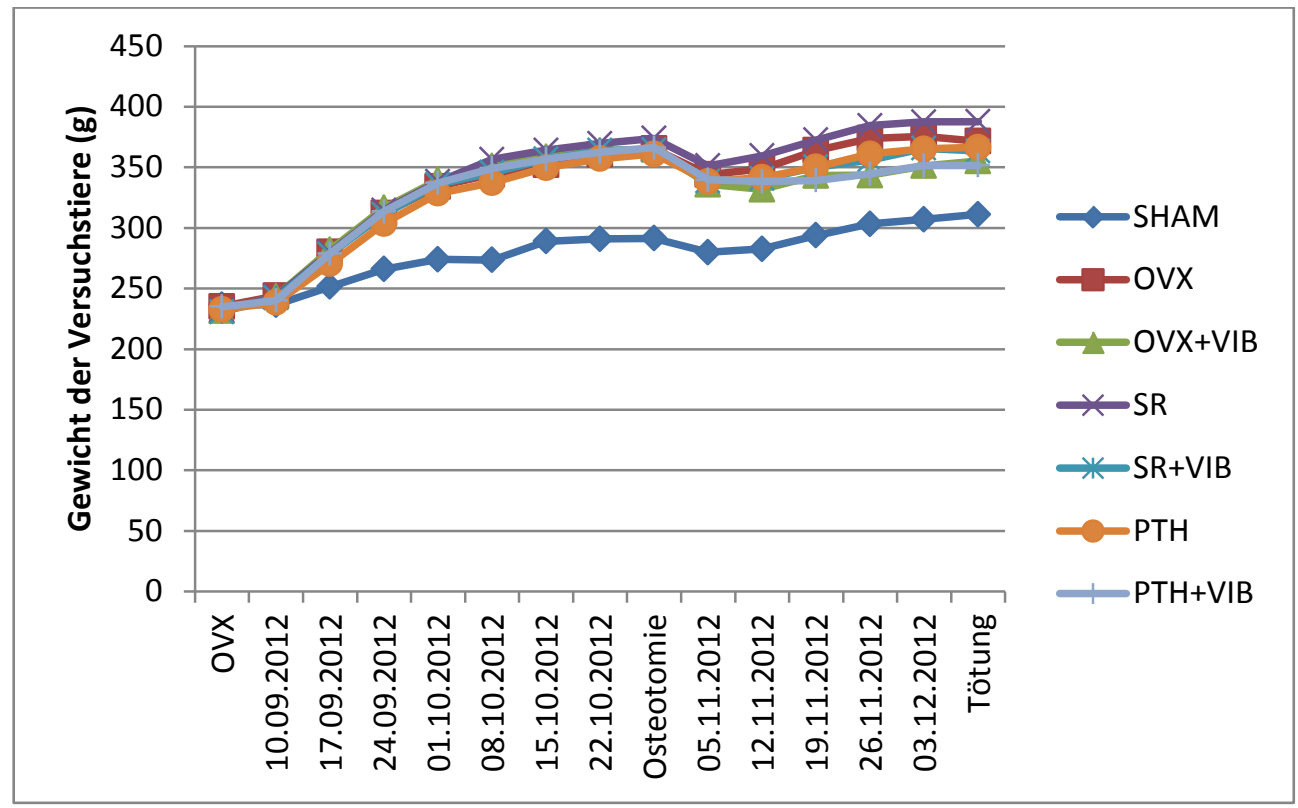

Abbildung 1: Gewichtsentwicklung der Versuchstiere über den Versuchszeitraum. 
Zum Zeitpunkt der Ovariektomie wurde kein Körpergewichtsunterschied gefunden ( $p=0,1044$; Mittelwerte mit Standardabweichung in Abb. 2 und Tab. 4). Da die Tiere bis zur Ovariektomie gleich behandelt wurden und dann zufällig auf die Versuchsgruppen verteilt wurden, entsprach dies der Erwartung.

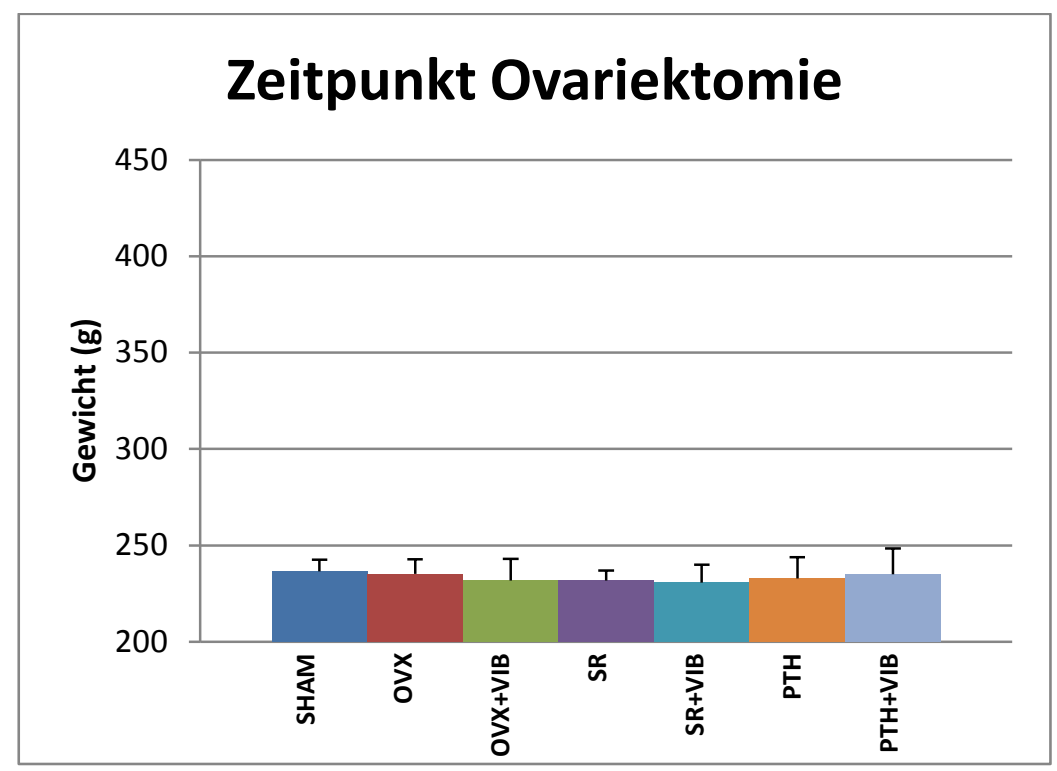

Abbildung 2: Gewicht der Versuchstiere zum Zeitpunkt der Ovariektomie 
Im Gegensatz zu dem Zeitpunkt der Ovariektomie konnte zum Zeitpunkt der Osteotomie - in Bezug auf das Körpergewicht - über alle Versuchsgruppen ein signifikanter Effekt nachgewiesen werden ( $p$-Wert $<0,0001$; Mittelwerte mit Standardabweichung in Abb. 3 und Tab. 4 ). Die Detailanalyse zeigte, dass im Vergleich zur SHAMVersuchsgruppe das Körpergewicht in allen anderen Versuchsgruppen signifikant erhöht war. Für alle anderen Vergleiche zwischen den Versuchsgruppen konnten keine signifikanten Unterschiede zwischen den Versuchsgruppen nachgewiesen werden.

Dies bedeutet, dass die Tiere, die einer Ovariektomie unterzogen wurden, bis zum Zeitpunkt der Osteotomie wesentlich stärker an Gewicht zunahmen.

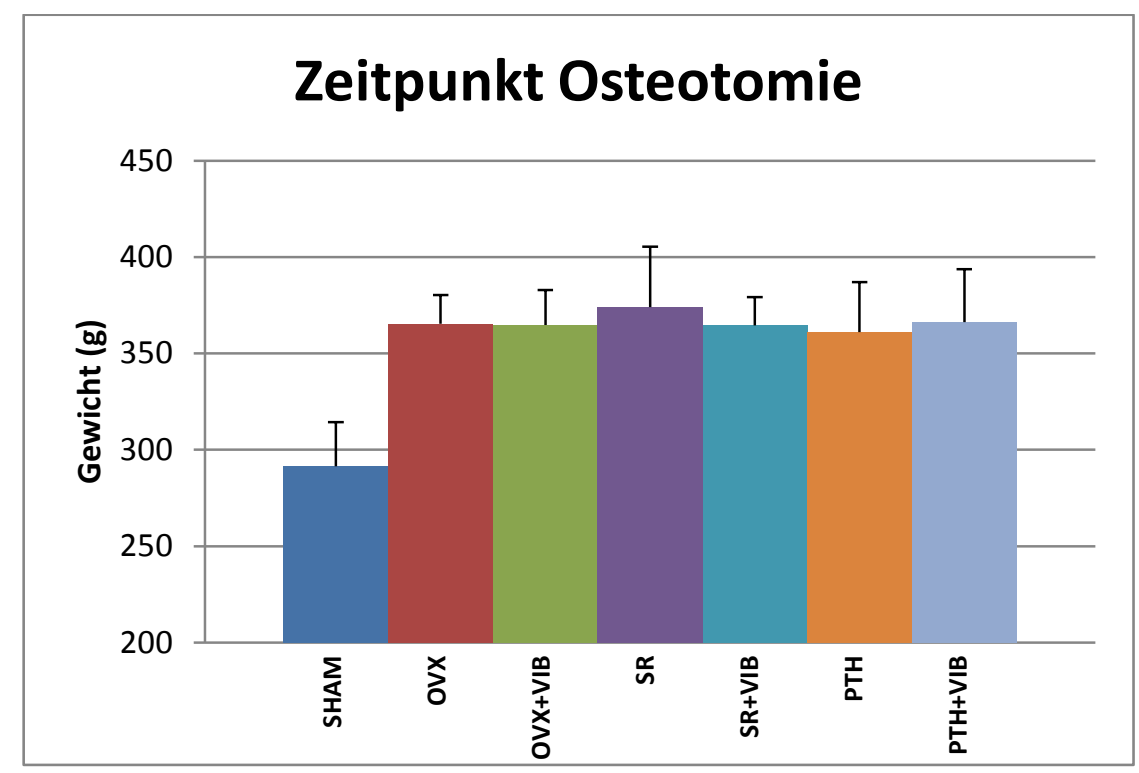

Abbildung 3: Gewicht der Versuchstiere zum Zeitpunkt der Osteotomie 
Zum Zeitpunkt der Tötung konnte erneut über alle Gruppen ein signifikanter Effekt bezüglich des Körpergewichtes nachgewiesen werden ( $p$-Wert $<0,0001$; Mittelwerte mit Standardabweichung in Abb. 4 und Tab. 4). Die Detailanalyse zeigte, dass die Tiere der SHAM-Versuchsgruppe zum Zeitpunkt der Osteotomie signifikant weniger wogen als die Tiere der Versuchsgruppen OVX, OVX+VIB, SR, SR+VIB, PTH und PTH+VIB. Die Detailanalyse zeigte, dass die Tiere in der SR-Versuchsgruppe signifikant mehr Gewicht hatten als die Tiere der PTH + VIB Versuchsgruppe. Für alle anderen Vergleiche konnten keine signifikanten Unterschiede zwischen den Versuchsgruppen nachgewiesen werden.

Dies bedeutet, dass die Tiere ohne Ovariektomie im Verlauf des Experiments weniger an Gewicht zunahmen als die Tiere, die einer Ovariektomie unterzogen worden waren.

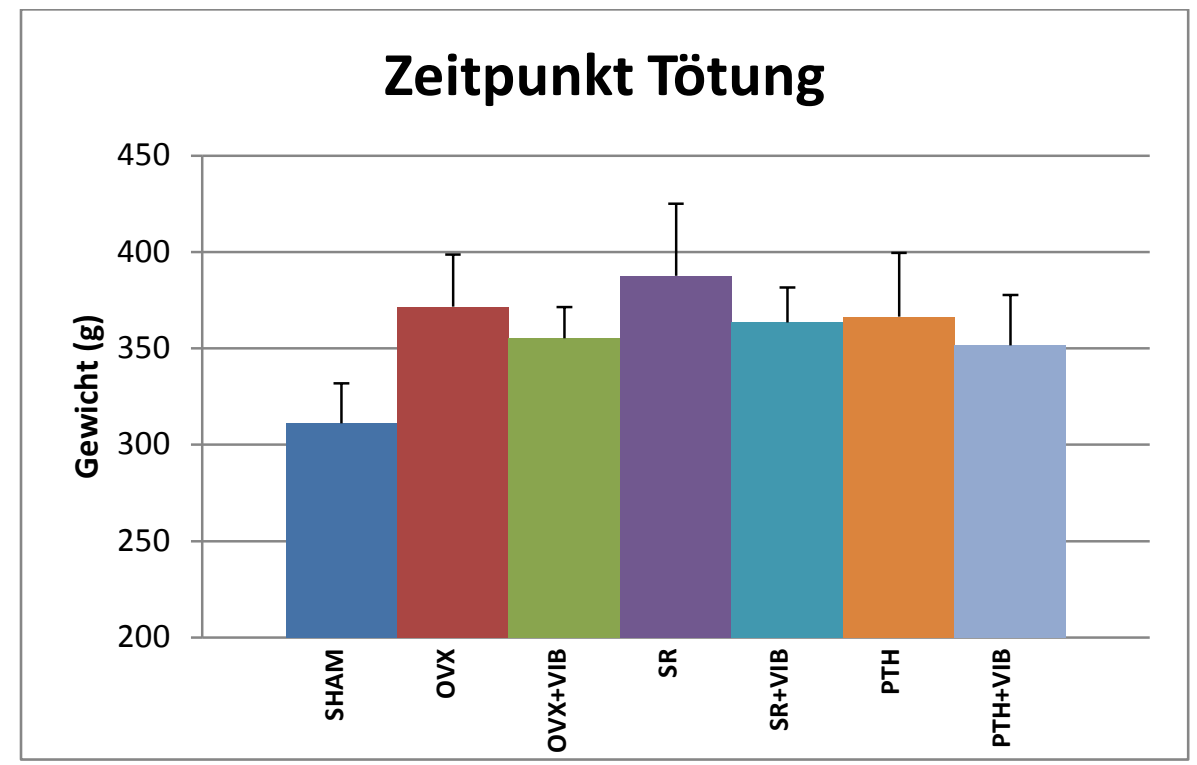

Abbildung 4: Gewicht der Versuchstiere zum Zeitpunkt der Tötung 
Tabelle 4: Durchschnittliches Gewicht der Versuchstiere pro Woche

\begin{tabular}{|c|c|c|c|c|c|c|c|c|c|c|c|c|c|c|}
\hline & \multicolumn{2}{|c|}{ SHAM } & \multicolumn{2}{|c|}{ OVX } & \multicolumn{2}{|c|}{ OVX+VIB } & \multicolumn{2}{|c|}{ SR } & \multicolumn{2}{|c|}{ SR+VIB } & \multicolumn{2}{|c|}{ PTH } & \multicolumn{2}{|c|}{ PTH+VIB } \\
\hline & Mittelwert & SD & Mittelwert & SD & Mittelwert & SD & Mittelwert & SD & Mittelwert & SD & Mittelwert & SD & Mittelwert & SD \\
\hline OVX & 236,58 & 5,88 & 235,17 & 7,64 & 231,67 & 11,36 & 231,85 & 5,13 & 230,71 & 9,35 & 232,77 & 11,08 & 234,92 & 13,41 \\
\hline $\begin{array}{l}\text { Osteotomie } \\
\text { 29.10.- } \\
01.11 .2012\end{array}$ & 291,45 & 22,85 & 365,36 & 14,85 & 364,80 & 17,99 & 373,92 & 31,50 & 364,46 & 14,79 & 361,00 & 25,91 & 366,20 & 27,44 \\
\hline $\begin{array}{l}\text { Tag der } \\
\text { Tötung } \\
\text { 10.-13.12.2012 }\end{array}$ & 311,18 & 20,77 & 371,60 & 27,06 & 355,17 & 16,23 & 387,64 & 37,45 & 363,36 & 18,33 & 366,45 & 33,04 & 351,64 & 26,00 \\
\hline
\end{tabular}

(SD = Standardabweichung) 


\subsection{Uterusgewicht}

Nach der Tötung der Tiere wurde das Gewicht der entnommenen Uteri einzeln gemessen, um den Erfolg der Ovariektomie zu überprüfen.

Über die Werte der Uterusgewichte konnte zum Zeitpunkt der Tötung insgesamt ein signifikanter Effekt nachgewiesen werden ( $p$-Wert $<0,0001$; Mittelwerte mit Standardabweichung in Abb. 5 und Tab. 5). Die Detailanalyse zeigte, dass im Vergleich zur SHAMVersuchsgruppe das Uterusgewicht in 6 anderen Versuchsgruppen signifikant niedriger war. Ein signifikant niedrigeres Uterusgewicht wurde in den Versuchsgruppen OVX, OVX + VIB, SR, $\mathrm{SR}+\mathrm{VIB}, \mathrm{PTH}$, und der Versuchsgruppe PTH + VIB gemessen. Für alle anderen Vergleiche konnten keine signifikanten Unterschiede zwischen den Versuchsgruppen nachgewiesen werden.

Anhand der gemessenen Uterusgewichte konnte gezeigt werden, dass die Ovariektomien erfolgreich durchgeführt worden sind.

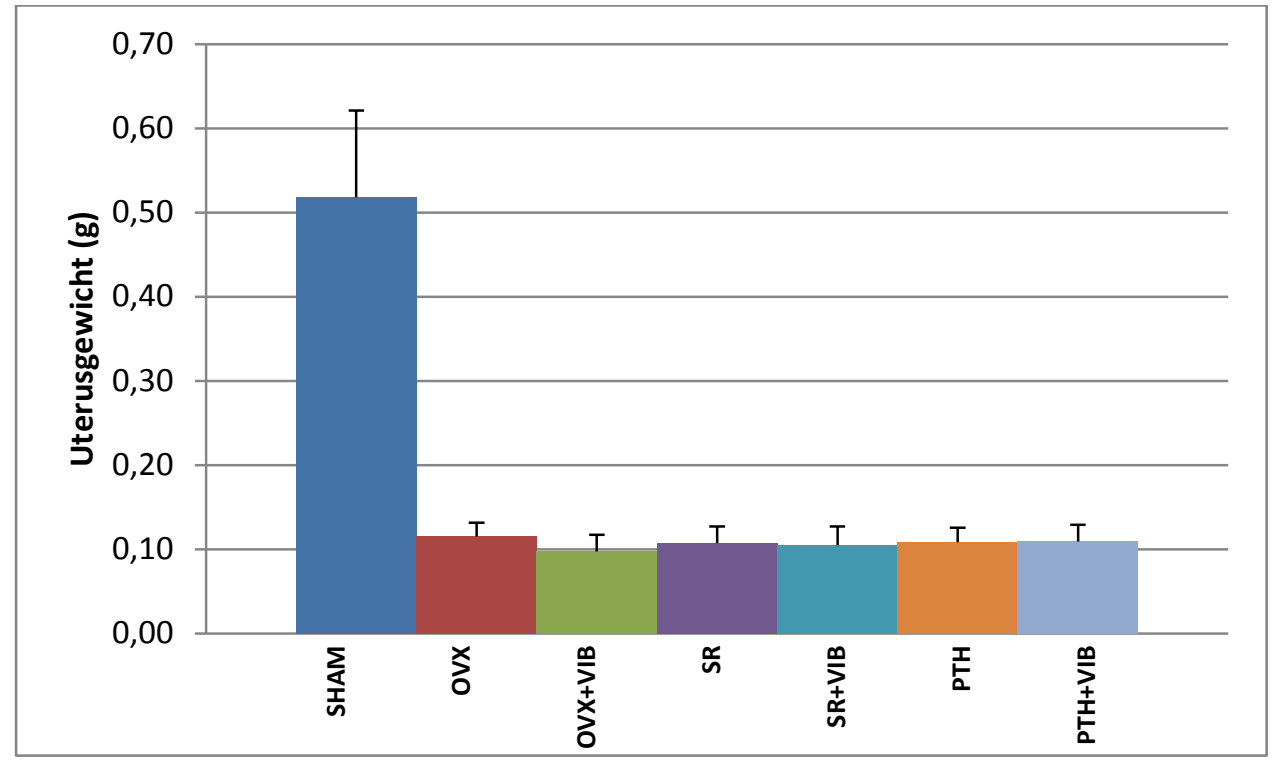

Abbildung 5: Uterusgewicht der Ratten nach der Tötung 
Tabelle 5: Mittleres Uterusgewicht der Ratten nach der Tötung

\begin{tabular}{|c|c|c|c|c|c|c|c|c|c|c|c|c|c|}
\hline \multicolumn{2}{|l|}{ SHAM } & \multicolumn{2}{|l|}{ OVX } & \multicolumn{2}{|c|}{ OVX+VIB } & \multicolumn{2}{|l|}{ SR } & \multicolumn{2}{|c|}{ SR+VIB } & \multicolumn{2}{|l|}{ PTH } & \multicolumn{2}{|c|}{ PTH+VIB } \\
\hline MW & SD & MW & SD & MW & SD & MW & SD & MW & SD & MW & SD & MW & SD \\
\hline 0,5182 & 0,1026 & 0,1150 & 0,0165 & 0,0973 & 0,0200 & 0,1073 & 0,0200 & 0,1050 & 0,0222 & 0,1082 & 0,0172 & 0,1091 & 0,0202 \\
\hline
\end{tabular}

(Gewicht in Gramm, MW = Mittelwert, SD = Standardabweichung) 


\subsection{Ergebnisse des biomechanischen Tests}

\subsubsection{Kompressionstest}

Bei der elastischen Verformung des Femur konnte kein signifikanter Unterschied gefunden werden $(p=0,1152)$. Es konnte kein Effekt der Medikamente SR und PTH, auch nicht in Kombination mit einer Vibrationstherapie oder einer alleinigen Vibrationstherapie nachgewiesen werden (Mittelwerte mit Standardabweichung in Abb. 6 und Tab. 6).

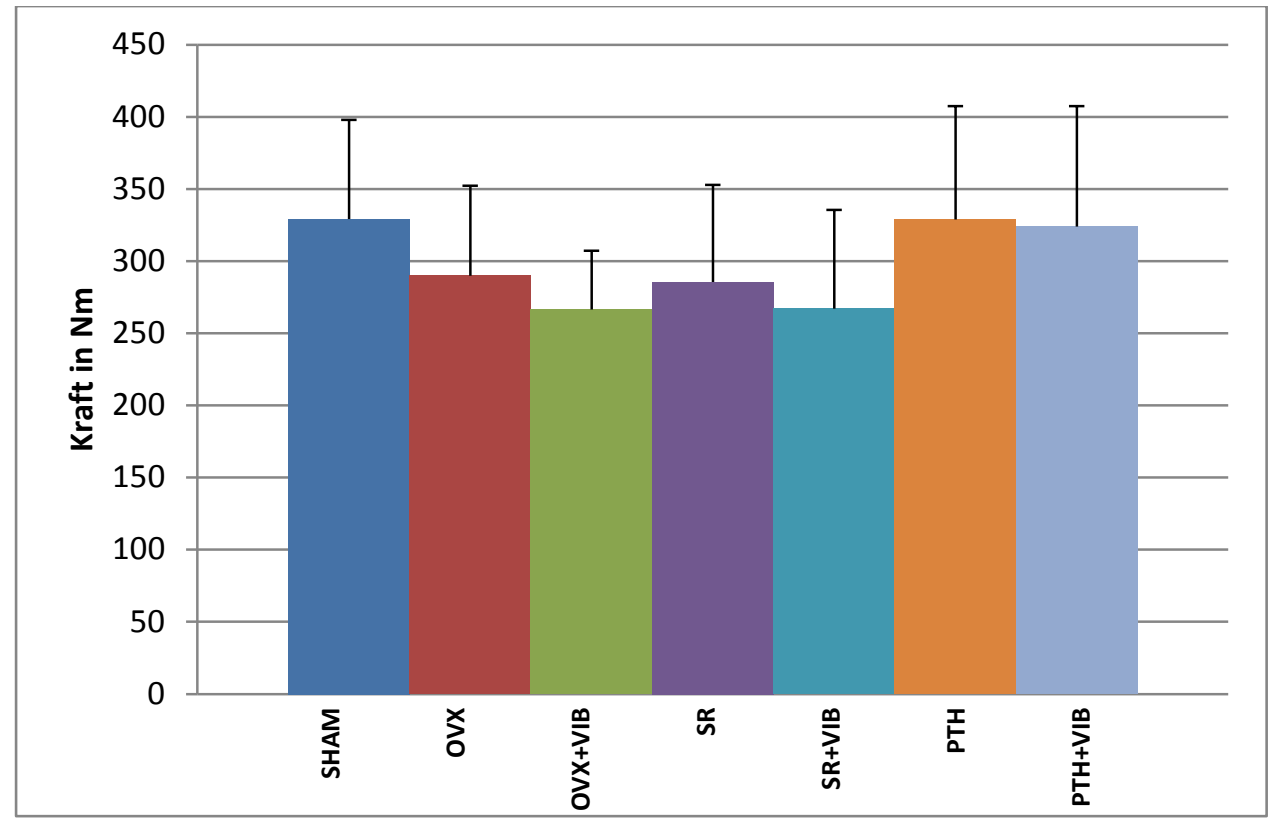

Abbildung 6: Durchschnittliche Steifigkeit

Tabelle 6: Mittelwerte der Steigung pro Versuchsgruppe

\begin{tabular}{lrr}
\hline Versuchsgruppe & Mittelwert & SD \\
\hline SHAM & 329,00 & 68,94 \\
OVX & 289,95 & 62,27 \\
OVX+VIB & 266,46 & 40,72 \\
SR & 285,42 & 67,43 \\
SR+VIB & 267,09 & 68,26 \\
PTH & 328,84 & 78,51 \\
\hline PTH+VIB & 323,83 & 83,52 \\
\hline (SD = Standardabweichung) & &
\end{tabular}




\subsubsection{Bruchtest}

Hinsichtlich der nötigen Maximalkraft (Fmax), die zum Brechen des Femur nötig war, konnte ein signifikanter Effekt nachgewiesen werden $(p=0,0003$; Mittelwerte mit Standardabweichung in Abb. 7 und Tab. 7). Die Detailanalyse zeigte, das die Maximalkraft (Fmax), die zum Brechen des Femur nötig war, in der PTH-Versuchsgruppe signifikant höher war, als in den Versuchsgruppen OVX, SR und SR+VIB. In der PTH+VIB-Versuchsgruppe war die Maximalkraft (Fmax), die zum Brechen des Femur nötig war, signifikant höher, als in den Versuchsgruppen, in denen nicht PTH verabreicht wurde und die Ratten ovariektomiert worden waren (OVX, OVX+VIB, SR, SR+VIB). Für alle anderen Vergleiche konnten keine signifikanten Unterschiede zwischen den Versuchsgruppen nachgewiesen werden.

Dies bedeutet, dass die Gabe von PTH (auch in Kombination mit der Vibrationstherapie) die Bruchfestigkeit des Knochens im Vergleich zu allen anderen Versuchsgruppen, in denen die Ratten ovariektomiert worden waren, erhöht hat, außer in der Versuchsgruppe OVX+VIB.

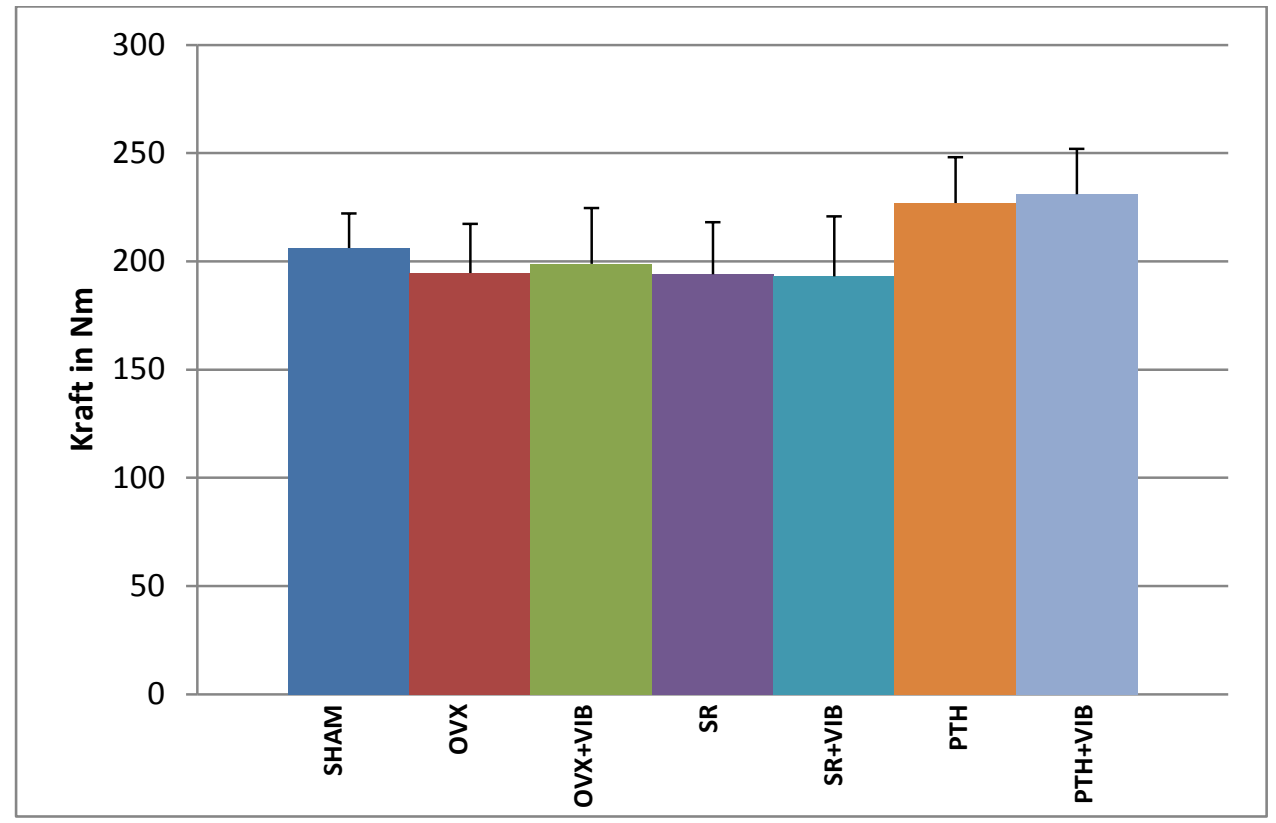

Abbildung 7: Durchschnittliche Maximalkraft bis zum Brechen des Knochens 
Tabelle 7: Durchschnittliche Maximalkraft bis zum Brechen des Knochens

\begin{tabular}{lrr}
\hline Versuchsgruppe & Mittelwert & SD \\
\hline SHAM & 206,07 & 16,10 \\
OVX & 194,65 & 22,69 \\
OVX+VIB & 198,79 & 25,92 \\
SR & 193,94 & 24,05 \\
SR+VIB & 192,99 & 27,87 \\
\hline PTH & 226,96 & 21,10 \\
\hline PTH+VIB & 230,95 & 21,03 \\
\hline
\end{tabular}

(SD = Standardabweichung) 


\subsection{Ergebnisse der Mikroradiographie}

Die Knochenflächendichte der medialen Kortikalis wurde auf Unterschiede zwischen den Versuchsgruppen untersucht. Es konnte kein signifikanter Unterschied gefunden werden $(p=0,0756)$. Für die Knochenflächendichte der medialen Kortikalis im Femur kann kein Effekt der Medikamente SR und PTH, auch nicht in Kombination mit einer Vibrationstherapie oder einer alleinigen Vibrationstherapie nachgewiesen werden (Mittelwerte mit Standardabweichung in Abb. 8 und Tab. 8).

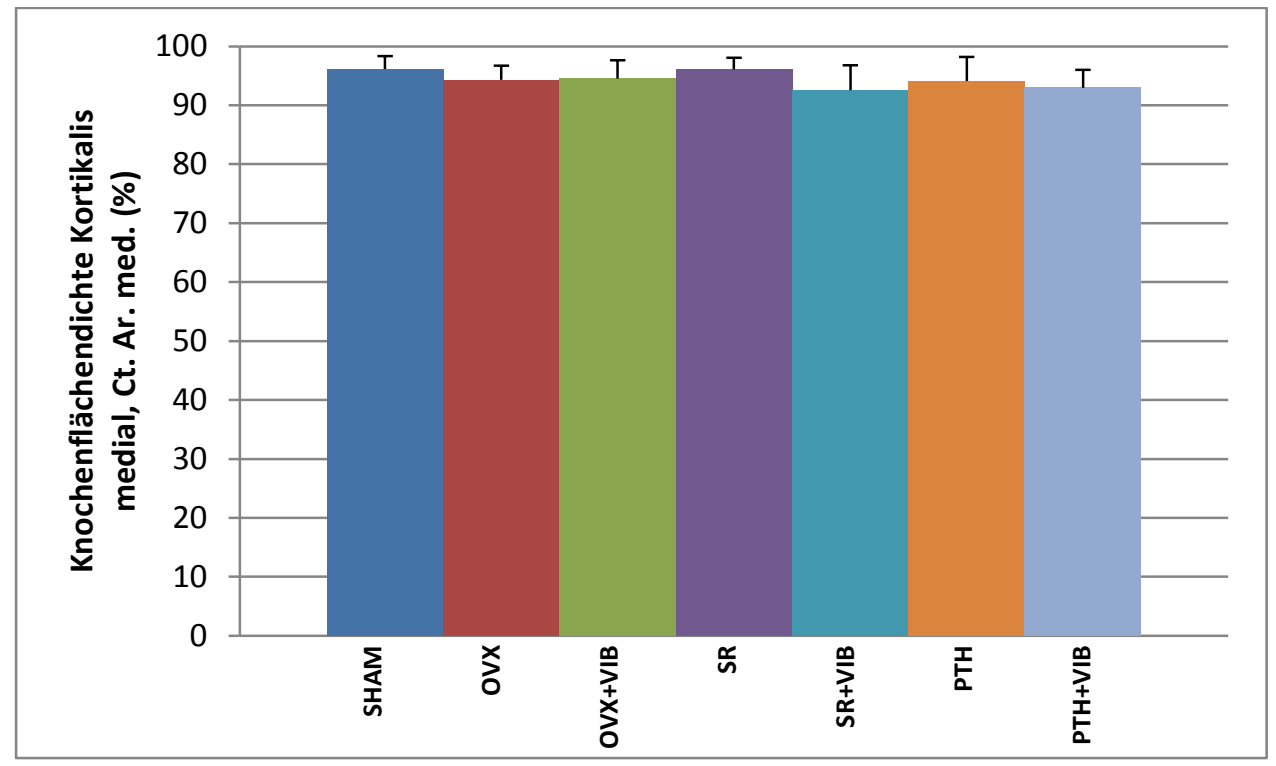

Abbildung 8: Die Knochenflächendichte Kortikalis medial 
Für die Anzahl der Trabekelkreuzungen im Femur konnte ebenfalls kein signifikanter Unterschied zwischen den Versuchsgruppen gefunden werden $(p=0,0966)$. Für die Anzahl der Trabekelkreuzungen im Femur konnte kein Effekt der Medikamente SR und PTH, auch nicht in Kombination mit einer Vibrationstherapie oder einer alleinigen Vibrationstherapie nachgewiesen werden (Mittelwerte mit Standardabweichung in Abb. 9 und Tab. 8).

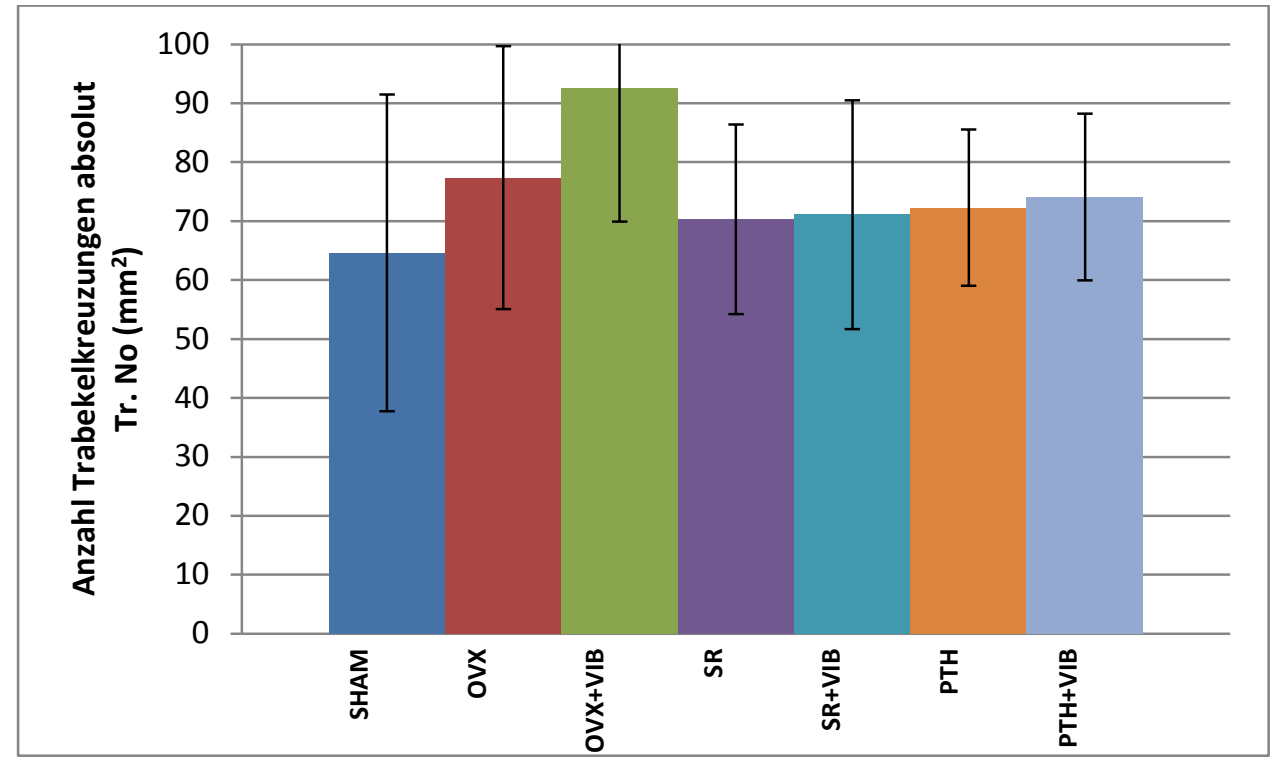

Abbildung 9: Anzahl der Trabekelkreuzungen 
Auch bei der Analyse der Dichte der Trabekelkreuzungen konnte kein signifikanter Unterschied gefunden werden $(p=0,7967)$. Für die Dichte der Trabekelkreuzungen im Femur konnte kein Effekt der Medikamente SR und PTH, auch nicht in Kombination mit einer Vibrationstherapie oder einer alleinigen Vibrationstherapie nachgewiesen werden (Mittelwerte mit Standardabweichung in Abb. 10 und Tab. 8).

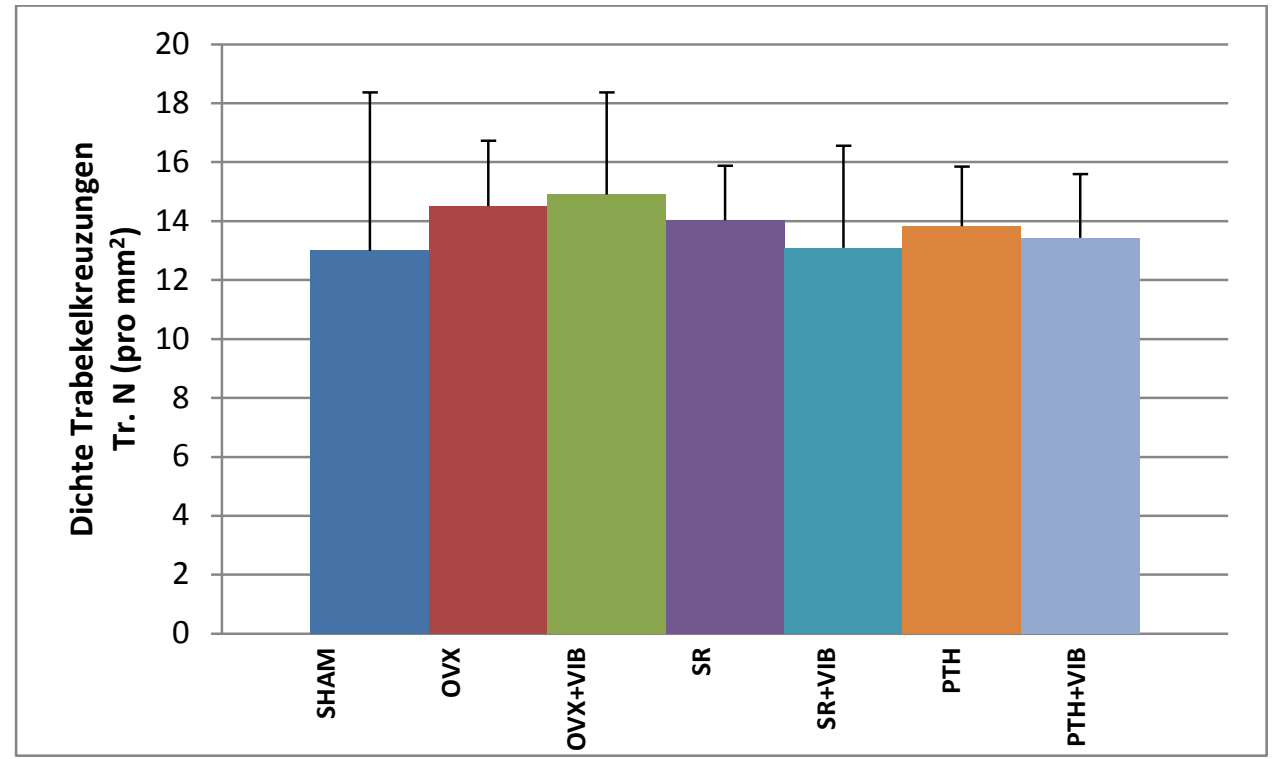

Abbildung 10: Dichte der Trabekelkreuzungen pro $\mathrm{mm}^{2}$ 
Der Vergleich der Werte der mittleren Trabekeldicke im Femur zeigte einen signifikanten Effekt ( $p=0,0068$; Mittelwerte mit Standardabweichung in Abb. 11 und Tab. 8). In der Detailanalyse war die mittlere Trabekeldicke in 4 Versuchsgruppen im Vergleich zur SHAMVersuchsgruppe signifikant reduziert. Signifikant dünnere Trabekel wurden in den Versuchsgruppen OVX, SR, SR+VIB, PTH+VIB gefunden. Für alle anderen Vergleiche konnten keine signifikanten Unterschiede zwischen den Versuchsgruppen nachgewiesen werden.

Dies bedeutet, dass die mittlere Trabekeldicke im Vergleich zur SHAM-Versuchsgruppe ohne Medikamentengabe die geringste Zunahme aufwies. Durch die Gabe von Strontiumranelat oder die Gabe von Strontiumranelat und Parathormon in Kombination mit Vibrationstherapie während der Versuchsphase, konnten ebenfalls nur wenig Zunahme in der mittleren Trabekeldicke erreicht werden.

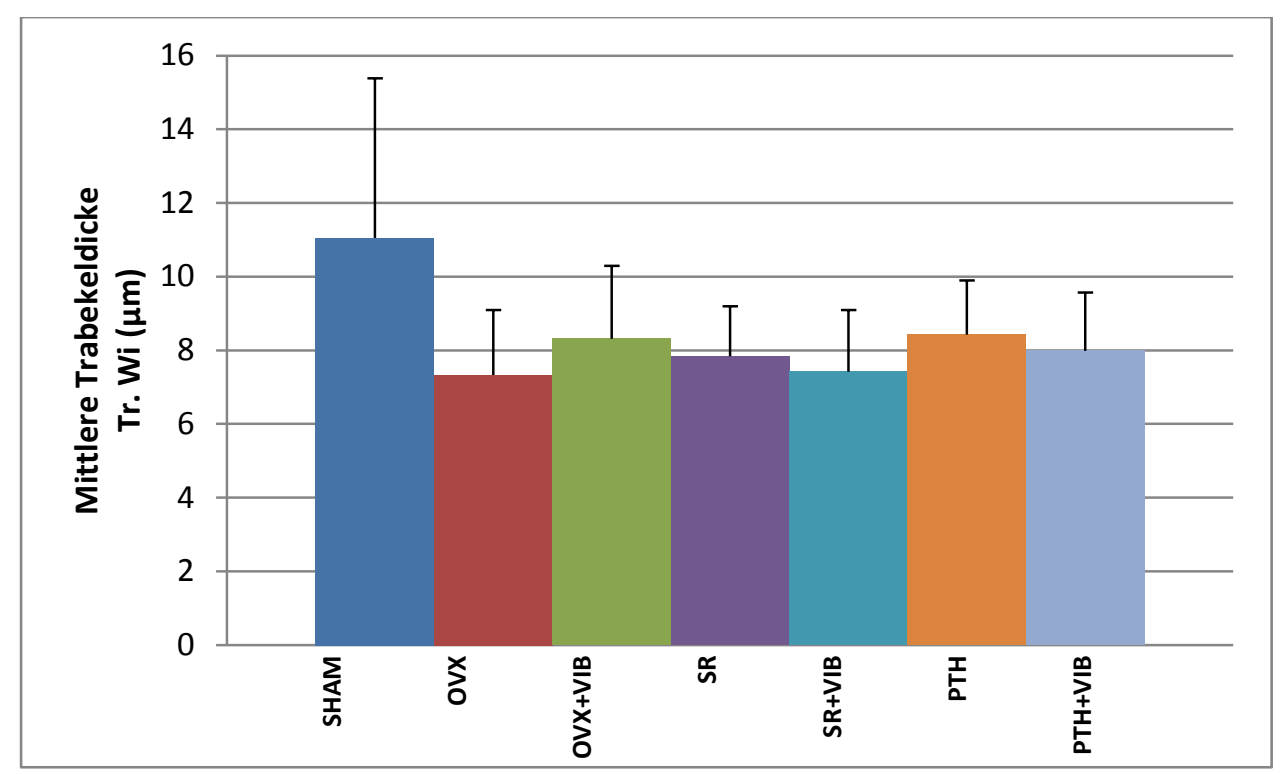

Abbildung 11: Mittlere Trabekeldicke 
Hinsichtlich der mittleren Fläche des Trabekelbereiches im Femur konnte ein signifikanter Effekt nachgewiesen werden $(p=0,0244$; Mittelwerte mit Standardabweichung in Abb. 12 und Tab. 8). Die Detailanalyse zeigte, dass die mittlere Fläche des Trabekelbereiches im Vergleich zur SHAM-Versuchsgruppe signifikant in der OVX+VIB-Versuchsgruppe erhöht war. Auch im Vergleich zur SR-Versuchsgruppe war die mittlere Fläche im Trabekelbereich in der OVX+VIB-Versuchsgruppe signifikant erhöht. Für alle anderen Vergleiche konnten keine signifikanten Unterschiede gefunden werden.

Dies zeigt, dass sich die mittlere Fläche des Trabekelbereiches im Femur im Vergleich zur SHAM-Gruppe durch die reine Vibrationstherapie signifikant verbessert hat.

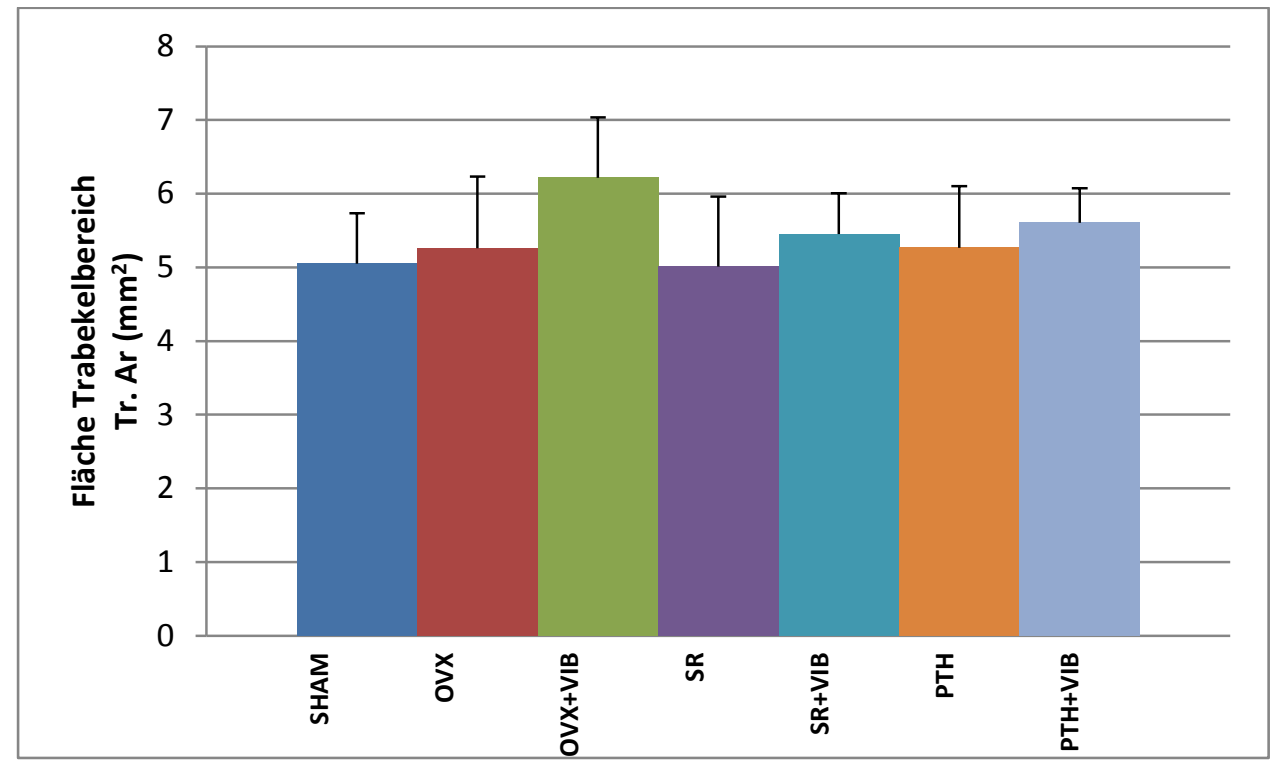

Abbildung 12: Mittlere Fläche des Trabekelbereiches 
Insgesamt konnte über die Knochendichte des Trabekelbereiches im Femur ein signifikanter Effekt nachgewiesen werden ( $p=0,0295$; Mittelwerte mit Standardabweichung in Abb. 13 und Tab. 8). Die Detailanalyse zeigte, dass im Vergleich zur SHAM-Versuchsgruppe die Knochendichte des Trabekelbereiches signifikant reduziert war in den Versuchsgruppen OVX und SR+VIB. Für alle anderen Vergleiche konnten keine signifikanten Unterschiede zwischen den Versuchsgruppen nachgewiesen werden.

Dies bedeutet, dass die Knochendichte des Trabekelbereiches im Vergleich zur SHAMGruppe am wenigsten durch die OVX und die Gabe von SR in Kombination mit der Vibrationstherapie verbessert wurde.

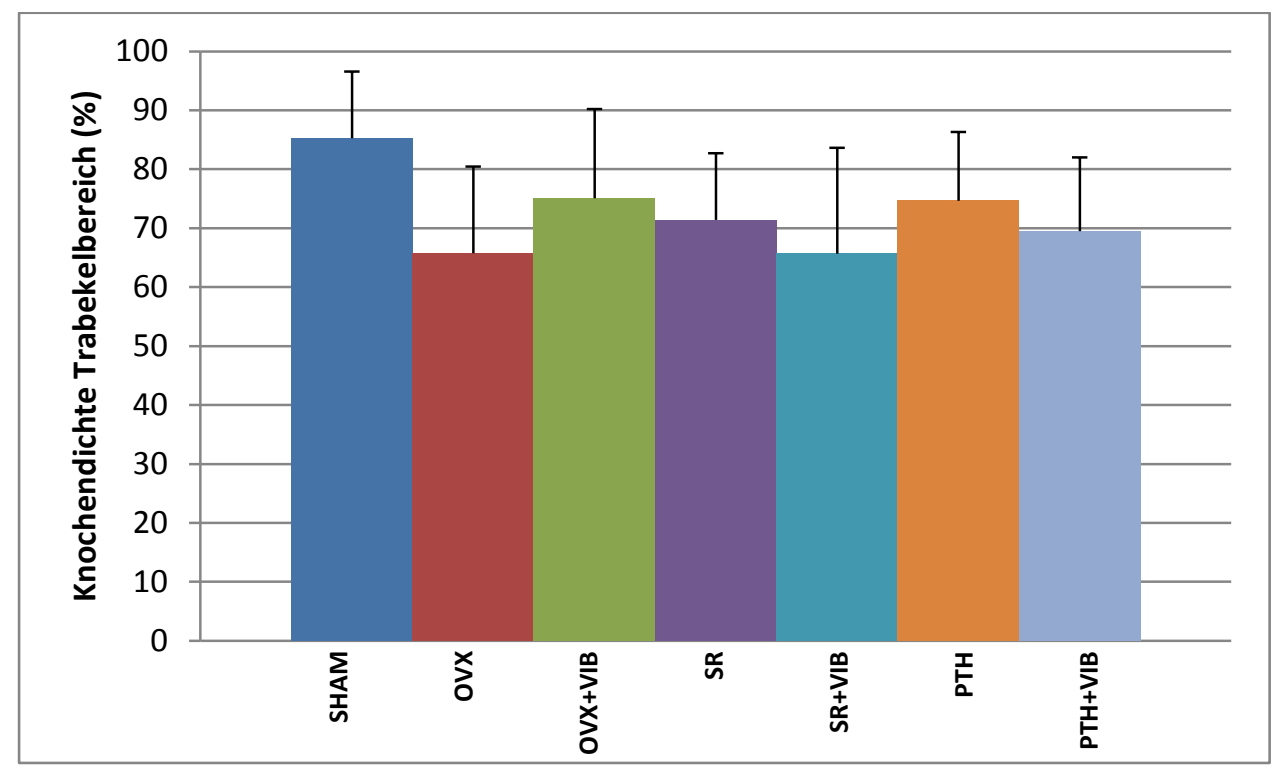

Abbildung 13: Knochendichte des Trabekelbereiches 
Tabelle 8: Übersicht der Knochendichtemessungen

\begin{tabular}{|c|c|c|c|c|c|c|c|c|c|c|c|c|c|c|}
\hline & \multicolumn{2}{|l|}{ SHAM } & \multicolumn{2}{|l|}{ OVX } & \multicolumn{2}{|c|}{ OVX+VIB } & \multicolumn{2}{|l|}{ SR } & \multicolumn{2}{|c|}{ SR+VIB } & \multicolumn{2}{|l|}{ PTH } & \multicolumn{2}{|c|}{ PTH+VIB } \\
\hline & MW & SD & MW & SD & MW & SD & MW & SD & MW & SD & MW & SD & MW & SD \\
\hline Knochendichte Kortikalis medial (\%) & 96,14 & 2,16 & 94,28 & 2,43 & 94,49 & 3,16 & 96,08 & 1,96 & 92,55 & 4,22 & 94,13 & 4,05 & 92,98 & 3,06 \\
\hline Anzahl Trabekelkreuzungen & 64,60 & 26,87 & 77,36 & 22,31 & 92,56 & 22,62 & 70,27 & 16,09 & 71,10 & 19,42 & 72,27 & 13,27 & 74,10 & 14,13 \\
\hline Dichte Trabekelkreuzungen ( pro $\mathrm{mm}^{2}$ ) & 12,99 & 5,38 & 14,51 & 2,21 & 14,90 & 3,47 & 14,03 & 1,85 & 13,10 & 3,45 & 13,83 & 2,03 & 13,44 & 2,16 \\
\hline Mittlere Trabekeldicke $(\mu \mathrm{m})$ & 11,05 & 4,33 & 7,33 & 1,76 & 8,32 & 1,98 & 7,84 & 1,36 & 7,42 & 1,67 & 8,42 & 1,48 & 7,98 & 1,59 \\
\hline Fläche Trabekelbereich $\left(\mathrm{mm}^{2}\right)$ & 5,05 & 0,69 & 5,26 & 0,97 & 6,22 & 0,82 & 5,01 & 0,95 & 5,45 & 0,55 & 5,27 & 0,84 & 5,61 & 0,47 \\
\hline Knochendichte Trabekelbereich (\%) & 85,27 & 11,30 & 65,76 & 14,67 & 75,09 & 15,13 & 71,41 & 11,30 & 65,70 & 17,90 & 74,68 & 11,61 & 69,49 & 12,53 \\
\hline
\end{tabular}

(MW = Mittelwert, SD = Standardabweichung) 


\subsection{Ergebnisse der Veraschung}

Der Phosphatgehalt der Femora wurde mithilfe der Veraschung des Knochens bestimmt.

Bei der Analyse des Phosphatgehaltes konnte kein signifikanter Unterschied gefunden werden ( $p=0,6683)$. Für den Phosphatgehalt im Femur konnte daher kein Effekt der Medikamente SR und PTH, auch nicht in Kombination mit einer Vibrationstherapie oder einer alleinigen Vibrationstherapie nachgewiesen werden. (Mittelwerte mit Standardabweichung in Abb. 14 und Tab. 9)

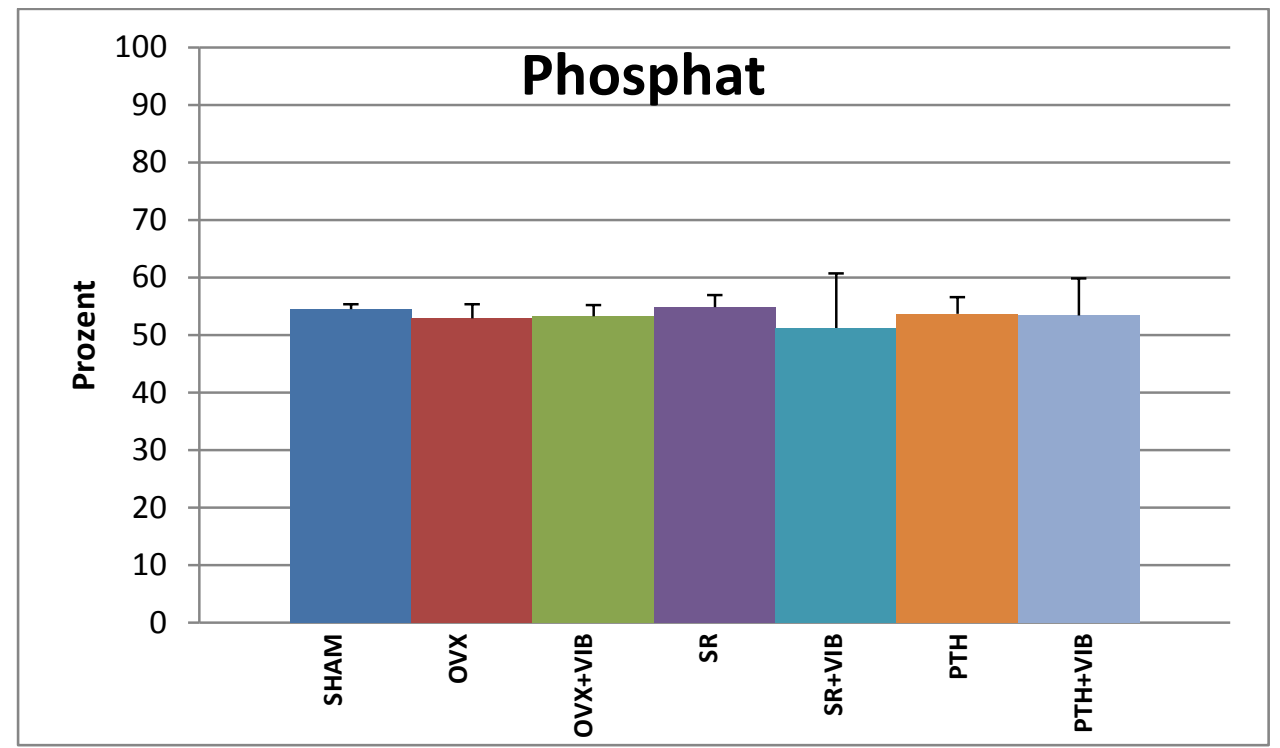

Abbildung 14: Phosphatgehalt nach Veraschung 
Der Kalziumgehalt der Femora wurde mithilfe der Veraschung des Knochens bestimmt.

Bei der Analyse des Kalziumgehaltes konnte kein signifikanter Unterschied gefunden werden $(p=0,4378)$. Für den Kalziumgehalt im Femur konnte kein Effekt der Medikamente SR und PTH, auch nicht in Kombination mit einer Vibrationstherapie oder einer alleinigen Vibrationstherapie nachgewiesen werden (Mittelwerte mit Standardabweichung in Abb. 15 und Tab. 9).

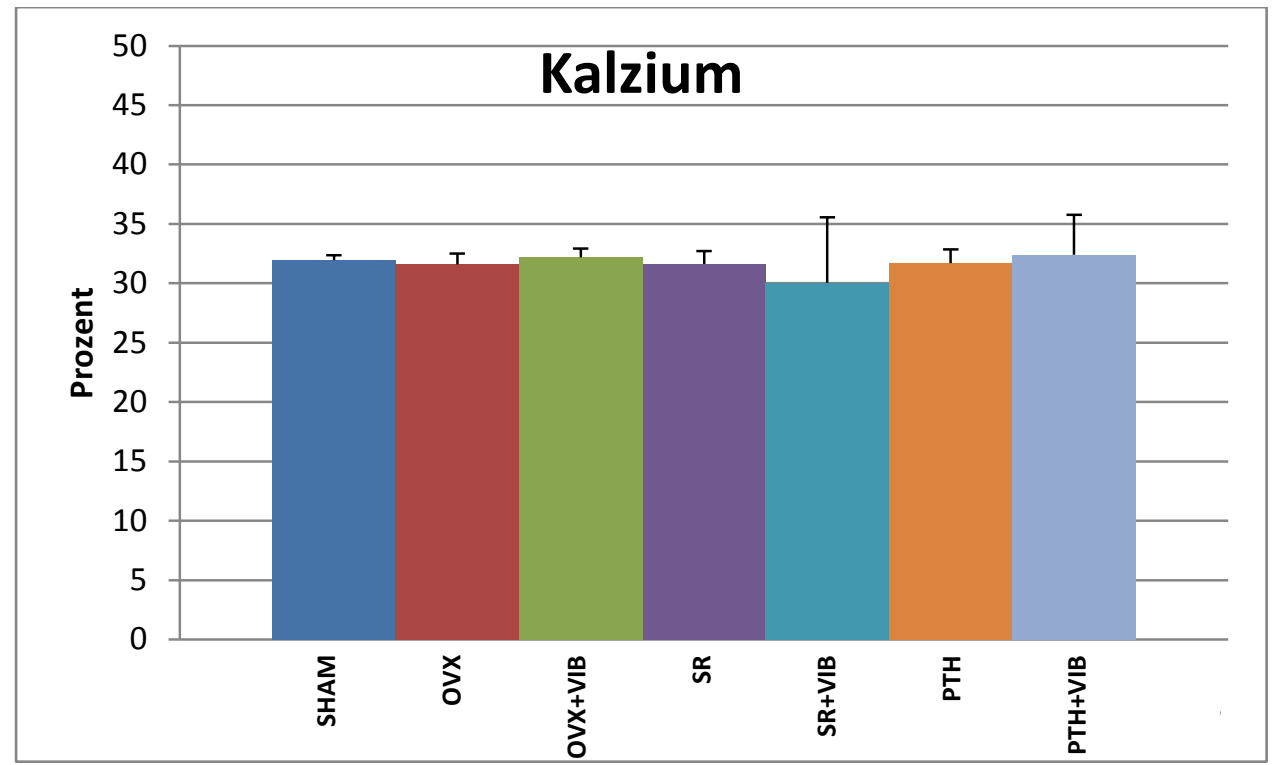

Abbildung 15: Kalziumgehalt nach Veraschung 
Aus den ermittelten Werten von Phosphat und Kalzium wurde $\operatorname{der} \mathrm{Ca}^{2+} / \mathrm{PO}_{4}$-Quotient bestimmt.

In der Analyse des $\mathrm{Ca}^{2+} / \mathrm{PO}_{4}$-Quotienten konnte kein signifikanter Unterschied gefunden werden ( $p=0,0569)$. Für den $\mathrm{Ca}^{2+} / \mathrm{PO}_{4}$-Quotienten im Femur konnte kein Effekt der Medikamente SR und PTH, auch nicht in Kombination mit einer Vibrationstherapie oder einer alleinigen Vibrationstherapie nachgewiesen werden (Mittelwerte mit Standardabweichung in Abb. 16 und Tab. 9).

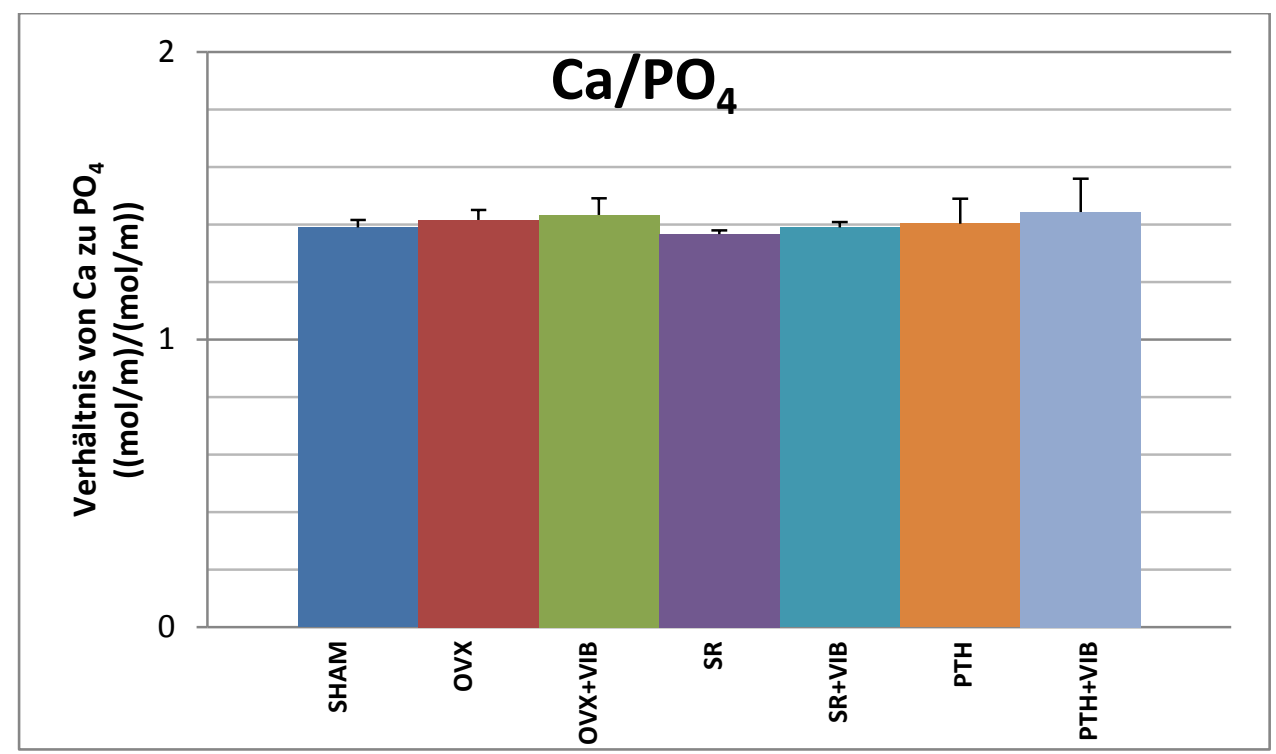

Abbildung 16: Kalzium-Phosphat-Quotient 
Um zu kontrollieren, ob die Strontiumranelatgabe erfolgreich war, wurde nach der Veraschung der Strontiumranelatgehalt bestimmt.

Insgesamt konnte über den Strontiumgehalt im Femur ein signifikanter Effekt nachgewiesen werden ( $p=0,0001$; Mittelwerte mit Standardabweichung in Abb. 17 und Tab. 9). Die Detailanalyse zeigte, dass in den Versuchsgruppen SR und SR+VIB der Strontiumgehalt signifikant höher war als in allen anderen Versuchsgruppen.

In der genaueren Analyse war der Strontiumgehalt in der SR-Versuchsgruppe signifikant höher, als in den Versuchsgruppen SHAM, OVX, OVX+VIB, PTH, PTH+VIB.

Laut Analyse war der Strontiumgehalt in der SR+VIB-Versuchsgruppe signifikant höher, als in den Versuchsgruppen SHAM, OVX, OVX+VIB, PTH und PTH+VIB.

Dies zeigt, dass die Gabe von Strontiumranelat den Strontiumgehalt in den Knochen der SR- und der SR+VIB-Versuchsgruppe signifikant im Vergleich zu allen anderen Versuchsgruppen erhöht hat.

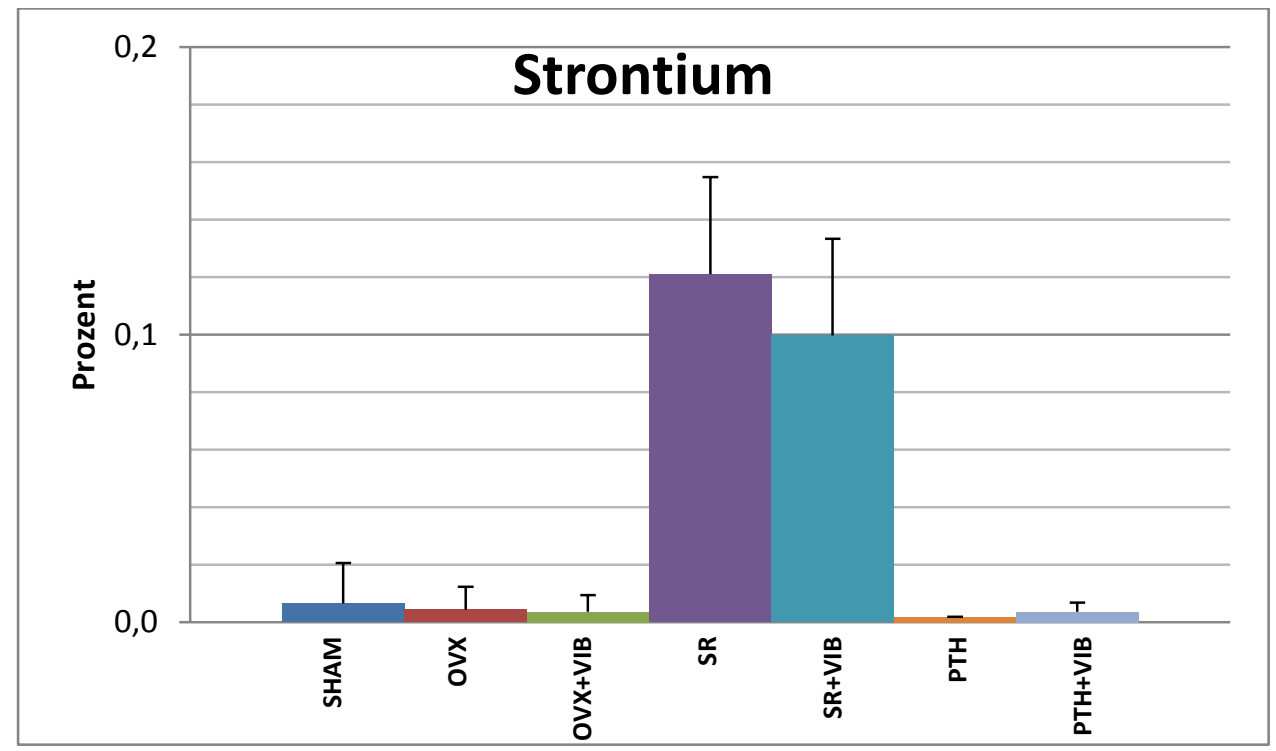

Abbildung 17: Strontiumgehalt nach Veraschung 
Zur Überprüfung der Aufnahme des Strontiumranelats in den Knochen wurde der Kalzium/Strontium-Quotient berechnet und zeigte zwischen den Versuchsgruppen signifikante Unterschiede ( $p<0,0001$; Mittelwerte mit Standardabweichung in Abb. 18 und Tab. 9). Die Analyse zeigte, das in den SR und SR+VIB-Versuchsgruppen der Kalzium/Strontium-Quotient signifikant niedriger war als in allen anderen Versuchsgruppen.

In der Analyse war der Kalzium/Strontium-Quotient in der SR-Versuchsgruppe signifikant niedriger als in den Versuchsgruppen SHAM, OVX, OVX+VIB, PTH und PTH+VIB.

Der Strontiumgehalt in der SR+VIB-Versuchsgruppe war signifikant höher als in den Versuchsgruppen SHAM, OVX, OVX+VIB, PTH und PTH+VIB.

Die Gabe von Strontiumranelat verringerte den Kalzium/Strontium-Quotienten in den Knochen der SR- und der SR+VIB-Versuchsgruppe signifikant im Vergleich zu allen anderen Versuchsgruppen verringert hat.

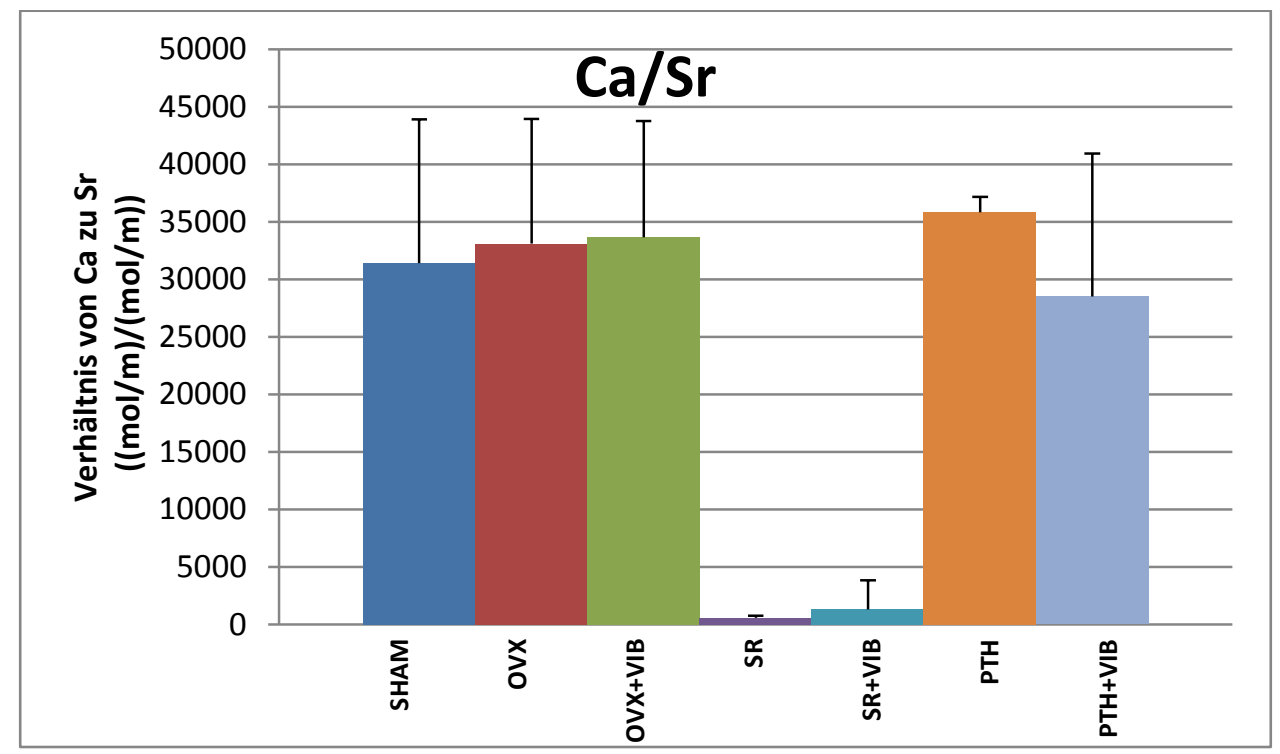

Abbildung 18: Kalzium-Strontium-Quotient nach Veraschung 
Tabelle 9: Übersicht der Ergebnisse zur Veraschung und der Bestimmung der Kalzium-, Phosphat- und Strontiumranelatmengen und deren Quotienten

\begin{tabular}{|c|c|c|c|c|c|c|c|c|c|c|c|c|c|c|}
\hline & SHAM & & OVX & & OVX+VIB & & SR & & SR+VIB & & PTH & & PTH+VIE & \\
\hline & MW & $\pm \mathrm{SD}$ & MW & $\pm \mathrm{SD}$ & MW & $\pm \mathrm{SD}$ & $\mathrm{MW}$ & $\pm \mathrm{SD}$ & MW & $\pm \mathrm{SD}$ & MW & $\pm S D$ & MW & $\pm \mathrm{SD}$ \\
\hline$\%(\mathrm{Ca})$ & 31,94 & 0,43 & 31,58 & 0,93 & 32,20 & 0,73 & 31,62 & 1,09 & 30,05 & 5,49 & 31,71 & 1,14 & 32,40 & 3,38 \\
\hline$\%\left(\mathrm{PO}_{4}\right)$ & 54,47 & 0,90 & 52,92 & 2,43 & 53,28 & 1,97 & 54,85 & 2,07 & 51,25 & 9,48 & 53,70 & 2,86 & 53,42 & 6,46 \\
\hline$c(\mathrm{Ca}) / c\left(\mathrm{PO}_{4}\right)$ & 1,39 & 0,03 & 1,42 & 0,04 & 1,43 & 0,06 & 1,37 & 0,01 & 1,39 & 0,02 & 1,40 & 0,09 & 1,44 & 0,12 \\
\hline$\%(\mathrm{Sr})$ & 0,01 & 0,01 & 0,00 & 0,01 & 0,00 & 0,01 & 0,12 & 0,03 & 0,10 & 0,03 & 0,00 & 0,00 & 0,00 & 0,00 \\
\hline $\mathrm{c}(\mathrm{Sr}) \mathrm{mol} / \mathrm{m}$ & 0,00 & 0,00 & 0,00 & 0,00 & 0,00 & 0,00 & 0,00 & 0,00 & 0,00 & 0,00 & 0,00 & 0,00 & 0,00 & 0,00 \\
\hline$c(\mathrm{Ca}) / c(\mathrm{Sr})$ & 31413 & 12502 & 33128 & 10798 & 33651 & 10087 & 611 & 159 & 1332 & 2510 & 35842 & 1327 & 28517 & 12407 \\
\hline
\end{tabular}

(SD = Standardabweichung, MW = Mittelwert) 


\section{Diskussion}

\subsection{Die Ratte als osteoporotisches Tiermodell}

Die physiologische Menopause existiert mit Ausnahme einiger Primaten bei keiner Tierart, so dass letztendlich kein Tiermodell der postmenopausalen Osteoporose beim Menschen tatsächlich entsprechen kann (Turner 2001). Im Tiermodell muss die Menopause daher durch eine Ovariektomie und den damit verbundenen Estrogenabfall hervorgerufen werden (Wronski et al. 1985; Wronski et al. 1986; Kalu 1991). Da die endokrinologischen Aufgaben der Sexualhormone in Ratte und Mensch vergleichbar sind, sorgt ein Estrogenmangel für ein ähnliches Beschwerdebild. Mensch und Ratte nehmen unter Estrogenmangel an Gewicht zu (Mayes und Watson 2004) und zeigen vergleichbare knochenmorphologische Veränderungen (Kalu 1991; Turner 2001). Bei Ratten findet der Knochenverlust im Rahmen einer Osteoporose am stärksten an der Tibia statt, beim Menschen kommt es hingegen eher zu einem Knochenverlust im Bereich der Wirbelsäule (Kalu 1991). Ein weiteres Merkmal des Rattenknochens ist das lebenslange Offenbleiben der femoralen Epiphysenfuge, während sich die Epiphysenfuge beim Menschen mit Abschluss des Längenwachstums verschließt (Lelovas et al. 2008).

Die Experimente der vorliegenden Studie wurden an ovariektomierten Ratten der Rasse Sprague-Dawley durchgeführt. Ovariektomierte Ratten sind das häufigste Tiermodell für Studien zum postmenopausalen Knochenverlust (Barlet et al. 1994). Die Ratte als Tiermodell ist auch deshalb so verbreitet, weil die Tiere unter standardisierten Bedingungen vergleichsweise einfach zu halten sind, dies ist besonders von Vorteil bei Experimenten mit einer großen Anzahl von Versuchstieren. Darüberhinaus ist die kurze Lebensspanne von Ratten gut geeignet, um die Einflüsse der Alterung auf den Knochen zu erfassen (Turner 2001). Die Ratte als osteoporotisches Tiermodell ist vielfach in der Forschung eingesetzt worden, so dass bereits eine breite Datenbasis zu den histomorphologischen Eigenschaften der Knochen existieren. Validiert wurde 
dieses Tiermodell unter anderem durch Experimente von Seidlova-Wuttke et al., die zeigen konnten, dass sich die Knochenmasse im Bereich der Tibiametaphyse von Ratten innerhalb von drei Monaten nach Ovariektomie bereits um über $50 \%$ reduziert hatte (Seidlova-Wuttke et al. 2003). Des Weiteren berichten Yamaura et al., dass bereits drei Tage nach Ovariektomie vermehrt Osteoklasten im Knochen nachweisbar waren und die Trabekeldicke innerhalb von 42 Tagen signifikant reduziert war (Yamaura et al. 1996). In einer weiteren Studie wurde gezeigt, dass mit dem Verlust der Knochensubstanz gleichzeitig die Stabilität des Knochens abnimmt (Mosekilde et al. 1993). Um Einflüsse von altersbedingten Knochenveränderungen auf die Ergebnisse auszuschließen, wurden für das vorliegende Experiment drei Monate alte geschlechtsreife Ratten verwendet.

In dieser Studie wurde als Untersuchungsregion der proximale Rattenfemur gewählt, da proximale Femurfrakturen und trochanterische Frakturen zu den häufigsten osteoporotischen Frakturen überhaupt zählen und daher eine hohe klinische Relevanz haben. Der proximale Femur enthält im Gegensatz zum Femurschaft sowohl trabekuläre als auch kortikale Knochenanteile. Diese Region ist daher besonders geeignet, um potentielle biomechanische Veränderungen nach antiosteoporotischer Behandlung mit Parathormon und Strontiumranelat zu detektieren. In diesem Bereich des Knochens finden sich außerdem Ansatzpunkte der Muskulatur, so dass sich in dieser Region auch die potentiellen Effekte einer Ganzkörpervibration besonders gut nachweisen lassen.

Die allgemeine Entwicklung der Ratten im Laufe des Experimentes verlief wie erwartet. Alle Ratten nahmen innerhalb des Versuchszeitraumes an Gewicht zu, wobei die ovariektomierten Ratten aufgrund des fehlenden Estrogens mehr an Gewicht zunahmen als die SHAM-operierten Tiere. Die Futteraufnahme während des Experimentes wurde stets überwacht und zeigte die erwartete verringerte Futteraufnahme nach den Operationen. Alle Ratten der ovariektomierten Versuchsgruppen hatten zum Zeitpunkt der Tötung ein deutlich verringertes Uterusgewicht als die Tiere der SHAM-Gruppe. Dies lässt sich dadurch erklären, dass der Estrogeneinfluss auf den Uterus durch die Entfernung der Ovarien unterbunden wurde und der Uterus folglich verkümmert ist. 


\subsection{Parathormon}

Parathormon wird bei postmenopausalen Frauen und Männern mit manifester Osteoporose und hohem Frakturrisiko als Therapeutikum eingesetzt. Eine kontinuierliche Gabe von PTH steigert die Knochenresorption, während es bei intermittierender subkutaner Gabe einen osteoanabolen Effekt hat und die Neubildung von Knochen fördert. Neer et al. konnten in Studien am Menschen zeigen, dass das Risiko für vertebrale Frakturen im Rahmen einer Therapie mit Parathormon um 65 \% gesenkt werden konnte (Neer et al. 2001).

Die hohe osteoanabole Wirkung des PTH spiegelt sich in den Ergebnissen der biomechanischen Tests wider. In der Versuchsgruppe PTH war die Biege- und Bruchfestigkeit der Femora gleich oder höher als in den anderen Versuchsgruppen. Auch in den vorangegangenen Studien an ovariektomierten Ratten konnte unter Therapie mit Parathormon die biomechanische Belastbarkeit der Knochen verbessert werden (Sehmisch et al. 2009b; Tezval et al. 2010).

Basierend auf den Ergebnissen des Bruchtests lag die Vermutung nahe, das sich mikroradiographisch eine Verbesserung der Mikroarchitektur zeigen würde, dies bestätigte sich jedoch nicht in dem erwarteten Maße. Die Femora der Versuchsgruppe SHAM wiesen eine signifikant höhere mittlere Trabekeldicke auf als die Versuchsgruppe PTH. In einer vorangegangenen Studie von Sehmisch et al. konnte allerdings gezeigt werden, dass eine Therapie mit PTH zu einer Dickenzunahme der Trabekel führen kann (Sehmisch et al. 2009b).

In der Versuchsgruppe OVX+VIB war die Anzahl der Trabekelkreuzungen und die mittlere Fläche des Trabekelbereiches im Vergleich zur Versuchsgruppe PTH erhöht.

Aufgrund der besseren Mikrostruktur in den Versuchsgruppen SHAM, OVX und OVX+VIB wäre eine höhere Bruchfestigkeit der Femora im Vergleich zur Versuchsgruppe PTH zu erwarten gewesen. Dieser Verdacht bestätigte sich jedoch nicht. Im Vergleich zu den Versuchsgruppen SHAM, OVX und OVX+VIB wurde sogar mehr Kraft benötigt, um die Femora der Versuchsgruppe PTH zu brechen.

Die naheliegendste Erklärung für dieses Ergebnis ist eine Neubildung von endostalem 
Knochen, welche ebenfalls im Rahmen der Studie von Sehmisch et al. beschrieben wurde. Die Bildung endostalen Knochens hat in der genannten Studie zu einer Verbesserung der mechanischen Stabilität des Knochens geführt (Sehmisch et al. 2009). Dies wäre auch im Einklang mit dem Wolffschen Gesetz: Demzufolge ist das Ziel der Knochenkonstruktion, eine möglichst hohe Stabilität bei gleichzeitig geringem Knochengewicht zu erlangen. In der vorliegenden Arbeit wurde der Anteil des endostalen Knochens allerdings nicht mikroradiographisch untersucht.

Die höhere Bruchfestigkeit durch eine Therapie mit PTH in Kombination mit der unveränderten kortikalen Knochendichte und der schlechteren bzw. gleichen Struktur des Trabekelnetzwerkes unterstützt die Annahme, dass auch in dieser Studie endostaler Knochen durch die PTH-Therapie gebildet wurde und dies zu der erhöhten Bruchfestigkeit geführt hat. Auch Komatsu et al. zeigten, dass unter Therapie mit PTH ein endostales Knochenwachstum stattfindet und die Knochenbildung im Markraum angeregt wird (Komatsu et al. 2009).

In den bisherigen Studien waren unter Therapie mit PTH hauptsächlich Verbesserungen des Endosts und des Trabekelnetzwerkes nachweisbar, letzteres konnte in dieser Studie nicht bestätigt werden. Die Ergebnisse der vorliegenden Studie legen jedoch den Schluss nahe, dass auch das ausschließlich endostale Knochenwachstum die Bruchgefahr signifikant verringert. Diese Hypothese muss jedoch in zukünftigen Studien untersucht werden.

\subsection{Strontiumranelat}

Strontiumranelat reduziert den Knochenabbau durch eine Hemmung der Differenzierung und Aktivität osteoklastischer Zellen und fördert den Knochenaufbau über eine Steigerung der Präosteoblastenreplikation (Marie 2006).

In der vorliegenden Studie konnte die Gabe von Strontiumranelat keine Verbesserung der Knochenfestigkeit im Vergleich zu den ovariektomierten Kontrolltieren bewirken. Strontiumranelat hatte in der mikroradiographischen Auswertung keinen verbessernden Effekt auf die Kortikalis und das trabekuläre Netzwerk des Femur. Einzig die Knochendichte des Trabekelbereiches erbrachte tendenziell höhere Werte als die nur ovariektomierte Versuchsgruppe OVX. 
In vorangegangenen Studien an ovariektomierten Ratten konnte Strontiumranelat den trabekulären Knochenverlust verhindern und die Mikroarchitektur und Festigkeit des Knochens verbessern (Marie et al. 1993). Wu et al. zeigten, dass die Strontiumranelattherapie zu einem periostalen und endostalen Knochenwachstum führte, eine bessere Knochenfestigkeit konnte dadurch allerdings nicht erzielt werden. Ferner konnte gezeigt werden, dass Strontiumranelat sich auch im trabekulären Knochen anlagert, signifikante Veränderungen in der Trabekeldicke wurden aber nicht festgestellt (Wu et al. 2013).

In der vorliegenden Studie zeigte die Berechnung des $\mathrm{Ca} / \mathrm{Sr}$-Quotienten, dass das Strontium im Knochengewebe eindeutig nachzuweisen war. Der Einbau des Strontiums in den Knochen führte allerdings weder bei der elastischen Verformung noch im Bruchtest zu besseren Ergebnissen als bei den ovariektomierten Kontrolltieren. Es liegt daher der Verdacht nahe, dass der gewählte Einwirkzeitraum von 35 Tagen als Wirkzeitraum für das Strontiumranelat auf die Knochenstruktur nicht ausreichend war. In vergleichbaren Studien zeigte sich, dass ein Therapiezeitraum von mindestens drei Monaten histomorphologische Verbesserungen im Sinne eines verminderten trabekulären Knochenverlustes zur Folge hatte. Dieser Effekt resultierte in einer verminderten Knochenresorption bei gleichzeitig kontinuierlicher Knochenproduktion (Marie et al. 1993). In einer Langzeitstudie über einen Zeitraum von zwei Jahren, in der unterschiedliche Strontiumranelatkonzentrationen getestet wurden, zeigten Ammann et al., dass der osteoprotische Knochenverlust durch die Behandlung mit Strontiumranelat effektiv verhindert werden konnte und dass sich durch die Behandlung dosisabhängig die Knochenfestigkeit und die Mikroarchitektur der Knochen verbesserte (Ammann et al. 2004). In einer weiteren Studie wurde die Wirkung von Strontiumranelat über den Therapiezeitraum eines Jahres untersucht. Auch in dieser Studie konnten die Mikroarchitektur und die Festigkeit des Knochens deutlich verbessert werden (Bain et al. 2009).

Strontiumranelat wurde 2014 nach Beendigung dieser Studie aufgrund zahlreicher kardiovaskulärer und thrombembolischer Nebenwirkungen in seiner Therapieempfehlung deutlich eingeschränkt (Rote Liste ${ }^{\circledR}$ 2014). 


\subsection{Vergleich der Wirksamkeit von Parathormon und Strontiumranelat}

Quesada-Gómez et al. führten eine Studie an postmenopausalen Frauen durch, in der der Effekt der Medikamente PTH und Strontiumranelat verglichen wurde. In der Studie konnte anhand der Knochenmarker BSAP (knochenspezifische alkalische Phosphatase) und PNP1 (N-terminales Propeptid von Prokollagen Typ 1) für PTH eine schnellere und größere Wirkung nachgewiesen werden als für Strontiumranelat (Quesada-Gómez et al. 2011).

Brüel et al. verglichen die Wirkung von PTH und Strontiumranelat und die Kombination aus PTH und Strontiumranelat an drei Monate alten immobilisierten Ratten. Durch die Gabe von PTH konnte die Architektur des Knochens und die Knochenfestigkeit verbessert werden. Die Therapie mit Strontiumranelat zeigte keine Effekte, auch nicht in Kombination mit PTH (Brüel et al. 2013).

Der Vergleich der Versuchsgruppen der vorliegenden Studie, in denen die Medikamente PTH und Strontiumranelat verabreicht wurden, ergab in der Mikroradiographie keine Unterschiede. Im Bruchtest konnte jedoch durch die Gabe von PTH eine deutliche Verbesserung der Knochenqualität erreicht werden, während für Strontiumranelat kein Effekt nachgewiesen werden konnte. Daher liegt die Schlussfolgerung nahe, dass für einen schnellen Behandlungserfolg bei Osteoporose die Verabreichung von PTH effektiver ist als die Gabe von Strontiumranelat.

\subsection{Ganzkörpervibration}

Bei der Ganzkörpervibration handelt es sich um eine Intervention für den Erhalt und die Verbesserung des Knochenskeletts bei Menschen mit einer verringerten Knochenmineraldichte. Ganzkörpervibration wird therapeutisch eingesetzt, um den Knochenaufbau zu fördern (Lanyon 1996) und den Knochenabbau zu verzögern (Rubin et al. 2000). In verschiedenen klinischen und tierexperimentellen Studien konnte gezeigt werden, dass mechanische Signale Regulatoren von Knochenmasse und Knochenarchitektur sind (De Gail et al. 1966; Goodship et al. 1998).

Im Rahmen dieser Studie konnte erneut nachgewiesen werden, dass Vibration zu einer 
qualitativen Verbesserung der Knochenstruktur führt. Dies zeigte sich insbesondere in der Anzahl der Trabekelkreuzungen und der mittleren Fläche des Trabekelbereiches. Darüberhinaus konnten die Dichte der Trabekelkreuzungen, die mittlere Trabekeldicke und die Knochendichte des Trabekelbereiches verbessert werden. Diese Ergebnisse stehen im Einklang mit der bisherigen Literatur: Rubin et al. vibrierten Schafe über den Zeitraum eines Jahres. In der anschließenden histomorphologischen Auswertung der Femora konnte das trabekuläre Knochenvolumen um 32 \% und die Trabekelanzahl um $45 \%$ gesteigert werden (Rubin et al. 2002). In einer weiteren Studie an ovariektomierten Ratten konnte ebenfalls ein signifikant höheres trabekuläres Knochenvolumen nach Ganzkörpervibration nachgewiesen werden: Judex et al. vibrierten ovariektomierte Ratten für 28 Tage 10 Minuten täglich bei 45 oder $90 \mathrm{~Hz}$, in der histomorphologischen Auswertung der Tibiae zeigte sich ein erhöhtes trabekuläres Knochenvolumen bei den Tieren, die mit $90 \mathrm{~Hz}$ vibriert worden waren (Judex et al. 2007). Sehmisch et al. zeigten den Effekt einer 2x täglichen Ganzkörpervibration über 35 Tage mit $90 \mathrm{~Hz}$ und untersuchten daraufhin die mikroradiologischen Veränderungen an den Wirbelkörpern der Ratten. Auch in dieser Studie konnte eine höhere Trabekelanzahl und eine Zunahme der Trabekeldicke im Vergleich zu den Kontrollratten detektiert werden (Sehmisch et al. 2009).

In dem vorliegenden Experiment wurden Veränderungen im Trabekelbereich gefunden, die jedoch keinerlei Auswirkung auf die Festigkeit des Knochens hatten.

Es konnte sogar gezeigt werden, dass die Versuchsgruppe OVX+VIB trotz der Veränderungen im Trabekelbereich im Kompressionstest schlechtere Werte erzielte als die Versuchsgruppe OVX ohne Vibration.

Flieger et al. untersuchten die Stabilität von Rattenfemora, nachdem die Tiere über 12 Wochen bei $50 \mathrm{~Hz}$ vibriert worden waren. Es zeigte sich eine erhöhte Stabilität und eine signifikant höhere Knochendichte bei den Tieren, die vibriert worden waren (Flieger et al. 1998). Oxlund et al. konnten nach Ganzkörpervibration ovariektomierter Ratten ebenfalls eine höhere mechanische Belastbarkeit für die Femora und Tibiae der Ratten nachweisen. Die Ratten waren über einen Zeitraum von 90 Tagen mit 17 oder $45 \mathrm{~Hz}$ vibriert worden. In den sich anschließenden Tests zur mechanischen Belastbarkeit zeigte sich in Bezug auf die Maximalkraft bei den Femora eine Verbesse- 
rung von $15 \%$ bei den mit $17 \mathrm{~Hz}$ vibrierten Tieren und eine Verbesserung von $19 \%$ bei den mit $45 \mathrm{~Hz}$ vibrierten Tieren (Oxlund et al. 2003).

Die Knochendichte und die mittlere Trabekeldicke hätten im vorliegenden Experiment möglicherweise länger und stärker durch die Vibration beeinflusst werden müssen, um mithilfe des Trabekelbereiches eine höhere Kompressionsfähigkeit oder auch eine höhere Bruchresistenz erreichen zu können. Dies ist auch daran erkennbar, dass die Versuchsgruppe SHAM eine größere mittlere Trabekeldicke und eine höhere Knochendichte im Trabekelbereich aufwies und im Kompressionstest weniger elastisch war.

Sehmisch et al. schließen aus ihren Ergebnissen, dass eine Erhöhung der Trabekeldicke zu einer höheren Bruchfestigkeit führt, eine Optimierung des Trabekelnetzwerkes schien die Bruchfestigkeit hingegen nicht zu verbessern (Sehmisch et al. 2009). In diesem Experiment wurden durch Vibration vor allem Veränderungen im Trabekelnetzwerk gefunden und nicht in der Trabekeldicke, eine höhere Bruchfestigkeit konnte demzufolge nicht detektiert werden.

\subsection{Vergleich der Wirksamkeit von Parathormon und Strontiumranelat in} Kombination mit einer Ganzkörpervibration

Das Hauptziel dieser Studie war es, herauszufinden, ob die medikamentösen Therapien mit Strontiumranelat und Parathormon synergistisch mit einer Ganzköpervibration wirken und die Knochenstruktur und Festigkeit osteoporotischer Knochen verbessern können.

Die Kombination aus Vibration und medikamentöser Therapie (SR+VIB; PTH+VIB), erzielte die gleichen Tendenzen in der Mikroradiographie. Es zeigte sich, dass die Dichte der Trabekelkreuzungen in den Vibrationsgruppen geringer war als in den Versuchsgruppen ohne Vibration. Gleiches gilt für die mittlere Trabekeldicke und die Knochendichte des Trabekelbereiches. Im Gegensatz hierzu war die mittlere Fläche des Trabekelbereiches bei den vibrierten Tieren tendenziell größer als in den rein medikamentös behandelten Versuchsgruppen.

Die Kombination von Medikamenten mit der Vibration zeigte insgesamt keine klaren Tendenzen. Es konnte jedoch gezeigt werden, dass die alleinige Vibration zu signifikan- 
ten Veränderungen im Trabekelbereich führt. Im Kompressionstest zeigte sich in der Versuchsgruppe SR + VIB eine etwas höhere Elastizität als in den Vergleichsgruppen. In der Theorie hat das Strontiumranelat einen hemmenden Einfluss auf die Osteoklasten, so dass diese nicht mehr als Aktivatoren der Osteoklasten fungieren können. In der Vibrationstherapie ist aber genau diese Aktivierung entscheidend für eine weitere und erfolgreiche Knochenbildung.

Bis zum Zeitpunkt dieser Studie gab es keine Studie, die die Wechselwirkungen einer Ganzkörpervibration mit Strontiumranelat untersucht hat. In unserem Experiment konnte durch die Kombination von Strontiumranelat und Vibration keine Verbesserung der untersuchten Parameter erzielt werden.

Im Gegensatz zu der Therapie mit Strontiumranelat kommt es bei der Kombination aus PTH und Vibration zu einer Osteoblastenaktivierung und Knochenneubildung. Der Effekt der Vibration auf den Knochen ist jedoch weitaus geringer als der Effekt durch Parathormon, es ist daher naheliegend, dass der zusätzliche Effekt der Vibration durch die medikamentöse Therapie mit PTH überdeckt worden ist.

Lynch et al. untersuchten über einen Zeitraum von 8 Wochen die Wirkung von PTH in Kombination mit Vibration an Mäusen. Eine zusätzliche Verbesserung der Ergebnisse der Versuchsgruppe PTH durch Ganzkörpervibration konnte nicht erzielt werden (Lynch et al. 2011).

Letztlich konnte eine kombinierte Therapie in unserer Studie zu keiner besseren Knochenfestigkeit und Verbesserung der Mikroarchitektur führen. Auch konnte die Ganzkörpervibration die Effekte einer alleinigen Parathormontherapie nicht verstärken. 


\subsection{Schlussfolgerung}

Das Hauptziel dieser Studie war es herauszufinden, ob die medikamentösen Therapien mit Strontiumranelat und Parathormon synergistisch mit einer Ganzköpervibration wirken und die Knochenstruktur und Festigkeit osteoporotischer Knochen verbessern. In der Versuchsgruppe PTH war die Biege- und Bruchfestigkeit der Femora höher als in den Vergleichsgruppen, obwohl das Trabekelnetzwerk im Rahmen dieser Therapie nachweislich nicht verbessert werden konnte. Die wahrscheinlichste Erklärung für die Verbesserung der Bruchfestigkeit ist eine vermehrte Neubildung von endostalem Knochen. Der Zusammenhang zwischen Endostbildung und einer Parathormontherapie sollte daher einen Schwerpunkt in zukünftigen Osteoporosestudien bilden.

Strontiumranelat hatte in der mikroradiographischen Auswertung keinen verbessernden Effekt auf die Kortikalis und das trabekuläre Netzwerk des Femur. Anhand bisheriger Studien muss davon ausgegangen werden, dass der gewählte Therapiezeitraum für die Wirkung des Strontiumranelats in dieser Studie nicht lang genug war. Es bedarf daher einer weiteren Klärung über die Länge erfolgsversprechender Therapiezeiträume und die optimalen Dosierungen.

Der Vergleich der Versuchsgruppen in der vorliegenden Studie zeigte, dass für einen schnellen Behandlungserfolg bei Osteoporose die Verabreichung von PTH effektiver ist als die Gabe von Strontiumranelat.

Im Rahmen dieser Studie konnte erneut nachgewiesen werden, dass Vibration zu einer qualitativen Veränderung der Knochenstruktur führt. Diese Veränderungen im Trabekelbereich hatten jedoch keinerlei Auswirkung auf die Festigkeit des Knochens.

Die Ergebnisse der Behandlung mit PTH oder Strontiumranelat konnten durch die Ganzkörpervibration nicht verbessert werden, im Falle von Strontiumranelat zeigte sich sogar eine höhere der Elastizität der Knochen. Die Ergebnisse unterstützen daher nicht die Hypothese, dass Ganzkörpervibration in Kombination mit PTH oder Strontiumranelat bessere Effekte erzielen kann als die rein medikamentösen Therapien. 


\section{Zusammenfassung der Arbeit}

Die Osteoporose ist charakterisiert durch einen progressiven Verlust an Knochengewebe und ist eine der häufigsten Komplikationen des Alters. Schätzungen zufolge sind weltweit etwa 200 Millionen Menschen an Osteoporose erkrankt, dies führte auch zur Aufnahme der Osteoporose in die WHO-Liste der 10 wichtigsten Volkskrankheiten. In einer Studie aus dem Jahr 2007 wurden die jährlichen Kosten für die Folgen dieser Erkrankung in Deutschland mit 5,4 Milliarden Euro beziffert.

Osteoporose bedeutet vermehrter Knochenabbau. Ursachen sind u.a. postmenopausaler Estrogenmangel, der wiederum dazu führt, dass sich die Lebenszeit der für die Knochenresorption zuständigen Osteoklasten verlängert, während die Lebenszeit der knochenproduzierenden Osteoblasten verkürzt wird. Außerdem sind die verringerten mechanischen Reize am Knochen durch fehlende körperliche Bewegung und ein endemischer Vitamin-D-Mangel, unter dem ein Großteil der Weltbevölkerung leidet, als ursächlich für das Auftreten von Osteoporose zu nennen.

Ziel dieser Arbeit ist es, herauszufinden, ob eine vertikale Ganzkörpervibrationstherapie in Kombination mit einer Gabe von Strontiumranelat (s. 1.6.3.6) oder Parathormon (s. 1.6.3.5) zu einer verbesserten Knochenstruktur im osteoporotischen Rattenfemur führt.

Zu diesem Zweck werden die Femora der Ratten nach Ganzkörpervibration und/oder medikamentöser Therapie mit Strontiumranelat oder Parathormon untersucht.

Nach der Tötung der Ratten wird die biomechanische Stabilität des Femur einem biochmechanischen Kompressionstest unterzogen. Anschließend wird der jeweilige prozentuale Gehalt von Kalzium, Phosphat und Strontiumranelat im Knochen gemessen, um den Einfluss der Vibration in Kombination mit Strontiumranelat oder PTH auf diese Parameter zu erfassen. Abschließend erfolgt die mikroradiographische Untersuchung der Knochen, um die Veränderungen der Knochenstruktur im Bereich der Kortikalis und im trabekulären Netzwerk zu erfassen.

Den Ergebnissen zufolge konnte nur durch die Gabe von Parathormon eine signifikante 
Verbesserung der Knochenstruktur erreicht werden, die die Bruchfestigkeit der osteoporotischen Knochen signifikant erhöhte. Strontiumranelat führte in diesem Experiment zu keiner Verbesserung der Knochenqualität. Letztlich sind weitere Studien erforderlich, um effektive Dosen und Therapiezeiträume zu ermitteln. Der Vergleich der Wirksamkeit zwischen Parathormon und Strontiumranelat zeigte, dass Parathormon schneller zu Therapieerfolgen führt als eine alleinige Therapie mit Strontiumranelat. Durch die Ganzkörpervibration konnten Verbesserungen der Knochenstruktur detektiert werden. Die Kombination aus medikamentöser Therapie mit Ganzkörpervibration zeigte keine signifikanten Therapieerfolge im Vergleich zur alleinigen Therapie mit Parathormon. 


\section{Abbildungsverzeichnis}

Abbildung 1: Gewichtsentwicklung der Versuchstiere über den Versuchszeitraum..... 36

Abbildung 2: Gewicht der Versuchstiere zum Zeitpunkt der Ovariektomie ..................37

Abbildung 3: Gewicht der Versuchstiere zum Zeitpunkt der Osteotomie ......................38

Abbildung 4: Gewicht der Versuchstiere zum Zeitpunkt der Tötung .............................39

Abbildung 5: Uterusgewicht der Ratten nach der Tötung.......................................... 41

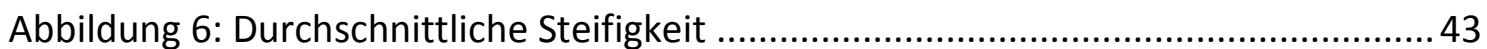

Abbildung 7: Durchschnittliche Maximalkraft bis zum Brechen des Knochens ............. 44

Abbildung 8: Die Knochenflächendichte Kortikalis medial........................................46

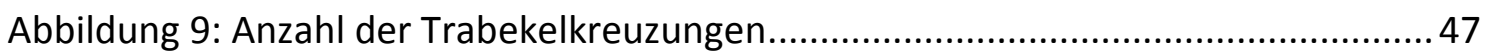

Abbildung 10: Dichte der Trabekelkreuzungen pro $\mathrm{mm}^{2}$....................................... 48

Abbildung 11: Mittlere Trabekeldicke ….............................................................. 49

Abbildung 12: Mittlere Fläche des Trabekelbereiches ....................................................50

Abbildung 13: Knochendichte des Trabekelbereiches ............................................. 51

Abbildung 14: Phosphatgehalt nach Veraschung ......................................................... 53

Abbildung 15: Kalziumgehalt nach Veraschung …....................................................5 54

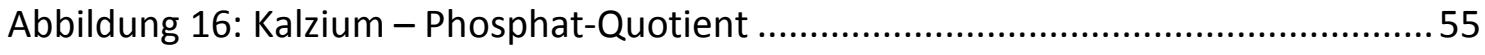

Abbildung 17: Strontiumgehalt nach Veraschung...................................................56

Abbildung 18: Kalzium - Strontium-Quotient nach Veraschung.................................57 


\section{Tabellenverzeichnis}

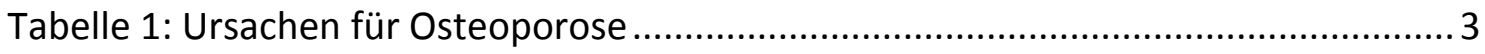

Tabelle 2: T-Werte in Abhängigkeit von Lebensalter und Geschlecht ......................... 14

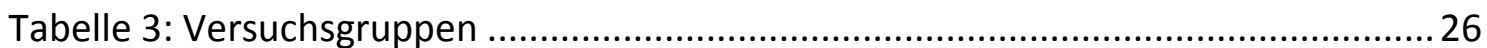

Tabelle 4: Durchschnittliches Gewicht der Versuchstiere pro Woche .......................... 40

Tabelle 5: Mittleres Uterusgewicht der Ratten nach der Tötung................................ 42

Tabelle 6: Mittelwerte der Steigung pro Versuchsgruppe ......................................... 43

Tabelle 7: Durchschnittliche Maximalkraft bis zum Brechen des Knochens ................. 45

Tabelle 8: Übersicht der Knochendichtemessungen .................................................. 52

Tabelle 9: Übersicht der Ergebnisse zur Veraschung und der Bestimmung der Kalzium-, Phosphat- und Strontiumranelatmengen und deren Quotienten ...............................58

Tabelle 10: Durchschnittliches Gewicht pro Woche der Versuchstiere ........................86

Tabelle 11: Futteraufnahme der Versuchstiere über den Versuchszeitraum ................87 


\section{Literaturverzeichnis}

Adachi JD, loannidis G, Olszynski WP, Brown JP, Hanley DA, Sebaldt RJ, Petrie A, Tenenhouse A, Stephenson GF, Papaioannou A, et al. (2002): The impact of incident vertebral and non-vertebral fractures on health related quality of life in postmenopausal women. BMC Musculoskelet Disord $\underline{3}, 11$

Ammann P, Shen V, Robin B, Mauras Y, Bonjour J-P, Rizzoli R (2004): Strontium ranelate improves bone resistance by increasing bone mass and improving architecture in intact female rats. J Bone Miner Res $\underline{19}, 2012-2020$

Arastéh K, Baenkler H-W, Bieber C, Brandt R, Chatterjee T: Duale Reihe Innere Medizin. Georg Thieme Verlag 2012

Bain SD, Jerome C, Shen V, Dupin-Roger I, Ammann P (2009): Strontium ranelate improves bone strength in ovariectomized rat by positively influencing bone resistance determinants. Osteoporos Int $\underline{20}, 1417-1428$

Barlet JP, Coxam V, Davicco MJ, Gaumet N (1994): Animal models of post-menopausal osteoporosis. Reprod Nutr Dev $\underline{34}, 221-236$

Bischoff-Ferrari HA, Dawson-Hughes B, Willett WC, Staehelin HB, Bazemore MG, Zee RY, Wong JB (2004): Effect of Vitamin D on falls: a meta-analysis. JAMA 291, 19992006 
Black DM, Cummings SR, Karpf DB, Cauley JA, Thompson DE, Nevitt MC, Bauer DC, Genant HK, Haskell WL, Marcus R, et al. (1996): Randomised trial of effect of alendronate on risk of fracture in women with existing vertebral fractures. Fracture Intervention Trial Research Group. Lancet 348, 1535-1541

Bone HG, Bolognese MA, Yuen CK, Kendler DL, Wang H, Liu Y, San Martin J (2008): Effects of denosumab on bone mineral density and bone turnover in postmenopausal women. J Clin Endocrinol Metab 93, 2149-2157

Borgström F (2006): Osteoporosis in health economic perspective. Lakartidningen $\underline{103}$, 2963-2965

Boyle WJ, Simonet WS, Lacey DL (2003): Osteoclast differentiation and activation. Nature $\underline{423}, 337-342$

Brown JP, Prince RL, Deal C, Recker RR, Kiel DP, de Gregorio LH, Hadji P, Hofbauer LC, Alvaro-Gracia JM, Wang $\mathrm{H}$, et al. (2009): Comparison of the effect of denosumab and alendronate on BMD and biochemical markers of bone turnover in postmenopausal women with low bone mass: a randomized, blinded, phase 3 trial. J Bone Miner Res $\underline{24}$, $153-161$

Brüel A, Vegger JB, Raffalt AC, Andersen JET, Thomsen JS (2013): PTH (1-34), but not strontium ranelate counteract loss of trabecular thickness and bone strength in disuse osteopenic rats. Bone $\underline{53}, 51-58$

Brunader R, Shelton DK (2002): Radiologic bone assessment in the evaluation of osteoporosis. Am Fam Physician $\underline{65}$, 1357-1364

Carlsöö S (1982): The effect of vibration on the skeleton, joints and muscles. A review of the literature. Appl Ergon 13, 251-258 
Chapuy MC, Arlot ME, Delmas PD, Meunier PJ (1994): Effect of calcium and cholecalciferol treatment for three years on hip fractures in elderly women. BMJ $\underline{308}$, 10811082

Cummings SR, Black DM, Thompson DE, Applegate WB, Barrett-Connor E, Musliner TA, Palermo L, Prineas R, Rubin SM, Scott JC, et al. (1998): Effect of alendronate on risk of fracture in women with low bone density but without vertebral fractures: results from the Fracture Intervention Trial. JAMA 280, 2077-2082

Cummings SR, San Martin J, McClung MR, Siris ES, Eastell R, Reid IR, Delmas P, Zoog $H B$, Austin M, Wang A, et al. (2009): Denosumab for prevention of fractures in postmenopausal women with osteoporosis. N Engl J Med $\underline{361}, 756-765$

Delmas PD (2002): Treatment of postmenopausal osteoporosis. Lancet $\underline{359}$, 20182026

Delmas PD (2008): Clinical potential of RANKL inhibition for the management of postmenopausal osteoporosis and other metabolic bone diseases. J Clin Densitom 11, $325-338$

Delmas PD, Bjarnason NH, Mitlak BH, Ravoux AC, Shah AS, Huster WJ, Draper M, Christiansen C (1997): Effects of raloxifene on bone mineral density, serum cholesterol concentrations, and uterine endometrium in postmenopausal women. $\mathrm{N}$ Engl J Med 337, 1641-1647

Döll CJ: Ganzkörpervibration unterschiedlicher Frequenz auf den osteoporotischen Lendenwirbelkörper der Ratte. Dissertation. Göttingen, Deutschland 2011, http://hdl.handle.net/11858/00-1735-0000-0006-B1A8-6 
Drenckhahn D (Hrsg.): Anatomie: Zellen- und Gewebelehre, Entwicklungslehre, Skelettund Muskelsystem, Atemsystem, Verdauungssystem, Harn- und Genitalsystem. 17. Auflage; Elsevier, Urban \& Fischer, München, Jena 2008

DVO: Entwurf für DVO-Leitlinien zur Prophylaxe, Diagnostik und Therapie der Osteoporose, Dachverband Osteologie e. V., 2009, www.dv-osteologie.de

Ettinger B, Black DM, Mitlak BH, Knickerbocker RK, Nickelsen T, Genant HK, Christiansen C, Delmas PD, Zanchetta JR, Stakkestad J, et al. (1999): Reduction of vertebral fracture risk in postmenopausal women with osteoporosis treated with raloxifene: results from a 3-year randomized clinical trial. Multiple Outcomes of Raloxifene Evaluation (MORE) Investigators. JAMA 282, 637-645

Fechtenbaum J, Cropet C, Kolta S, Horlait S, Orcel P, Roux C (2005): The severity of vertebral fractures and health-related quality of life in osteoporotic postmenopausal women. Osteoporos Int 16, 2175-2179

Felsenberg D, Stege U, Degner C, Börst H, Bock O (2012): Ergebnisse der nichtinterventionellen PERSPECTIVES-Studie. Osteologie 21, 15-21

Flieger J, Karachalios T, Khaldi L, Raptou P, Lyritis G (1998): Mechanical stimulation in the form of vibration prevents postmenopausal bone loss in ovariectomized rats. Calcif Tissue Int $\underline{63}, 510-514$

Frost HM (1994): Wolff's Law and bone's structural adaptations to mechanical usage: an overview for clinicians. Angle Orthod $\underline{64}, 175-188$

De Gail P, Lance JW, Neilson PD (1966): Differential effects on tonic and phasic reflex mechanisms produced by vibration of muscles in man. J Neurol Neurosurg Psychiatr $\underline{29}, 1-11$ 
Gardner MJ, Demetrakopoulos D, Shindle MK, Griffith MH, Lane JM (2006): Osteoporosis and skeletal fractures. HSS J $\underline{2}, 62-69$

Genant HK, Delmas PD, Chen P, Jiang Y, Eriksen EF, Dalsky GP, Marcus R, San Martin J (2007): Severity of vertebral fracture reflects deterioration of bone microarchitecture. Osteoporos Int $\underline{18}, 69-76$

Goodship AE, Cunningham JL, Oganov V, Darling J, Miles AW, Owen GW (1998): Bone loss during long term space flight is prevented by the application of a short term impulsive mechanical stimulus. Acta Astronaut $\underline{43}, 65-75$

Gusi N, Raimundo A, Leal A (2006): Low-frequency vibratory exercise reduces the risk of bone fracture more than walking: a randomized controlled trial. BMC Musculoskelet Disord $\underline{7}, 92$

Häussler B, Gothe H, Göl D, Glaeske G, Pientka L, Felsenberg D (2007): Epidemiology, treatment and costs of osteoporosis in Germany-the BoneEVA Study. Osteoporos Int $18,77-84$

Herold G: Innere Medizin 2014. 1. Auflage; Herold, Gerd, Köln 2013

Johnell O, Kanis JA, Odén A, Sernbo I, Redlund-Johnell I, Petterson C, De Laet C, Jönsson B (2004): Mortality after osteoporotic fractures. Osteoporos Int $\underline{15}$, 38-42

Judex S, Lei X, Han D, Rubin C (2007): Low-magnitude mechanical signals that stimulate bone formation in the ovariectomized rat are dependent on the applied frequency but not on the strain magnitude. J Biomech $\underline{40}, 1333-1339$

Junqueira LCU, Carneiro J, Gratzl M: Histologie. 6. Auflage; Springer Medizin Verlag, Heidelberg 2004 
Kalu DN (1991): The ovariectomized rat model of postmenopausal bone loss. Bone Miner $\underline{15}, 175-191$

Kanis JA, Barton IP, Johnell O (2005): Risedronate decreases fracture risk in patients selected solely on the basis of prior vertebral fracture. Osteoporos Int $\underline{16}, 475-482$

Kanis JA, Burlet N, Cooper C, Delmas PD, Reginster J-Y, Borgstrom F, Rizzoli R (2008): European guidance for the diagnosis and management of osteoporosis in postmenopausal women. Osteoporos Int $\underline{19}, 399-428$

Kanis JA, Oden A, Johansson H, Borgström F, Ström O, McCloskey E (2009): FRAX and its applications to clinical practice. Bone $\underline{44}, 734-743$

Komatsu DE, Brune KA, Liu H, Schmidt AL, Han B, Zeng QQ, Yang X, Nunes JS, Lu Y, Geiser AG, et al. (2009): Longitudinal in vivo analysis of the region-specific efficacy of parathyroid hormone in a rat cortical defect model. Endocrinology 150, 1570-1579

De Laet CEDH, van der Klift M, Hofman A, Pols HAP (2002): Osteoporosis in men and women: a story about bone mineral density thresholds and hip fracture risk. J Bone Miner Res 17, 2231-2236

Lane NE (2006): Epidemiology, etiology, and diagnosis of osteoporosis. Am J Obstet Gynecol $\underline{194}$, 3-11

Lanyon LE (1996): Using functional loading to influence bone mass and architecture: objectives, mechanisms, and relationship with estrogen of the mechanically adaptive process in bone. Bone $\underline{18}, 37-43$

Lelovas PP, Xanthos TT, Thoma SE, Lyritis GP, Dontas IA (2008): The laboratory rat as an animal model for osteoporosis research. Comp Med $\underline{58}, 424-430$ 
Lin JT, Lane JM (2004): Osteoporosis: a review. Clin Orthop Relat Res 126-134

Link TM, Majumdar S (2003): Osteoporosis imaging. Radiol Clin North Am 411, 813-839

Lynch MA, Brodt MD, Stephens AL, Civitelli R, Silva MJ (2011): Low-magnitude wholebody vibration does not enhance the anabolic skeletal effects of intermittent PTH in adult mice. J Orthop Res $\underline{29}$, 465-472

Marcus R, Wang O, Satterwhite J, Mitlak B (2003): The skeletal response to teriparatide is largely independent of age, initial bone mineral density, and prevalent vertebral fractures in postmenopausal women with osteoporosis. J Bone Miner Res $\underline{18}, 18-23$

Marie PJ (2006): Strontium ranelate: a dual mode of action rebalancing bone turnover in favour of bone formation. Curr Opin Rheumatol $\underline{18}, 11-15$

Marie PJ, Hott M, Modrowski D, De Pollak C, Guillemain J, Deloffre P, Tsouderos Y (1993): An uncoupling agent containing strontium prevents bone loss by depressing bone resorption and maintaining bone formation in estrogen-deficient rats. J Bone Miner Res $\underline{8}, 607-615$

Mayes JS, Watson GH (2004): Direct effects of sex steroid hormones on adipose tissues and obesity. Obes Rev $\underline{5}, 197-216$

McClung MR, Lewiecki EM, Cohen SB, Bolognese MA, Woodson GC, Moffett AH, Peacock M, Miller PD, Lederman SN, Chesnut CH, et al. (2006): Denosumab in postmenopausal women with low bone mineral density. N Engl J Med 354, 821-831

Meunier PJ, Roux C, Seeman E, Ortolani S, Badurski JE, Spector TD, Cannata J, Balogh A, Lemmel E-M, Pors-Nielsen S, et al. (2004): The effects of strontium ranelate on the risk of vertebral fracture in women with postmenopausal osteoporosis. N Engl J Med $\underline{350}$, 459-468 
Minne HW, Pfeifer M, Begerow B, Pollähne W (2002): Osteoporose. Internist (Berl) $\underline{43}$, $1430-1452$

Miyakoshi N, Itoi E, Kobayashi M, Kodama H (2003): Impact of postural deformities and spinal mobility on quality of life in postmenopausal osteoporosis. Osteoporos Int $\underline{14}$, 1007-1012

Mosekilde L, Danielsen CC, Knudsen UB (1993): The effect of aging and ovariectomy on the vertebral bone mass and biomechanical properties of mature rats. Bone $\underline{14}, 1-6$

Neer RM, Arnaud CD, Zanchetta JR, Prince R, Gaich GA, Reginster JY, Hodsman AB, Eriksen EF, Ish-Shalom S, Genant HK, et al. (2001): Effect of parathyroid hormone (134) on fractures and bone mineral density in postmenopausal women with osteoporosis. N Engl J Med $\underline{344}, 1434-1441$

Orwoll ES, Scheele WH, Paul S, Adami S, Syversen U, Diez-Perez A, Kaufman JM, Clancy AD, Gaich GA (2003): The effect of teriparatide [human parathyroid hormone (1-34)] therapy on bone density in men with osteoporosis. J Bone Miner Res $\underline{18}, 9-17$

Oxlund BS, Ørtoft G, Andreassen TT, Oxlund H (2003): Low-intensity, high-frequency vibration appears to prevent the decrease in strength of the femur and tibia associated with ovariectomy of adult rats. Bone $\underline{32}, 69-77$

Parfitt AM, Drezner MK, Glorieux FH, Kanis JA, Malluche H, Meunier PJ, Ott SM, Recker RR (1987): Bone histomorphometry: standardization of nomenclature, symbols, and units. Report of the ASBMR Histomorphometry Nomenclature Committee. J Bone Miner Res $\underline{2}, 595-610$

Parker MJ, Gillespie LD, Gillespie WJ (2000): Hip protectors for preventing hip fractures in the elderly. Cochrane Database Syst Rev CD001255 
Paulsen F, Lüllmann-Rauch R: Taschenlehrbuch Histologie. 3. Auflage; Georg Thieme Verlag, Stuttgart 2012

Pfeilschifter J (2006): 2006 DVO-guideline for prevention, diagnosis, and therapy of osteoporosis for women after menopause, for men after age 60 executive summary guidelines. Exp Clin Endocrinol Diabetes 114, 611-622

Quesada-Gómez JM, Muschitz C, Gómez-Reino J, Greisen H, Andersen HS, Dimai HP (2011): The effect of PTH(1-84) or strontium ranelate on bone formation markers in postmenopausal women with primary osteoporosis: results of a randomized, openlabel clinical trial. Osteoporos Int 22, 2529-2537

Rahn BA (1976): The fluorochrome sequence labeling of the bone. Nova Acta Leopold $\underline{44}, 249-255$

Reginster JY, Seeman E, De Vernejoul MC, Adami S, Compston J, Phenekos C, Devogelaer JP, Curiel MD, Sawicki A, Goemaere S, et al. (2005): Strontium ranelate reduces the risk of nonvertebral fractures in postmenopausal women with osteoporosis: Treatment of Peripheral Osteoporosis (TROPOS) study. J Clin Endocrinol Metab $\underline{90}$ $2816-2822$

Rogers MJ, Frith JC, Luckman SP, Coxon FP, Benford HL, Mönkkönen J, Auriola S, Chilton KM, Russell RG (1999): Molecular mechanisms of action of bisphosphonates. Bone $\underline{24}, 73-79$

Rossouw JE, Anderson GL, Prentice RL, LaCroix AZ, Kooperberg C, Stefanick ML, Jackson RD, Beresford SAA, Howard BV, Johnson KC, et al. (2002): Risks and benefits of estrogen plus progestin in healthy postmenopausal women: principal results From the Women's Health Initiative randomized controlled trial. JAMA $\underline{288}, 321-333$ 
Rote Liste ${ }^{\circledR}$ : Arzneimittelverzeichnis für Deutschland. Auflage: 1; Rote Liste Service GmbH, Frankfurt am Main 2014

Roth, A, Abendroth K (2006): Osteoporose. Orthopädie und Unfallchirurgie up2date 1 , $223-248$

Rubin C, Turner AS, Mallinckrodt C, Jerome C, McLeod K, Bain S (2002): Mechanical strain, induced noninvasively in the high-frequency domain, is anabolic to cancellous bone, but not cortical bone. Bone $30,445-452$

Rubin J, Murphy T, Nanes MS, Fan X (2000): Mechanical strain inhibits expression of osteoclast differentiation factor by murine stromal cells. Am J Physiol, Cell Physiol $\underline{278}$, $1126-1132$

Seeman E (2003): The structural and biomechanical basis of the gain and loss of bone strength in women and men. Endocrinol Metab Clin North Am 32, 25-38

Sehmisch S, Galal R, Kolios L, Tezval M, Dullin C, Zimmer S, Stuermer KM, Stuermer EK (2009a): Effects of low-magnitude, high-frequency mechanical stimulation in the rat osteopenia model. Osteoporos Int 20, 1999-2008

Sehmisch S, Erren M, Rack T, Tezval M, Seidlova-Wuttke D, Richter J, Wuttke W, Stuermer KM, Stuermer EK (2009b): Short-term effects of parathyroid hormone on rat lumbar vertebrae. Spine 34, 2014-2021

Seidlova-Wuttke D, Hesse O, Jarry H, Christoffel V, Spengler B, Becker T, Wuttke W (2003): Evidence for selective estrogen receptor modulator activity in a black cohosh (Cimicifuga racemosa) extract: comparison with estradiol-17beta. Eur J Endocrinol $\underline{149}$, $351-362$ 
Stewart JA, Cochrane DJ, Morton RH (2009): Differential effects of whole body vibration durations on knee extensor strength. J Sci Med Sport 12, 50-53

Sutton EE, Riche DM (2012): Denosumab, a RANK ligand inhibitor, for postmenopausal women with osteoporosis. Ann Pharmacother $\underline{46}$, 1000-1009

Tezval M, Stuermer EK, Sehmisch S, Rack T, Stary A, Stebener M, Konietschke F, Stuermer KM (2010): Improvement of trochanteric bone quality in an osteoporosis model after short-term treatment with parathyroid hormone: a new mechanical test for trochanteric region of rat femur. Osteoporos Int 21, 251-261

Turner AS (2001): Animal models of osteoporosis-necessity and limitations. Eur Cell Mater $\underline{1}, 66-81$

Verschueren SMP, Roelants M, Delecluse C, Swinnen S, Vanderschueren D, Boonen S (2004): Effect of 6-month whole body vibration training on hip density, muscle strength, and postural control in postmenopausal women: a randomized controlled pilot study. J Bone Miner Res $\underline{19}$, 352-359

Wakeling JM, Nigg BM, Rozitis Al (2002): Muscle activity damps the soft tissue resonance that occurs in response to pulsed and continuous vibrations. J Appl Physiol $\underline{93}$, 1093-1103

Welsch U: Lehrbuch Histologie: Zytologie, Histologie, mikroskopische Anatomie. Elsevier, Urban \& Fischer Verlag 2006

Wolff J: Das Gesetz der Transformation der Knochen. Hirschwald, Berlin 1852

Wronski TJ, Lowry PL, Walsh CC, Ignaszewski LA (1985): Skeletal alterations in ovariectomized rats. Calcif Tissue Int $\underline{37}, 324-328$ 
Wronski TJ, Walsh CC, Ignaszewski LA (1986): Histologic evidence for osteopenia and increased bone turnover in ovariectomized rats. Bone $\underline{7}, 119-123$

Wülker N: Taschenlehrbuch Orthopädie und Unfallchirurgie. Georg Thieme Verlag 2010

Wu Y, Adeeb SM, Duke MJ, Munoz-Paniagua D, Doschak MR (2013): Compositional and material properties of rat bone after bisphosphonate and/or Strontium ranelate drug treatment. J Pharm Pharm Sci 16, 52-64

Yamaura M, Nakamura T, Tsurukami H, Hijioka A, Narusawa K, Ohnishi H, Ohta T, Hosoda K (1996): Local bone turnover in the metaphysis of the proximal tibia and the lumbar vertebra during the early periods after ovariectomy in rats. Calcif Tissue Int $\underline{58}$, $52-59$ 


\section{Appendix}

Daten

1. Durchschnittliches Gewicht pro Woche der Versuchstiere in Gramm (Tab. 10)

2. Futteraufnahme der Versuchstiere (in Gramm pro Tier) über den Versuchszeitraum (Tab. 11) 
Tabelle 10: Durchschnittliches Gewicht pro Woche der Versuchstiere

\begin{tabular}{|c|c|c|c|c|c|c|c|c|c|c|c|c|c|c|}
\hline \multirow[b]{2}{*}{ Datum } & \multicolumn{2}{|c|}{ SHAM } & \multicolumn{2}{|c|}{ OVX } & \multicolumn{2}{|c|}{ OVX+VIB } & \multicolumn{2}{|c|}{ SR } & \multicolumn{2}{|c|}{ SR+VIB } & \multicolumn{2}{|c|}{ PHT } & \multicolumn{2}{|c|}{ PHT+VIB } \\
\hline & Mittelwert & $\mathrm{SD}$ & Mittelwert & $\mathrm{SD}$ & Mittelwert & SD & Mittelwert & $\mathrm{SD}$ & Mittelwert & SD & Mittelwert & $\mathrm{SD}$ & Mittelwert & $\mathrm{SD}$ \\
\hline OVX & 236,58 & 5,88 & 235,17 & 7,64 & 231,67 & 11,36 & 231,85 & 5,13 & 230,71 & 9,35 & 232,77 & 11,08 & 234,92 & 13,41 \\
\hline 10.09 .2012 & 236,58 & 15,22 & 243,92 & 5,87 & 243,42 & 8,85 & 243,54 & 8,46 & 242,14 & 10,26 & 238,38 & 9,66 & 240,18 & 11,14 \\
\hline 17.09.2012 & 251,50 & 10,69 & 280,08 & 14,51 & 282,00 & 12,91 & 279,69 & 14,44 & 278,57 & 10,47 & 270,46 & 14,06 & 278,91 & 14,39 \\
\hline 24.09.2012 & 265,92 & 13,80 & 312,08 & 17,65 & 316,42 & 16,04 & 314,54 & 18,44 & 311,23 & 13,05 & 303,62 & 20,83 & 313,55 & 20,48 \\
\hline 01.10 .2012 & 274,00 & 12,50 & 334,25 & 17,05 & 339,58 & 16,52 & 338,23 & 19,90 & 336,00 & 14,84 & 328,62 & 22,55 & 337,09 & 22,29 \\
\hline 08.10.2012 & 273,50 & 25,16 & 344,17 & 13,85 & 350,83 & 17,46 & 356,62 & 22,39 & 345,64 & 15,44 & 337,38 & 23,97 & 349,18 & 23,26 \\
\hline 15.10 .2012 & 288,92 & 15,14 & 352,00 & 17,07 & 358,67 & 17,32 & 364,08 & 25,58 & 356,77 & 16,19 & 349,69 & 24,39 & 356,73 & 25,31 \\
\hline 22.10 .2012 & 290,83 & 16,71 & 360,75 & 17,74 & 363,83 & 17,91 & 369,62 & 24,98 & 363,93 & 16,24 & 357,08 & 27,29 & 362,55 & 23,39 \\
\hline $\begin{array}{l}\text { Osteotomie } \\
\text { 29.10.- } \\
01.11 .2012\end{array}$ & 291,45 & 22,85 & 365,36 & 14,85 & 364,80 & 17,99 & 373,92 & 31,50 & 364,46 & 14,79 & 361,00 & 25,91 & 366,20 & 27,44 \\
\hline 05.11 .2012 & 279,91 & 21,59 & 344,00 & 17,73 & 335,91 & 17,65 & 351,27 & 31,24 & 338,73 & 17,07 & 338,36 & 25,73 & 339,64 & 26,47 \\
\hline 12.11.2012 & 282,64 & 19,92 & 348,80 & 19,11 & 331,82 & 19,85 & 359,45 & 32,50 & 340,50 & 18,52 & 341,55 & 26,45 & 338,27 & 24,60 \\
\hline 19.11.2012 & 293,82 & 18,66 & 363,90 & 21,74 & 343,18 & 18,90 & 372,55 & 34,65 & 350,27 & 19,72 & 350,18 & 27,74 & 339,18 & 23,76 \\
\hline 26.11.2012 & 303,18 & 19,40 & 374,00 & 22,18 & 343,55 & 18,47 & 384,45 & 36,36 & 356,09 & 20,52 & 361,09 & 30,67 & 344,45 & 23,84 \\
\hline 03.12.2012 & 307,09 & 17,87 & 375,60 & 24,93 & 351,18 & 21,78 & 387,55 & 36,72 & 365,75 & 19,26 & 365,09 & 30,17 & 351,45 & 26,31 \\
\hline $\begin{array}{l}\text { Tag der } \\
\text { Tötung } 10 .- \\
13.12 .2012\end{array}$ & 311,18 & 20,77 & 371,60 & 27,06 & 355,17 & 16,23 & 387,64 & 37,45 & 363,36 & 18,33 & 366,45 & 33,04 & 351,64 & 26,00 \\
\hline
\end{tabular}


Tabelle 11: Futteraufnahme der Versuchstiere über den Versuchszeitraum

\begin{tabular}{|c|c|c|c|c|c|c|c|c|c|c|c|c|c|c|}
\hline \multirow[b]{2}{*}{ Datum } & \multicolumn{2}{|c|}{ SHAM } & \multicolumn{2}{|c|}{ OVX } & \multicolumn{2}{|c|}{ OVX+VIB } & \multicolumn{2}{|c|}{ SR } & \multicolumn{2}{|c|}{ SR+VIB } & \multicolumn{2}{|c|}{ PTH } & \multicolumn{2}{|c|}{ PTH+VIB } \\
\hline & Mittelwert & SD & Mittelwert & SD & Mittelwert & SD & Mittelwert & SD & Mittelwert & SD & Mittelwert & SD & Mittelwert & SD \\
\hline 10.09 .2012 & 89,58 & 21,29 & 62,75 & 24,82 & 76,83 & 7,61 & 76,63 & 3,96 & 81,03 & 17,45 & 75,20 & 27,09 & 50,33 & 14,81 \\
\hline 17.09.2012 & 142,33 & 4,51 & 166,08 & 5,82 & 175,50 & 16,64 & 170,38 & 18,45 & 174,37 & 14,57 & 177,63 & 11,28 & 184,17 & 26,27 \\
\hline 24.09.2012 & 144,58 & 1,23 & 174,08 & 5,38 & 176,17 & 9,17 & 180,72 & 12,04 & 179,17 & 9,06 & 181,63 & 9,03 & 191,25 & 22,52 \\
\hline 01.10 .2012 & 150,58 & 6,44 & 170,75 & 7,28 & 201,50 & 49,86 & 181,17 & 9,41 & 189,87 & 22,18 & 200,63 & 21,52 & 219,31 & 37,90 \\
\hline 08.10.2012 & 167,58 & 11,73 & 135,25 & 21,70 & 94,42 & 30,17 & 74,62 & 52,62 & 183,88 & 20,10 & 177,75 & 8,45 & 204,81 & 38,16 \\
\hline 15.10 .2012 & 191,92 & 30,00 & 162,92 & 3,38 & 183,08 & 38,27 & 177,65 & 9,09 & 169,03 & 10,01 & 168,03 & 8,20 & 177,56 & 19,17 \\
\hline 22.10.2012 & 166,75 & 5,52 & 180,33 & 2,77 & 151,83 & 66,55 & 155,62 & 56,90 & 189,95 & 2,94 & 101,53 & 37,98 & 176,64 & 5,96 \\
\hline \multicolumn{15}{|l|}{ Osteotomie } \\
\hline \multicolumn{15}{|l|}{ 29.10.- } \\
\hline 01.11 .2012 & 147,25 & 16,78 & 145,83 & 29,54 & 149,25 & 17,10 & 156,32 & 21,70 & 157,08 & 19,51 & 176,37 & 46,42 & 188,14 & 34,80 \\
\hline 05.11 .2012 & 71,89 & 13,68 & 72,42 & 28,47 & 92,67 & 23,72 & 82,83 & 30,56 & 75,84 & 22,96 & 49,33 & 8,08 & 83,33 & 35,92 \\
\hline 12.11.2012 & 128,92 & 6,02 & 114,36 & 33,80 & 155,33 & 77,64 & 134,50 & 25,77 & 124,76 & 24,34 & 109,22 & 29,73 & 141,67 & 51,54 \\
\hline 19.11.2012 & 146,42 & 1,42 & 133,97 & 29,71 & 176,75 & 85,88 & 144,25 & 24,74 & 136,95 & 21,72 & 124,05 & 34,35 & 152,75 & 52,70 \\
\hline 26.11.2012 & 152,06 & 11,23 & 133,67 & 24,83 & 172,42 & 85,86 & 145,58 & 25,24 & 134,89 & 30,86 & 124,75 & 37,91 & 161,42 & 55,99 \\
\hline 03.12 .2012 & 143,89 & 2,44 & 132,94 & 23,92 & 171,33 & 81,55 & 140,92 & 21,91 & 130,26 & 26,49 & 124,85 & 37,29 & 167,08 & 57,62 \\
\hline \multicolumn{15}{|l|}{ Tag der } \\
\hline \multicolumn{15}{|l|}{ Tötung 10.- } \\
\hline 13.12.2012 & 173,64 & 38,04 & 143,86 & 16,19 & 51,67 & 51,92 & 153,00 & 13,76 & 134,18 & 33,25 & 157,45 & 68,33 & 204,83 & 64,97 \\
\hline
\end{tabular}




\section{Danksagung}

Mein Dank gilt Herrn Prof. Dr. Stürmer für die Möglichkeit meine Doktorarbeit in seiner Abteilung anfertigen zu dürfen und meinem Doktorvater, Herrn PD Dr. Sehmisch für die sehr gute Betreuung meiner Arbeit.

Ganz besonders bedanken möchte ich mich bei den Mitarbeiterinnen des Labors, Anette Witt, Ramona Castro-Machguth und Dr. Marina Komrakova für das stetige Vorantreiben meiner Arbeit und die schöne Zeit im Labor. 